NBER WORKING PAPER SERIES

\title{
THE INFLUENCE OF EARLY LIFE HEALTH CONDITIONS ON LIFE COURSE HEALTH
}

Manuel Flores Mallo

Barbara L. Wolfe

Working Paper 27174

http://www.nber.org/papers/w27174

\author{
NATIONAL BUREAU OF ECONOMIC RESEARCH \\ 1050 Massachusetts Avenue \\ Cambridge, MA 02138 \\ May 2020
}

This paper uses data from SHARE Waves 1, 2, 3, 4, 5, 6 and 7 (DOIs: 10.6103/SHARE.w1.700, 10.6103/SHARE.w2.700, 10.6103/SHARE.w3.700, 10.6103/SHARE.w4.700, 10.6103/ SHARE.w5.700, 10.6103/SHARE.w6.700, 10.6103/SHARE.w7.700), as well as from the generated Job Episodes Panel (DOI: 10.6103/SHARE.jep.700). See, correspondingly, BörschSupan et al. (2013) and Brugiavini et al. (2019) for methodological details. The SHARE data collection has been funded by the European Commission through FP5 (QLK6-CT-2001-00360), FP6 (SHARE-I3: RII-CT-2006-062193, COMPARE: CIT5-CT-2005-028857, SHARELIFE: CIT4-CT-2006-028812), FP7 (SHARE-PREP: GA N²11909, SHARE-LEAP: GA N²27822, SHARE M4: GA N²61982) and Horizon 2020 (SHARE-DEV3: GA N 676536 , SERISS: GA N ${ }^{\circ} 654221$ ) and by DG Employment, Social Affairs \& Inclusion. Additional funding from the German Ministry of Education and Research, the Max Planck Society for the Advancement of Science, the U.S. National Institute on Aging (U01_AG09740-13S2, P01_AG005842, P01_AG08291， P30_AG12815， R21_AG025169, Y1-AG-4553-01， IAG_BSR06-11, OGHA_04-064, HHSN271201300071C) and from various national funding sources is gratefully acknowledged (see www.share-project.org). The views expressed herein are those of the authors and do not necessarily reflect the views of the National Bureau of Economic Research.

NBER working papers are circulated for discussion and comment purposes. They have not been peer-reviewed or been subject to the review by the NBER Board of Directors that accompanies official NBER publications.

(C) 2020 by Manuel Flores Mallo and Barbara L. Wolfe. All rights reserved. Short sections of text, not to exceed two paragraphs, may be quoted without explicit permission provided that full credit, including $\odot$ notice, is given to the source. 
The Influence of Early Life Health Conditions on Life Course Health

Manuel Flores Mallo and Barbara L. Wolfe

NBER Working Paper No. 27174

May 2020

JEL No. D1,I10,I14,J0

\begin{abstract}
$\underline{\text { ABSTRACT }}$
We expand on earlier studies investigating the links between early health and later health by including different dimensions of early-life health and multiple life course outcomes consisting of the age of onset of serious cardiovascular diseases (CVDs) and multiple job-related health outcomes. The four dimensions of childhood health are mental, physical, self-rated general health and severe headaches or migraines. The data set we use includes 21 countries from the Survey of Health, Ageing and Retirement in Europe. We find that the different dimensions of childhood health have unique ties to later outcomes. For men, early mental health problems play a stronger role for life course job-related health outcomes, but early poor or fair general health is more strongly linked to the spike in onset of CVDs in their late 40s. For women, these links between childhood health dimensions and life course outcomes are less clear-cut than for men. The spike in onset of CVDs in their late 40s is driven by those with severe headaches or migraines while those with early physical health problems generally do better as captured by job-related outcomes. We also explore and control for possible mediating factors and assess the importance of omitted variables using a test proposed by Oster (2019).
\end{abstract}

Manuel Flores Mallo

Universitat Internacional de Catalunya

Immaculada, 22

08017 Barcelona

Spain

mflores@uic.es

Barbara L. Wolfe

3458 Social Science Building

University of Wisconsin

Madison, WI 53706

and NBER

BWolfe@wisc.edu 
Previous studies have illustrated the multidimensional nature of health (Kalwij and Vermeulen, 2008) and have shown that both childhood-specific diseases and childhood health summary variables contain useful information about adult health (Smith, 2009a, 2009b). In our study, we will elaborate on these findings and explore the influence that different dimensions of early-life health have on the onset of specific health conditions and permanent or temporary withdrawals from the labor force over the life course and other potential mediating factors. In particular, we will explore the link between four dimensions of early-life health and regular use of dental care since childhood and 1) the probability of having an onset of one of six health conditions including five cardiovascular diseases and chronic lung disease over the life course in five-year intervals over ages 16-80; 2 ) the probability of having 1+ or 2+ episodes of ill health during adulthood; 3 ) the accumulated number of career gaps in employment in five-year intervals over ages $25-64 ; 4$ ) the probability of leaving the labor force in five-year intervals over ages 25-64; and 5) the probability of having retired from a job because of own ill health. We will also look at mediating factors including the years in full-time education, and an alternate measure, the probability of having a low, medium or high education level, the probability of having ever worked, the probability of being ever married, and the probability of having ever had a natural child. In doing so, we will control for the current country of residence, cohort, and measures of family socio-economic status (SES) when a child. Our analysis sample includes men and women from 20 European countries plus Israel.

\section{Literature Review}

There is a growing literature that demonstrates that the SES-health gradient in adulthood has its origins in an individual's early life (Case et al., 2002; Currie and Stabile, 2003). Two chapters in recent volumes of the Handbook of Labor Economics (Almond and Currie, 2011a; Black and Devereux, 2011), for instance, show that adverse health events in early life and parental SES have long-lasting effects on later life health and SES-related outcomes such as earnings and work effort. Several theories exist for such a relationship. For instance, the fetal-origins hypothesis (e.g. Barker, 1995; Almond and Currie, 2011b) suggests a direct link from the prenatal period to adult health that may be independent of social class in adult life, life course models assume that illness and deprivation during childhood may have long-term consequences for health during adulthood, either directly through the illness itself or indirectly by restricting educational achievement and life opportunities (e.g. Kuh and Wadsworth, 1993) and pathways models suggest that the observed SES-health gradient in adulthood is only indirectly attributable to early life events through later life events (e.g. Marmot et al., 2001). Later studies for the U.K. (Case et al., 2005) and the U.S. (Case and Paxson, 2008) also present evidence in line with the theoretical predictions and show that having good health during childhood and growing up in a more comfortable environment result in a higher level of education, and good health and higher economic status later in life. All these findings are important to policymakers because they may suggest that policies aimed at improving children's health and SES have long-lasting benefits for both the individual and society because of increased human capital accumulation, hence 
better employment opportunities, and better later life health (see also Marmot et al., 2012).

Several recent studies find causal impacts of very specific exogenous early life events on later life outcomes. A recent review of these is quite helpful and quite exhaustive (Almond et al., 2018) so we largely skip this literature. To provide a flavor, we note a few: using the 1918 influenza pandemic as a measure of a health shock around birth is shown to relate to later life outcomes such as education, health and SES (e.g. Almond, 2006; Nelson, 2010; Almond and Mazumder, 2005). Chen and Zhou (2007) show that the 1959-1961 famine in China adversely affected height, earnings and labor supply, and Barreca (2010) shows that malaria exposure adversely affects educational attainment and increases poverty risk. Painter et al. (2005) and Roseboom et al. $(2001,2006)$ provide evidence on long-term effects on later life health of prenatal under nutrition during the Dutch famine of 1944/1945. In addition, van den Berg et al. (2006) show that economic conditions around birth-measured by the business cycle-affect mortality later in life. Bhalotra and Venkataranani (2015) show that a decrease in pneumonia in infancy reduces work related disabilities. Their emphasis is on the role of the introduction of antibiotics in the infants' state of residence. Another study by Kesternich et al. (2014) uses the experience of war to investigate its influence on adult outcomes including health, education, and net worth.

In work slightly more closely tied to the question we explore below, several authors have established a link between low birth weight and adult health. See for example Figlio et al. (2014) and Bharadoy et al. (2014).

In terms of specific health conditions, Currie and Stabile (2006, 2009), Fletcher and Wolfe $(2008,2009)$ and Currie et al. (2010) show that childhood mental health problems have long-term effects on outcomes that are larger than those of specific physical health conditions. Currie et al. (2010) used data from the Manitoba, Canada for 50,000 children and their siblings. They linked health data to information on school performance and welfare use after age 18 and compared children with mental health issues with their own siblings. They examined the effects of having been diagnosed or treated for mental health problems in four different age ranges, $0-3,4-8,9-13$, and 14-18, and compared the impact of mental health problems with those of having been diagnosed or treated for asthma and injuries. They found that mental health conditions have more serious consequences than these two physical health conditions.

One of the missing aspects of most of these studies is that the focus is on the fetal period and that of young children. As Currie (2020) points out, adolescent is quite understudied and calls these ages "the missing middle". P.10. Yang et al. (2017) put this differently as "A dominant paradigm to explain the early- and later-life connection is the sensitive period model, which posits that exposures during sensitive periods of development (e.g., gestation, birth, childhood, and adolescence) induce enduring structural and functional changes in organisms through biological programming that are difficult to reverse and, in turn, affect later disease risk (Barker, 1998; Ben-Shlomo and Kuh, 2002; Guo and Harris, 
2000)." The authors further suggest that the focus on gestation, birth and early childhood is based on a model that early-life conditions have stronger effects on adult outcomes than conditions experienced at subsequent time points. But do they? And, at what age are these effects most commonly manifested? Yang et al. (2017) go on to study the influence of SES on two measures of health, inflammation and metabolic syndrome of adults by age group. Their most relevant finding for us is that the link from SES to health of older adults is through SES as an adult rather than as a child. ${ }^{3}$ The effect of SES as a child does influence SES as an adult, so an indirect effect is found.

The literature most closely tied to our research is far more limited. One early paper is by Case et al. (2005), that uses the National Child Development Study, which followed all children born in Great Britain (Scotland, England and Wales) in the week of March 3, 1958 from birth through to age 42 to study the link between childhood health and adult health, as well as education and SES. The key early health measure they use is the number of physician-assessed chronic health conditions observed at ages 7 and 16; the key adult health measure is selfreported health at ages 23,33 and 42 . They find that chronic health conditions at age 16 are tied to adult health at all three points in time while the effects of conditions at age 7 faded over time. When they go on to look at type of conditions, they find that physical impairments; mental and emotional conditions; and systems conditions all contribute approximately equally to poorer health at age 42 . They interpret this as consistent with a life course model.

A more recent paper that uses data similar to ours is a study by Smith et al. (2012). Their data are taken from the China Health and Retirement Longitudinal Study (CHARLS) that focused initially on two provinces in China and was modeled after the U.S. Health and Retirement Study (HRS) and the Survey of Health, Aging and Retirement in Europe (SHARE). They explore the tie between childhood health, measured by self-reported general health (SRH) before age 16, and adult health, measured also by SRH, as well as doctor diagnoses of chronic illnesses, depression, lifestyle and health behaviors (physical activities, smoking, drinking), activities of daily living (ADLs), and instrumental activities of daily living (IADLs) as an adult. They plot the percentage of respondents reporting good or better health over ages 45-80 and show that those whose childhood health was good or better are four times more likely to have a good or better health as an adult than those with poorer health as a child. The authors find strong statistical associations of childhood health on adult health outcomes but, interestingly, mainly only for Chinese women. Their main outcomes are measured in 10-year age intervals with sensitivity checks for five-year and oneyear intervals.

Our contribution goes beyond these two studies in the following ways: 1) We use four measures of childhood health before age 16: self-reported or general health, a measure of physical health, a measure of mental health and a measure of

\footnotetext{
${ }^{3}$ Yang et al. (2017) state "In late adulthood [...], current SES completely mediated the associations between early-life SES and both biomarker outcomes, supporting a pathway model whereby the influence of childhood SES on adult physiology operates through adult SES."
} 
severe headaches or migraines. These measures are more extensive than those used in other studies although, as in the study of China, they are retrospective. 2) We measure multiple aspects of adult health with a focus on both job-tied health and onset of specific health conditions. This is unique in our knowledge of the literature. 3) We measure outcomes over all of adult life in 5-year intervals. This is similar to the approach used by Smith et al. (2012) for China but more detailed and more closely tied to work. We also focus on exactly at what age a person is most likely influenced by each particular type of health problem we measure.

\section{Model and approach}

\section{Data}

We use individual-level data from SHARE, a multidisciplinary and representative cross-national panel of the European population aged 50 and up. As explained further below, our measures of childhood health problems and our life course measures of health problems in each year are mainly retrospective. For life course health conditions and job-tied health measures they include, correspondingly, data over ages 16 to 80 and 25 to 64 in one-year intervals, which we combine into five-year buckets. ${ }^{4}$

In the work reported below, we use data from the first seven waves of SHARE that were collected in approximately biannual periods between 2004/05 and 2017 (Börsch-Supan et al., 2013). These include information on sociodemographic background characteristics, current health and socioeconomic status. We construct our life course health measures using information from the regular Waves 1, 2, 4, 5 and 6 . These waves include a question on a battery of health conditions (PH006) and on their age of onset (PH009). We focus on six conditions including five cardiovascular diseases (CVDs) and lung disease that are asked in all these waves to reconstruct our life course health profiles. ${ }^{5}$ Most of our other data are from two retrospective waves, Wave 3, also known as SHARELIFE (2008/09), and Wave 7 (2017), where a SHARELIFE questionnaire was administered to all respondents who did not participate in Wave 3. SHARELIFE was, thereby, expanded to 14 additional countries that entered SHARE after Wave 3 plus Israel, which had exited SHARE in Wave 3 and returned in Wave 5. SHARELIFE contains retrospective information on respondents' early life circumstances and work careers. Interviewers in SHARELIFE used a life history calendar to guide respondents to answer questions as accurately as possible. Accuracy might be an issue for self-recalled measures in SHARE such as wages, especially when they were earned a long time ago. Our life course

\footnotetext{
${ }^{4}$ Our analysis here includes what we call job-tied health measures including gaps in work or retirement. While these can occur for multiple reasons, our discussion assumes health-related reasons are a primary factor, but the reader may wish to skip these measures and focus on those that more directly measure later health.

5 Wave 7 has also a regular panel, which includes question PH006 but not question PH009. This prevents us from using the eight newly added countries in this wave (Finland, Lithuania, Latvia, Slovakia, Romania, Bulgaria, Malta and Cyprus) in our analysis.
} 
analyses focus on measures of health tied to employment, which are likely less subject to recall problems than earnings measures. ${ }^{6}$

Our analysis sample includes men and women from 21 SHARE countries. ${ }^{7}$ Our initial sample consists of 65,178 respondents aged 50 and over in the interview year of SHARELIFE (in Wave 3 or 7). Our final sample includes $93 \%$ of these respondents, 26,741 men and 34,151 women. We drop those with missing values in childhood health variables and other childhood SES controls, reducing our sample by 1,186 and 2,791 values, respectively. We also exclude 309 respondents with missing values for regular dental care since childhood.

\section{Measures of Early Health}

In this research, we use retrospective self-assessed data on general, physical, mental health, and severe headaches or migraines that refer to the period before an individual attained age 16. This categorization is fairly typical in studies of health status: physical health is based on reports of experiencing a set of illnesses that are primarily physical in nature; mental health is based on a set of severe mental illnesses; and general health is based on a more subjective overall assessment of health (Smith, 2009a, 2009b). Our measures attempt to make full use of the rich data that were collected. Our measure of general health is the commonly used self-reported five-point scale, excellent to poor, which we convert to a binary variable identifying the two lowest categories of health, poor or fair health. ${ }^{8}$ Our measure of physical health is created from a polychoric Principal Component Analysis (PCA) (Kolenikov and Angeles, 2009) and includes count variables for the following: respiratory problems (asthma, other respiratory problems, and allergies); infectious diseases (polio, severe diarrhea, meningitis/encephalitis, appendicitis and other infectious diseases); cardiovascular diseases (diabetes or high blood sugar and heart troubles); disorders of the sense organs (chronic ear problems, speech impairment, and difficulty in seeing even with eyeglasses); and other serious health conditions an individual suffered before age 16. Polychoric PCA is applied to the pooled samples of men and women, respectively, and we keep the first principal component (PC), which explains the largest proportion of the total variance (30\% for men and $32 \%$ for women). All the factor loadings on the first PC have an expected sign in determining childhood physical health (results available

\footnotetext{
${ }^{6}$ The retrospective data on our job-tied health measures is taken from the third release of the retrospective SHARE Job Episodes Panel (JEP) (Brugiavini et al., 2019). JEP contains cleaned information on the start and end dates of all job spells that SHARELIFE respondents had during their working life, a measure of the intensity of hours worked in each job spell, and additional information on their year of retirement and non-employment spells.

${ }^{7}$ In JEP, from the initial 90,999 respondents, we drop 4,638 with missing hours worked in a job spell. We further lose 20,349 respondents when retrieving health histories from Waves 1,2,4,5 and 6 for all respondents in JEP. However, around 70\% of these respondents we lose are from the newly added eight SHARELIFE countries in Wave 7, which we cannot use in our analysis (see fn. 5). We then also drop 834 respondents that are below age 50.

${ }^{8}$ Childhood self-reported health in SHARELIFE contains a sixth category "changing," which includes 0.4 percent of the sample and is recorded only if the respondent spontaneously answers that his childhood health varied a great deal. We also include this group in our measure of poor/fair health.
} 
upon request). We then create a dummy variable indicating whether an individual is one standard deviation below the mean in the distribution of this first PC and call this our index of childhood physical health. Our measure of mental health is based on responses to questions of whether the individuals experienced emotional, nervous, or psychiatric problems, or epilepsy fits or seizures before age 16 . The values for these health variables, along with average background measures, are available for men and women in Table 1.

We also have information on severe headaches or migraines. Since it is not clear whether to call these physical or mental health, or both in some sense, we instead use the response as an additional measure of childhood health. The last early health variable is an incomplete measure of access to health care or preventive use including adulthood: whether or not they report having had regular dental care since childhood (also, a 0-1 variable). We caution that this latter measure may partly measure SES rather than serve purely as a measure of access or use of preventive health care.

The four plus one measures of health we use are largely independent. The correlations between any two of them, overall, are quite low, as shown in appendix Table A-1 (the correlations for men (women) are .06 (.08) for mental and physical health, .13(.13) for mental and poor health, .21 (.24) for physical and poor health, .09 (.10-.12) between severe headaches and mental, poor or physical health, and -.01-.09 (-.01-.08) between mental, poor or physical health and regular dental care since childhood.

\section{Later Measures of Health}

Our later measures of health include two types of measures; a set of aggregate measures over working years or to the age of interview in SHARELIFE (Wave 3 or 7) and then a set of measures reported by five-year intervals over ages 16-20 and going to age 60-64 for job-tied health or to age 76-80 for health conditions (see fn. 4).

In the first set of aggregate measures, we include 1) whether an individual ever reported one or 2) two or more periods of poor health in adulthood or 3) retired due to health problems. Next, we explore 4) the fraction of years worked in total and 5) the fraction of years worked full-time, both over years 20 and 64 or the age of interview in SHARELIFE if below age 64 .

In terms of outcome measures reported over five-year intervals, we include: 6) whether an individual had a gap in their employment. We use five-year intervals over ages 21 to 64 (or the age of interview in SHARELIFE if below age 64) where the responses are cumulative. Related to the gap measure, we have 7) whether or not an individual had retired, another cumulative measure also over ages 25 to 64. Finally, we include a measure built up from reports of particular health conditions and measured in five-year intervals from age 16-20 to 76-80. The aggregate conditions reported here include five CVDs. These comprise a heart attack or other heart problems, high blood pressure, high blood cholesterol, a stroke or cerebral vascular disease, and diabetes. We also did sensitivity checks 
on single CVDs or adding step-wise chronic lung disease and cancer to the overall set of CVDs (in the appendix we show the results for the five CVDs along with lung disease; all other ones are available upon request). The respondents are asked if they ever had each of these conditions and if so, the age they first had the condition. We think of these reports as a measure of incidence.

The full sample of 26,741 men and 34,151 women report these outcome measures through age 50 , but the sample then becomes smaller because not all are yet in that age bracket, there is slight attrition, and mortality further reduces the sample. The smallest number report if they retired due to health, 16,975 men and 17,685 women (this excludes those that have not yet retired).

Table 1 provides the means, standard deviations (SDs) and number of observations for all of these, except for the health conditions, whose incidence rate by age is shown in Figure 1. We note that the pattern observed of a rapid increase in incidence of a health condition, i.e. a CVD, is likely dominated by hypertension (high blood pressure), which is the most common of these diseases, which tends to be rare until middle age or the mid forties. McGrath et al. (2019) find that hypertension accounted for the greatest burden in terms of Disability Adjusted Life Years among middle and older age adults in the US. Because of this established pattern we highlight CVD in our analysis below. ${ }^{9}$

\section{Other variables}

Given the multi-country and multi-cohort nature of the data, in all estimates we add fixed effects for country of residence and year of birth in five-year intervals. The mean age of the sample is 67.1 (66.8) for men (women). The oldest in the sample were born before WWI $(0.08 \%$ of the sample). We also include measures of the socio-economic status of the family when the individual was age 10 including number of rooms per person, number of facilities and number of books in their home. In addition, we control for whether or not the individual was born in an urban area.

We also have a set of non-health outcomes, which we explore in their own right, and which we explore as potentially part of the life-course that mediate the relationship between early health and later health. These include years in fulltime education, whether final education in ISCED units was $<3,3-4$ or 5-6, whether they ever married, and, whether they ever had a natural child. The average number of years of schooling for our sample is 14.2 (13.3) for men (women). Means, SDs and number of observations for all these variables are reported in Table 1 by gender.

\section{Results}

\footnotetext{
${ }^{9}$ For example, Hardy, Lawlor and Kuh in a frequently referenced article stated "Coronary heart disease (CHD) and stroke are rare until middle age, but the pathophysiological process of atherosclerosis, which ultimately leads to cardiovascular disease (CVD), is initiated in early life." (Hardy et al., 2015). This life course perspective is fully consistent with our exploration.
} 
We begin our discussion with our descriptive results. At its core, we look at the six later health outcomes one at a time as a function of either all four early health measures or those we term our core early health measures: mental health, physical health and poor/fair health. Next we estimate reduced form equations which control for birth cohort and country fixed effects and measures of SES as a child: born in an urban area, facilities, books and rooms per person in the home at the age of 10 and regular dental care since childhood.

First, we look at the age patterns of three of our later health outcome measures. We begin with CVD health conditions and compare the age-specific incidence of those with early mental health, physical health or poor/fair health to those without any of these three early conditions, and we do so separately for men and women. Figure 1 has four graphs. Those on the left show the first incidence of the included conditions, while those on the right show the accumulated probabilities of having these conditions, or prevalence, the top ones for men and bottom ones for women. All are from ages 16-20 until ages 76-80. The graphs include responses based on the following question which also lists the conditions: 'About how old were you when you were first told by a doctor that you had a heart attack or any other heart problem/high blood pressure/high blood cholesterol/a stroke or cerebral vascular disease/diabetes?'

The overall first incidence pattern for these combined serious conditions increases by age hitting a maximum at ages 46-50, except for women who had poor/fair early health and men with no childhood health problems who hit this maximum a decade later. But the difference for those that had a childhood condition suggests that for men, the highest incident rates up to age 46-50 is for those who had a childhood mental illness followed by those with a childhood physical illness and those with poor/fair general health. The pattern changes at 46-50 years, where those with poor general health as a child now show the greatest incidence over the older years. Those with early mental illness actually have the lowest incidence beginning at 56-60, perhaps because they are the most likely to have already experienced these conditions. The graph on the right showing the cumulative probabilities (once a person reports they had an illness, they have a one for that indicator) suggests that those who had an early mental condition have the highest prevalence to age 60 but beyond age 60 , those who had poor/fair general health as a child gradually overtake them in terms of reports of these serious conditions. At all times, those males who did not report one of these conditions as a child report the lowest prevalence rate.

Women show a similar pattern but with slight differences from men. As noted, again incidence rates are highest at ages 46-50, except for women with early poor health, but it is less clear that the rate is consistently highest for those who had an early mental health condition. After 46-50, the incidence rate is greatest for those who reported early poor/fair health, a group whose incidence of CVD peaks at ages 56-60. Again, those with early mental illness actually have the lowest incidence for women at older ages (after 51-55), perhaps because they are the most likely to have already experienced these conditions, but the 
differences are small enough early on that the overall incidence appears greatest for those with early poor health. After age 66-70, there is no noticeable difference in the cumulative probability of having one or more of these serious diseases for those who had a physical or mental condition or did not report having an early health condition.

Turning to our next measure of later health, in Figure 2 we first look at those who report gaps in work over ages 25-64.10 The top graph is for men, the bottom for women. Here, we see that those who had an early mental health condition report the greatest number of gaps for both genders, but the pattern is far starker for men.

Among men, by age 35, on average, those who reported an early mental health condition report more than one gap; the average number for them increases to 2.4 by age 45 and to nearly 6 by age 60 . Those with poor/fair health as a child report the second highest number of gaps, but they are far below those reported by men with an early mental health condition. Men with a childhood physical health problem appear to not differ from those with no childhood health problem.

Turning to women, first we note the much larger number of gaps in working than for men. This difference may be tied to both norms and childbearing. Still, up until age 56-60, women who had an early mental health condition report the greatest number of work gaps. Interestingly, there is a suggestion that those with early physical health problems had fewer gaps that those with no early health condition, but the differences are small. A possible insight for this is discussed below where we find increased schooling for women with early physical health problems, and also a slightly lower probability of marrying and having a child.

Our last measure of later health is the pattern of retiring by age shown in Figure 3 , again for men (top) and women (bottom). For men we find that by age 60 close to $60 \%$ of these European men retire, but the rate at earlier ages is greatest for those who had an early mental health condition. The difference is starkest at age 50. The pattern for women is similar although the rate of retirement is slightly higher than for men at nearly every age. Again, for women, those who had an early mental health condition are more likely to retire at every age but particularly so at ages 41-50.

Ties to later health

The pattern of descriptive results suggests that, for all three health outcomes (CVDs, gaps and retirement), men and women with early mental health problems had earlier health problems as adults than those with other early conditions or who were healthy as children. Those who reported poor/fair health as children had more health issues than others of their age except as noted, for those with

\footnotetext{
${ }^{10}$ As discussed above, gaps in work can occur for multiple reasons; our discussion assumes health related reasons are a primary factor but the reader may wish to skip this measure and focus on those that more directly measure later health.
} 
mental health issues. In most cases, for these individuals, their health problems came later in life than those with early mental health conditions. For retirement, differences remain until about age 60 .

But, what of our broader indicators of later health, does the same overall results hold? Here we turn to regressions in which we control for country of residence and cohort fixed effects, SES as a child, as well as our measure of health care utilization. In Table 2, when we look at those who ever worked we find a strong negative influence of early mental health among men (a negative coefficient suggesting a reduction of $3.9 \%$ points). Among women, an early physical health problem is statistically significantly tied to ever worked and for them, the coefficient is positive and significant. Next, we look at number of career gaps for men; here again it is those with mental health issues that have the largest number of gaps (an increase greater than 3 gaps). Men with early poor health have nearly one additional gap while those with severe headaches as a child have about a half gap more on average than those with no such health conditions. Among women it is those who reported poor/fair health and then those who reported early mental health conditions that have an increased number of gaps, nearly 2 for those with poor early health and nearly 1.5 for those for early mental health issues. Women who had early physical problems have about a half gap less than otherwise healthy women. Two related alternative measure of life course health in Table 2 are the fraction of years worked and the fraction of years worked full-time. Once again we see the far stronger tie from early mental health (-.12 and -.13) and to a lesser extent early poor/fair (-.03 and -.04) than physical health among men. The results are quite similar for both outcomes. Early severe headaches or migraines also appear tied to reduced years working and working full time though the coefficients are smaller (-.014 and -.02). The results for women are quite similar although the coefficients are only about a third of those for men.

Finally, for this phase of our analysis we look at three more direct later health outcomes; reported one or more significant periods of ill health during adulthood, two or more significant periods of ill health during adulthood and retired due to poor health. For men, the regressions show that those with early mental health conditions are most likely to report all three of these, followed by those with poor/fair health, except in the case of retirement due to poor health where those with severe headaches as a child are about as likely to retire early due to poor health as those with poor/fair early health. Most of these results are statistically significant at .05 levels of significance. For women the pattern also shows a higher probability for all three later health outcomes among those who had early mental health conditions; followed by who had early poor/fair health. Thus, all of these later health outcomes suggest a far larger tie from early mental health problems to later health problems than for overall poor/fair health, physical health or severe headaches. We note here that our indicator of health care utilization, dental care, is tied to better long-term health as captured by ever worked, career gaps and a single period of ill health in adulthood, but not by (not) retired due to health or (not having) multiple periods of ill health. Perhaps these latter make receiving dental care more difficult. 
As part of our exploration of the influence of early health on later health, we also briefly address the influence of early health on human capital accumulation and then on measures of wellbeing such as if the person ever married and ever had a natural child (see Table 3). For education, we include years in full-time schooling (Columns 1) and three indicators of levels as used by many European countries low or ISCED 0-2, medium or ISCED 3-4 and high or ISCED 5-6 (Columns 2 to 4, respectively). For both men and women, we find a similar and what we view as very interesting pattern: those who reported early physical health conditions receive more schooling than others, controlling for family SES, cohort and country of residence. For males the coefficient on years of schooling is .36 while for females it is slightly greater at .42. This suggests that parents may invest more in education for children with physical health problems, perhaps with a view they require added schooling to succeed in the labor market. In contrast to the findings for those with physical health problems, among females those with poor/fair health receive somewhat less schooling with a coefficient of -.31 . Dental care is strongly and positively tied to years of schooling for men and women.

Turning to the regressions using the three categories of completed schooling we find that men with early mental health conditions are more likely to have completed just a low level of education and less likely to have medium or high completed schooling. In contrast and consistent with the results for years of schooling, men with early physical health conditions are less likely to have low education and somewhat more likely to have medium or high years of schooling. For women, the results are again consistent where those with early physical health problems are less likely to have low education and more likely to have medium and especially high education. In the case of women, we find no consistent pattern of a tie between mental health and schooling but do find that those with poor/fair health are more likely to have less schooling (ISCED 0-2) and less likely to have a medium or high education level, and more years of education. Women who had severe headaches also are more likely to have low levels of schooling but the point estimates are smaller than for those with poor/fair health. Overall then we find a consistent finding that those children who had an early physical health condition were likely on average to accumulate more human capital in the form of years of schooling than those with other conditions or who were healthy as children.

Turning to our estimates for measures of wellbeing we have only two: ever married (Columns 5) and ever had a natural child (Columns 6). The ties between early health and ever married or having a natural child are stronger for men than for women. Women with early mental health problems are slightly less likely to ever marry (-.03) or have a natural child (-.04). For men, these coefficients are equal to -.09, that is, 2-3 times as large in absolute terms. Men with early poor/fair health are also less likely to marry (-.03), and are less likely to have a natural child (-.04). The latter difference is only slightly lower in absolute terms for women (-.03). No significant differences are found for men and women with severe headaches during childhood, but women with early physical health 
problems are slightly less likely to have ever married and ever had had a natural child (-0.01). Thus, for our two measures of wellbeing, the ties to early life, while relatively small, are larger for men, and in particular for those who had early mental health problems.

Ties to life course health

We now turn to our regression analysis where each of our later health outcomes serve as a dependent variable, our four early health variables are the right-hand side variables of primary interest and we include controls for birth cohort, country of residence, childhood SES variables and regular use of dental care. As a test of robustness, we also include the additional mediators that were found to be significantly influenced by our early health measures, namely years of fulltime schooling, ever married and having a natural child. In addition, we assess the importance of omitted variables using a test proposed by Oster (2019). The results from these sensitivity checks are included in the appendix. None of the robustness checks change the main results or the conclusions from our paper.

We already looked at our broader indicators of later health in the results presented above so, here, we look at indicators of later health by five-year intervals beginning with the tie to serious health conditions as an adult. We focus on initial incidence of CVDs. These are shown in Figure 4 for men in Panel A and women in Panel B (the full set of estimates is given in appendix tables A-3 and A4). We calculated heteroskedasiticty-robust standard errors and show the $95 \%$ confidence intervals on the figures. Among men, the results suggest that those who had an overall poor/fair health and to a lesser extent a physical health problem as a child are slightly more likely (about 1 p.p.) to incur a CVD early in adulthood, from age 16 to 40 . For those with childhood mental health problems there is limited evidence of a significant association with CVDs over men's life course, except for a marginally significant increase in the early 30 s (about 2 p.p.) and decline in the late 50s (3 p.p.). Importantly, the spike in CVDs at ages 46-50 shown in Figure 1 is driven entirely by those with poor/fair health as a child. The actual coefficient is close to 3 p.p. and significant at a $1 \%$ level. As shown in appendix figure A-2, the differences across these childhood health indicators are statistically significant at ages 46-50 (and again at 76-80). These results suggest a much higher likelihood of CVDs among middle age men who had poor/fair health as a child. In contrast to men, among women those with a mental condition by age 15 are about 2 p.p. more likely to experience an initial CVD at age 16-20 and 21-25 and again at 36-40. The first two age periods are significantly different from those who had a physical or overall poor/fair health. A finding not shown in the figure is the higher probability of women who experienced severe headaches as a child having an initial CVD at ages 46-50 (with a coefficient of +.025 ) continuing throughout their 50 s. Thus we find quite different patterns by gender where men with early poor/fair health are at increased risk of a CVD especially at ages 46-50 while women with early mental health problems are at greater risk in their late teens, early twenties and 36-40. Women with severe headaches are more likely to experience an initial CVD at ages 46-50, the age at which men with poor health appeared at greater risk. 
In appendix figure A-3 we show a similar analysis where we extend the health conditions studied to include lung conditions. The pattern essentially replicates the analysis described above that focuses only on CVDs. Then in appendix figure A-7 we extend the right-hand side variables to include years of full-time schooling, whether ever married and whether the individual had a natural child. The inclusion of these variables does not change the results for men or women. Finally, in appendix figures A-13 and A-16, we show the main estimates from Figure 4 (where we added severe headaches or migraines) along with Oster's (2019) identified set of estimates using different thresholds for the key parameters in this test (see Appendix A.1 for details). Importantly, the main results, as discussed above, regarding e.g. the increased risk of a CVD at ages 4650 for men with early poor/fair health and women with severe headaches, remain robust. The identified sets we obtain exclude the zero suggesting that there is a small positive causal effect of these childhood health variables on life course onset of a CVD. This effect is not at all negligible for childhood mental health problems. Thus, these three tests of robustness provide additional evidence of the pattern by which our four early health conditions are tied to the future pattern of CVDs, or important health conditions over the life course.

Our next later health indicator that we measure over the life course is gaps in one's career measured only for those who ever worked. In this case we measure accumulated gaps so once you have a gap, that gap remains as a measure of your health as you age. The results are shown in figure 5 (the full set of estimates is given in appendix tables A-5 for men and A-6 for women). We measure this outcome only over ages 21-25 to 61-64. Men show a very clear pattern in which those who had early mental health problems have a higher number of gaps at every age beginning at 21-25 and continuing through 61-64. The average number of gaps reaches 3 for these men by the time they reach 56-60. The second group of men with higher numbers of gaps are those who had poor/fair health as a child but this pattern does not really begin until the early 30 s and only reaches nearly one gap by age 61-64. These differences in estimates are statistically significant comparing mental to physical, poor/fair health and across all three of these early health conditions for all of our included ages. These results are shown in figure A-5. If we add years of full-time schooling, ever married and ever had a child to the right-hand side variables, the patterns remain although there is a slight dampening of the ties with a maximum of about 2.6 rather than 3 at ages 56-60 (see figure A-8). Performing Oster's (2019) test for omitted variables provides evidence that our estimates of childhood mental health problems and poor/fair health are robust to taking unobserved factors into account (see figures A-14 and A-17).

For women, we see a quite different pattern where those with poor/fair health as a child have more career gaps beginning at age 21-25, and eventually reaching nearly two additional gaps by 61-64. Women who experienced early mental health problems show an increase in gaps but they only begin at ages 51-55 at about one gap and increase to about 1.3 gaps by 61-64. Women who experienced early physical problems are slightly less likely to have a gap than those who were healthy, or had these other early conditions (0.4 gaps less by age 61-64), a finding consistent with our other findings on the pattern of work related 
outcomes for women. The observed differences are statistically significant as shown in figure A-5 comparing women with mental, poor or physical health over the entire studied life course, as well as those with poor early health compared to those with an early physical health problem. For women this pattern remains without any dampening when we add schooling, marriage and birth of a natural child as right-hand side controls (figure A-8) and when we take unobserved factors into account (figures A-14 and A-17).

Our final later life course health outcome is age of retirement. As shown in figure 6 , the pattern for men and women is similar (the full set of estimates is given in appendix tables A-7 for men and A-8 for women). Men with early mental health problems are more likely to retire early than other men. By ages 41-45 the gap in probability of a man who had an early mental health problem is .05 which increases to about .07 at 46-50. In contrast, men with poor/fair health as a child are also more likely to retire early than other men but the difference is less than half that of men with a mental health condition. Their pattern increases as they age reaching a maximum at 56-60. These observed differences are statistically significant comparing men with the three early health conditions over ages 3640 through 56-60 (see figure A-6). The pattern remains when we add schooling, ever married and ever had a natural child to the control variables (figures A-9 and A-12) and when we use Oster's method to take unobserved factors into account (figures A-15 and A-18). Women who had an early mental health condition are also the most likely to retire at nearly every age studied. At ages $51-55$, the difference in probability reaches .1. Those who had early poor/fair health are also more likely to retire over the period studied but the differences are about one-third of women with an early mental health problem. The differences comparing the three groups of women with early health problems are statistically significant over ages 36-40 through 60-64 (see figure A-6). This pattern is replicated when we add schooling, ever married and ever had a natural child as controls (figures A-9 and A-12) and when we compute Oster's identified set of estimates using different thresholds for the key parameters in this test (see figures A-15 and A-18 and Appendix A.1 for details).

\section{Discussion and Conclusion}

In this paper, we explored the influence of four specific dimensions of early-life health on the onset of specific health conditions and permanent or temporary withdrawals from the labor market over the life course. The four specific dimensions of early life are mental health issues, physical health problems, poor or fair general health and severe headaches or migraines, all by age 15 . The life course health related outcomes we explored included 1) the probability of having an onset of cardiovascular related health conditions (and then adding chronic lung disease) in five-year intervals over ages $16-80 ; 2$ ) the probability of having $1+$ or 2+ episodes of ill health during adulthood; 3 ) the fraction of years employed and those worked full-time; 4) the accumulated number of career gaps in employment in five-year intervals over ages $25-64 ; 5$ ) the probability of leaving the labor force in five-year intervals over ages 25-64; and 6) the probability of having retired from a job because of own ill health. We conducted the analysis separately by gender and controlled for cohort and country of 
residence fixed effects, childhood SES indicators and use of dental care since childhood. We then tested the robustness of our results to the inclusion of possible mediating factors (schooling, ever married and ever had a natural child) and more generally by implementing an omitted variables test proposed by Oster (2019). None of the robustness checks changed the main results or the conclusions from our paper.

We see our primary contributions as our focus on the links between different dimensions of childhood health and multiple life course outcomes including the age of onset of serious cardiovascular conditions and job-related health outcomes. This is unique in our knowledge of the literature. We found that the different dimensions of childhood health have unique ties to later outcomes. This is best illustrated for men.

For men, early mental problems play a stronger role for all life course job-related health outcomes, but early poor or fair general health is more strongly linked to the onset of CVDs. In particular, the spike in CVDs in the late 40s, shown in the descriptive analysis, is driven entirely by men with poor or fair general health as a child. For included work-related measures of life course health, it is men with early mental health problems who do worst. They have the lowest probability of having ever worked (about 4 p.p. less), and when they work, they accumulate the greatest number of work gaps; the average number of gaps for them rose to 2 by age 45 and to 3 by age 60 . We also found this pattern when we looked at the fraction of years worked and the fraction of years worked full-time, where again we found a far stronger tie from early mental health (-12 and -13 p.p.) than for men with other early health conditions. Finally, men with early mental health conditions were also the most likely to retire early due to health $(+8$ p.p.). These differences where often only about one third as large for those with early poor or fair general health and mostly insignificant for those with early physical health problems as a child.

For women, the links between the different dimensions of childhood health and the multiple life course outcomes are less clear-cut than for men. Differently than for men, women who had a mental health condition early in life are more likely than others to experience an onset of a CVD in their early to mid-adult years but not thereafter, and the initial and largest spike in the onset of a CVD at ages 4650 is driven by women who had severe headaches by age 15 . Turning to life course work-tied measures, we first found a seemingly surprising outcome: early physical health problems are generally tied to better work-related outcomes. Women with early physical problems are more likely to work (+ 2.5 p.p.) than other women and when they work, they accumulate slightly fewer gaps than women without physical health problems (about 0.4 gaps less by age 60). Instead, women who reported poor/fair health and early mental health conditions have an increased number of gaps, nearly 1.7 for those with poor early health and 1.3 for those for early mental health issues by age 60 . Our last measure of work-tied health, age at retirement, again finds no negative tie to physical health but instead that women who had an early mental health condition are also the most likely to retire at nearly every age studied followed 
by those who had early poor/fair health but the differences are about one-third of women with an early mental health problem.

What might explain this seeming puzzle? We looked at intermediary outcomes such as schooling as well as whether an individual ever married or had a natural child. For both men and women, we find those who reported early physical health conditions receive more schooling than others, controlling for family SES, cohort and country of residence fixed effects. For females, the tie is slightly stronger than for males This suggests that parents, especially parents of daughters may invest more in education for children with physical health problems, perhaps with a view they require added schooling to succeed in the labor market. The ties between early health and ever married or having a natural child are, somewhat surprisingly, larger for men than for women. Women with early mental health problems are slightly less likely to ever marry ( -3 p.p.) or have a natural child ( -4 p.p.). For men, these coefficients are 2-3 times as large in absolute terms. Men with early poor/fair health are also slightly less likely to marry. For both men and women we find no such negative ties for those with early physical health problems.

These findings provide both part of an explanation for our results and add evidence that it is important to distinguish by type of early health problem (and gender) to predict (and counter) life cycle health consequences. But more generally, our study shows that investigating the links between multiple different dimensions of childhood health and multiple health-related life course outcomes enables a better understanding of how health inequalities originate and are shaped over people's lives. 


\section{References}

Almond, D. (2006). 'Is the 1918 Influenza Pandemic over? Long-term effects of in utero influenza exposure in the post-1940 U.S. population', Journal of Political Economy, Vol. 114, pp. 672-712.

Almond, D. and Currie, J. (2011a). 'Human capital development before age five', in Ashenfelter O. and Card D. (eds), Handbook of Labor Economics, Vol. 4B, chap. 15. Amsterdam: Elsevier Science B.V., pp. 1315-1486.

Almond, D. and Currie, J. (2011b). 'Killing me softly: The Fetal Origins Hypothesis', Journal of Economic Perspectives, Vol. 25, pp. 153-172.

Almond, D., Currie, J. and Duque, V. (2018). 'Childhood circumstances and adult outcomes: Act II', Journal of Economic Literature, Vol. 56, pp. 1360-1446.

Almond, D. and Mazumder, B. (2005). "The 1918 Influenza Pandemic and subsequent health outcomes: an analysis of SIPP data', American Economic Review: Papers \& Proceedings, Vol. 95, pp. 258-262.

Altonji, J., Elder, T. and Taber, C. (2005). 'Selection on observed and unobserved variables: Assessing the effectiveness of Catholic schools', Journal of Political Economy, Vol. 113, pp. 151-184.

Barker, D. J. P. (1995). 'Fetal origins of coronary heart disease', British Medical Journal, Vol. 311, pp. 171-174.

Barker, D. J. (1998). 'In utero programming of chronic disease', Clinical Science (London), Vol. 95, pp. 115-28.

Barreca, A. I. (2010). 'The long-term economic impact of in utero and postnatal exposure to malaria', Journal of Human Resources, Vol. 45, pp. 865-892.

Ben-Shlomoadler, Y. and Kuh, D. (2002). 'A life course approach to chronic disease epidemiology: conceptual models, empirical challenges and interdisciplinary perspectives', International Journal of Epidemiology, Vol. 31, pp. 285-93.

Bhalotra, S. and Venkataramani, A. (2015). Shadows of the Captain of the Men of Death: Health Innovation, Human Capital Investment, and Institutions, Unpublished.

Bharadwaj, P., Eberhard, J. P. and Neilson, C. A. (2018). 'Health at Birth, Parental Investments, and Academic Outcomes', Journal of Labor Economics, Vol. 36, pp. 349-94.

Bharadwaj, P., Lundborg, P. and Rooth, D. O. (2014). The Effects of Birth Weight over the Life Cycle, Working Paper. 
Black, S. E. and Devereux, P.J. (2011). 'Recent developments in intergenerational mobility', in Ashenfelter O. and Card D. (eds), Handbook of Labor Economics, Vol. 4B, chap. 16. Amsterdam: Elsevier Science B.V., pp. 1487-1541.

Börsch-Supan, A., Brandt, M., Hunkler, C., Kneip, T., Korbmacher, J., Malter, F., Schaan, B., Stuck, S. and Zuber, S. (2013). 'Data Resource Profile: The Survey of Health, Ageing and Retirement in Europe (SHARE)', International Journal of Epidemiology, Vol. 42, pp. 992-1001.

Brugiavini, A., Orso, C. E., Genie, M. G., Naci, R. and Pasini, G. (2019). Combining the retrospective interviews of wave 3 and wave 7: the third release of the SHARE Job Episodes Panel, SHARE Working Paper Series (36-2019). Munich: Munich Center for the Economics of Aging (MEA).

Case, A., Fertig, A. and Paxson, C. (2005). 'The Lasting Impact of Childhood Health and Circumstance', Journal of Health Economics, Vol. 24, pp. 365-89.

Case, A., Lubotsky, D. and Paxson, C. (2002). 'Economic status and health in childhood: the origins of the gradient', American Economic Review, Vol. 92, pp. 1308-1334.

Case, A. and Paxson, C. (2008). 'Height, health and cognitive function at older ages', American Economic Review: Papers \& Proceedings, Vol. 98, pp. 463-467.

Chen, Y. and Zhou, L. A. (2007). 'The long-term health and economic consequences of the 1959-1961 famine in China', Journal of Health Economics, Vol. 26, pp. 659-681.

Currie, J. (2020). 'Child health as human capital', Health Economics, Vol. 29, pp. 452-463.

Currie, J. and Stabile, M. (2003). 'Socioeconomic status and health: why is the relationship stronger for older children?', American Economic Review, Vol. 93, pp. 1813-1823.

Currie, J. and Stabile, M. (2006). 'Child mental health and human capital accumulation: The Case of ADHD', Journal of Health Economics, Vol. 25, pp. 10941118.

Currie, J. and Stabile, M. (2009). 'Mental health in childhood and human capital', in Gruber J. (ed), An Economic Perspective on the Problems of Disadvantaged Youth. University of Chicago Press for the National Bureau of Economic Research, Chicago, IL.

Currie, J., Stabile, M., Manivong, P. and Roos, L. (2010). 'Child health and young adult outcomes', Journal of Human Resources, Vol. 45, pp. 517-548. 
Figlio, D., Guryan, J., Karbownik, K. and Roth, J. (2014). 'The Effects of Poor Neonatal Health on Children's Cognitive Development', American Economic Review, Vol. 104, pp. 3921-55.

Fletcher, J. and Wolfe, B. (2009). 'Long-Term Consequences of Childhood ADHD on Criminal Activities', The Journal of Mental Health Policy and Economics, Vol. 12, pp. 119-38.

Fletcher, J. and Wolfe, B. (2008). 'Child Mental Health and Human Capital Accumulation: The Case of ADHD Revisited', Journal of Health Economics, Vol. 27, pp. 794-800.

Guo, G. and Harris, K. M. (2000). 'The mechanisms mediating the effects of poverty on children's intellectual development', Demography, Vol. 37, pp. 43147.

Hardy, R., Lawlor, D. and Kuh, D. (2015). 'A life course approach to cardiovascular aging', Future Cardiology, Vol. 11, pp. 101-113.

Kesternich, I., Siflinger, B., Smith, J. P. and Winter, J. K. (2014). 'The effects of World War II on economic and health outcomes across Europe', Review of Economics and Statistics, Vol. 96, pp. 103-118.

Kolenikov, S. and Angeles, G. (2009). 'Status measurement with discrete proxy variables: Is principal component analysis a reliable answer?', Review of Income and Wealth, Vol. 55, pp. 128-165.

Kuh, D. J. L. and Wadsworth, M. E. J. (1993). 'Physical health status at 36 years in a British national birth cohort', Social Science \& Medicine, Vol. 37, pp.905-916.

Marmot, M., Allen, J., Bell, R., Bloomer, E. and Goldblatt, P. on behalf of the Consortium for the European Review of Social Determinants of Health and the Health Divide (2012). 'WHO European review of social determinants of health and the health divide', Lancet, Vol. 380, pp. 1011-1029.

Marmot, M. G., Brunner, S. and Hemingway, S. (2001). 'Relative contributions of early life and adult socioeconomic factors to adult morbidity in the Whitehall II study', Journal of Epidemiology \& Community Health, Vol. 55, pp. 301-307.

McGrath, R., Al Snih, S., Markides, K., Hall, O. and Peterson, M. (2019). 'The burden of health conditions for middle-aged and older adults in the United States: disability-adjusted life years', BMC Geriatrics, Vol. 19, No. 100.

Mian, A. and Sufi, A. (2014). 'What explains the 2007-2009 drop in employment?', Econometrica, Vol. 82, pp. 2197-2223.

Nelson, R. E. (2010). 'Testing the fetal origins hypothesis in a developing country: evidence from the 1918 Influenza Pandemic', Health Economics, Vol. 19, pp. 1181-1192. 
Oster, E. (2019). 'Unobservable selection and coefficient stability: Theory and evidence', Journal of Business \& Economic Statistics, Vol. 37, pp. 187-204.

Painter, R. C., Roseboom, T. J. and Bleker, O. P. (2005). 'Prenatal exposure to the Dutch famine and disease in later life: an overview', Reproductive Toxicology, Vol. 20, pp. 345-352.

Roseboom, T. J., van der Meulen, J. H. P., Ravelli, A.C. J., Osmond, C., Barker, D. J. P. and Bleker, O. P. (2001). 'Effects of prenatal exposure to the Dutch famine on adult disease in later life: an overview', Molecular and Cellular Endocrinology, Vol. 185, pp. 93-98.

Roseboom, T., de Rooij, S. and Painter, R. (2006). 'The Dutch famine and its longterm consequences for adult health', Early Human Development, Vol. 82, pp. 485491.

Smith, J. P. (2009a). 'Reconstructing childhood health histories', Demography, Vol. 46, pp. 387-403.

Smith, J. P. (2009b). 'The impact of childhood health on adult labor market outcomes', Review of Economics and Statistics, Vol. 91, pp. 478-489.

Smith, J. P., Shen, Y., Strauss, J., Zhe, Y. and Zhao, Y. (2012). 'The Effects of Childhood Health on Adult Health and SES in China', Economic Development and Cultural Change, Vol. 61, pp. 127-156.

van den Berg, G. J., Lindeboom, M. and Portrait, F. (2006). 'Economic conditions early in life and individual mortality', American Economic Review, Vol. 96, pp. 290-302.

Yang, Y. C., Gerken, K., Schorpp, K., Boen, C. and Harris, K. M. (2017). 'Early-Life Socioeconomic Status and Adult Physiological Functioning: A Life Course Examination of Biosocial Mechanisms', Biodemography and Social Biology, Vol. 63, pp. 87-103. 


\section{Figures and Tables}

Figure 1: Probability of Having a Cardiovascular Disease by Age and Childhood Health for Men and Women ${ }^{a}$ Panel A. Probability of onset

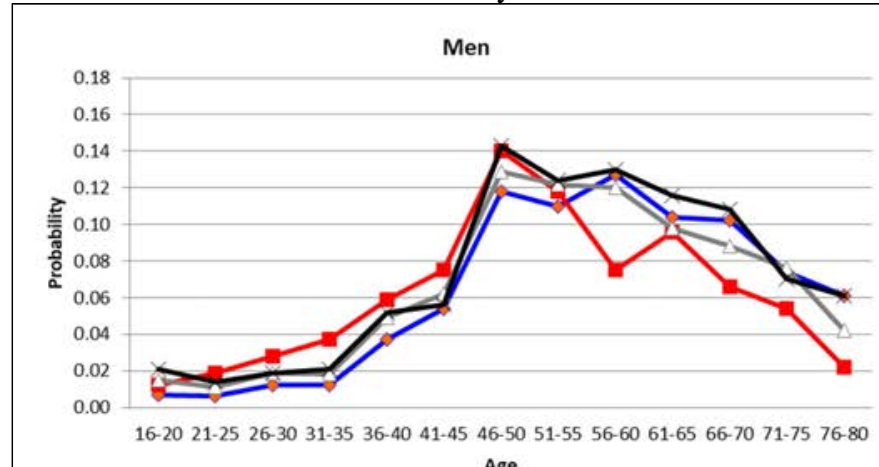

Age

$\longrightarrow$ Healthy $\rightarrow$ Mental $\rightarrow$ Physical $\longrightarrow$ Poor

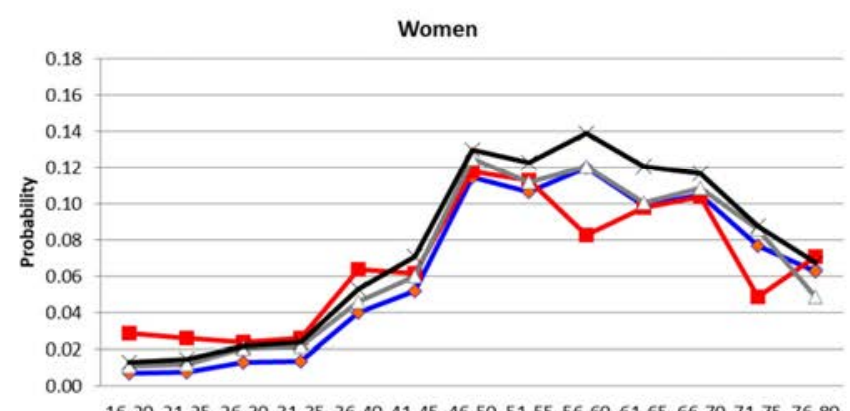

Age

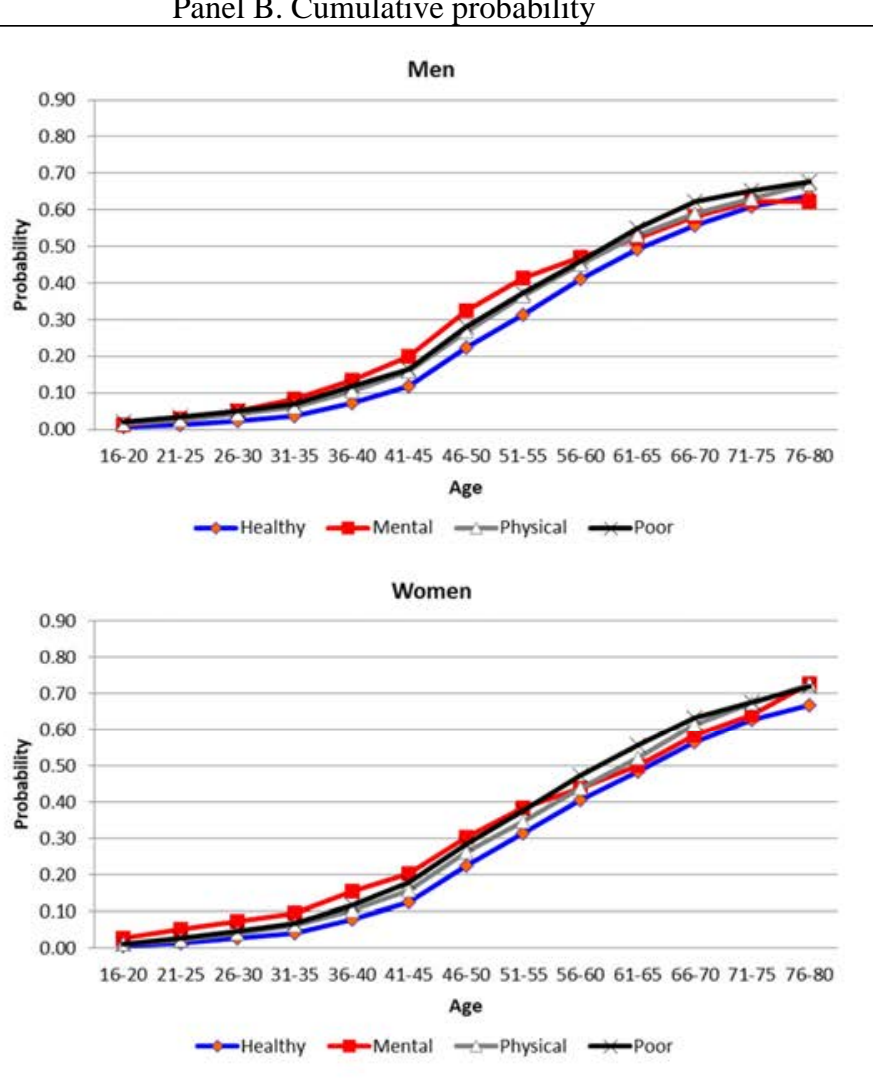

${ }^{a}$ CVDs include a heart attack or other heart problems, high blood pressure, high blood cholesterol, a stroke or cerebral vascular disease, and diabetes. Physical includes individuals one standard deviation below the mean in an index of childhood physical health and Poor/fair those with "Poor, fair or changing childhood SRH". The numbers of respondents used are given in Table A-2. 
Figure 2: Accumulated Career Gaps since Career Start by Age and Childhood Health for Men and Women ${ }^{\mathrm{a}}$

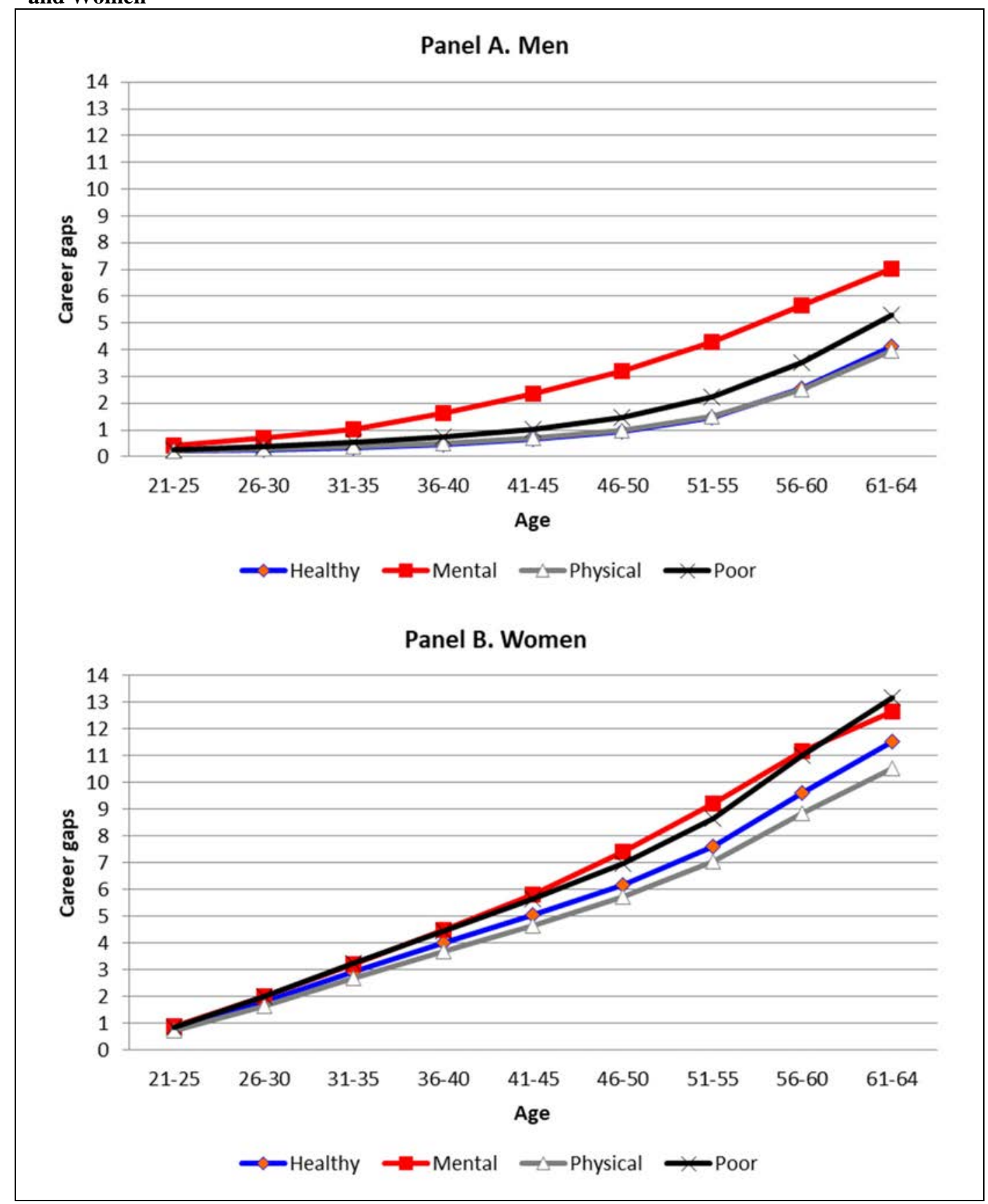

${ }^{\text {a }}$ Physical includes individuals one standard deviation below the mean in an index of childhood physical health and Poor/fair those with "Poor, fair or changing childhood SRH". The sample includes people below age 64 . 
Figure 3: Cumulative Probability of Retiring by Age and Childhood Health for Men and Women $^{\mathrm{a}}$

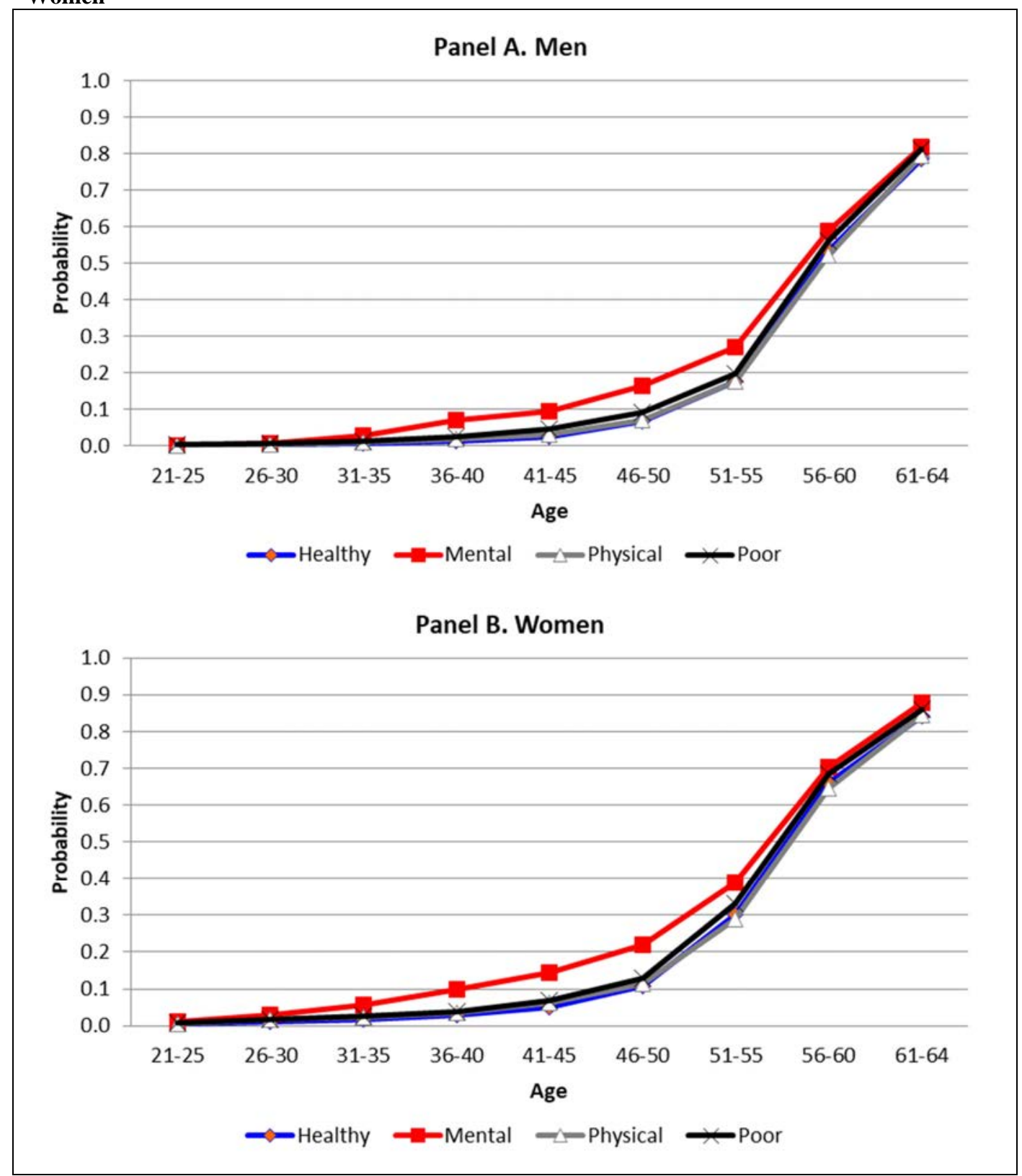

${ }^{\text {a }}$ Physical includes individuals one standard deviation below the mean in an index of childhood physical health and Poor/fair those with "Poor, fair or changing childhood SRH". The figure refers to people who report having retired from a job. 
Figure 4: Estimates of mental and physical health problems and poor self-reported health prior to age 16 from linear regressions on CVDs (0-1) for men and women over ages 16 to 80 years in Europe ${ }^{\mathrm{a}}$

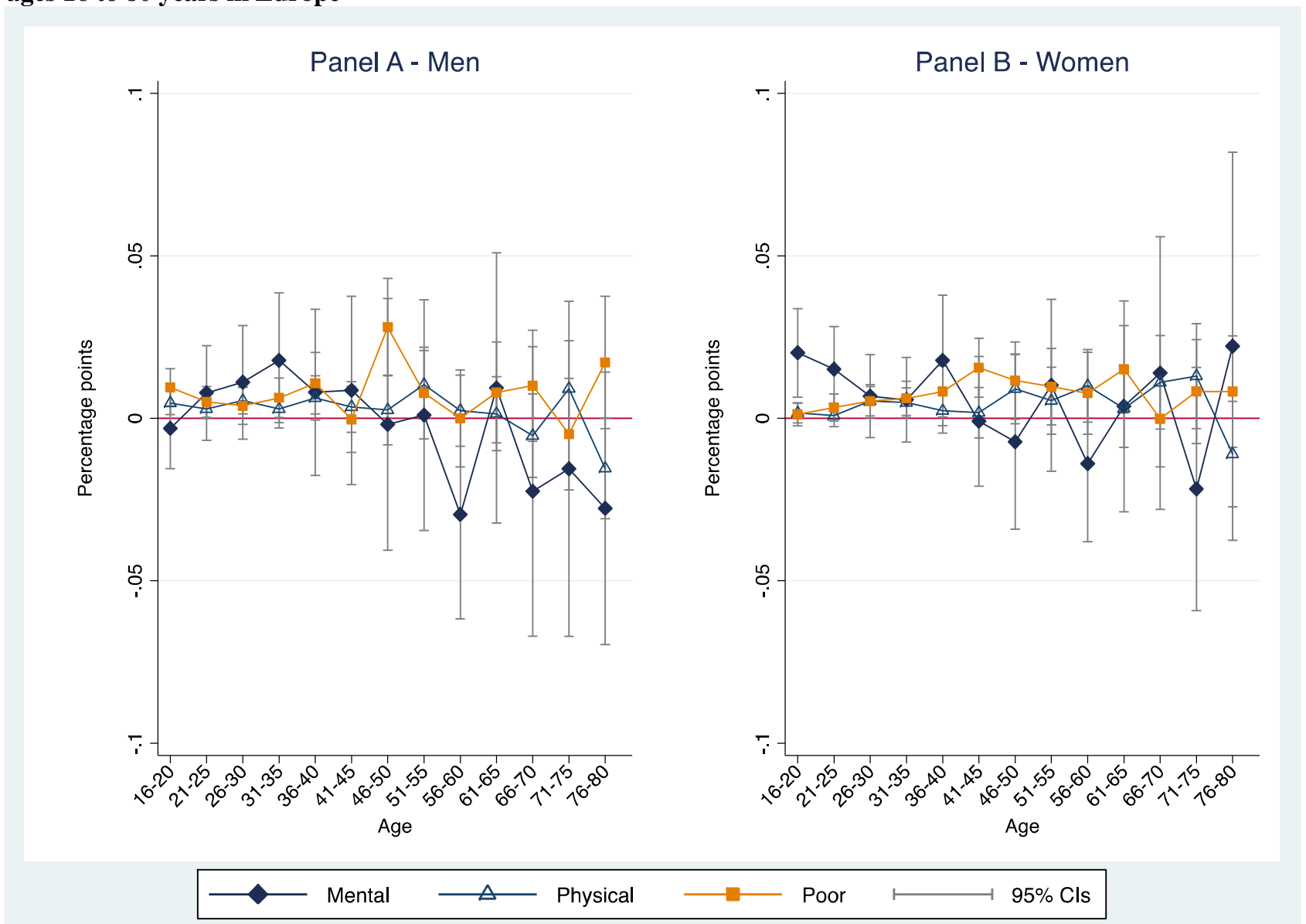

a The figure shows OLS estimates for Mental health problems (0-1), Physical health problems (0-1) and Poor childhood SRH (0-1) obtained from estimating linear models on the probability of having a CVD (0-1) at five-year intervals over ages 16 to 80 years, separately for men and women in Europe. Physical includes those one standard deviation below the mean in an index of childhood physical health and Poor those with "Poor, fair or changing childhood SRH". All models include all the variables listed in Table 1, except age and the mediating factors, plus country dummies and five-year cohort dummies. 95\% confidence intervals are based on robust standard errors. The full set of estimates are shown in Tables A-3 and A-4. 
Figure 5: Estimates of mental and physical health problems and poor self-reported health prior to age 16 from linear regressions on accumulated career gaps since career start from age 21 to 64 or the latest age observed for men and women in Europe ${ }^{\mathrm{a}}$

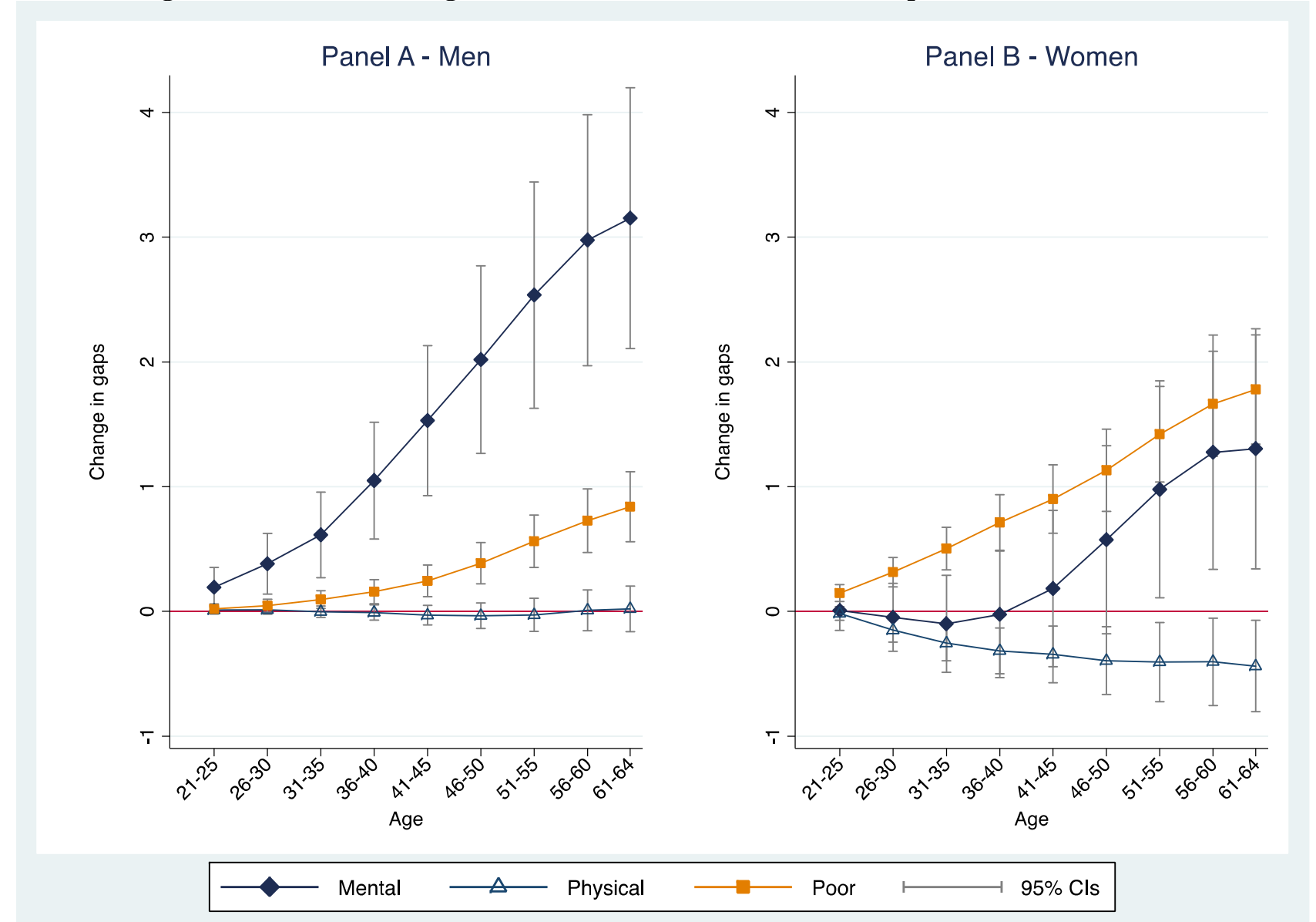

a The figure shows OLS estimates for Mental health problems (0-1), Physical health problems (0-1) and Poor childhood SRH (0-1) obtained from estimating linear models on accumulated career gaps between age 21 to 64 or the latest age observed, separately for men and women in Europe. Physical includes those one standard deviation below the mean in an index of childhood physical health and Poor those with "Poor, fair or changing childhood SRH". All models include all the variables listed in Table 1, except age and the mediating factors, plus country dummies and five-year cohort dummies. 95\% confidence intervals are based on robust standard errors. The full set of estimates are shown in Tables A-5 and A-6. 
Figure 6: Estimates of mental and physical health problems and poor self-reported health prior to age 16 from linear regressions on the probability of retiring from a job from age 21 to 64 or the latest age observed for men and women in Europe ${ }^{a}$

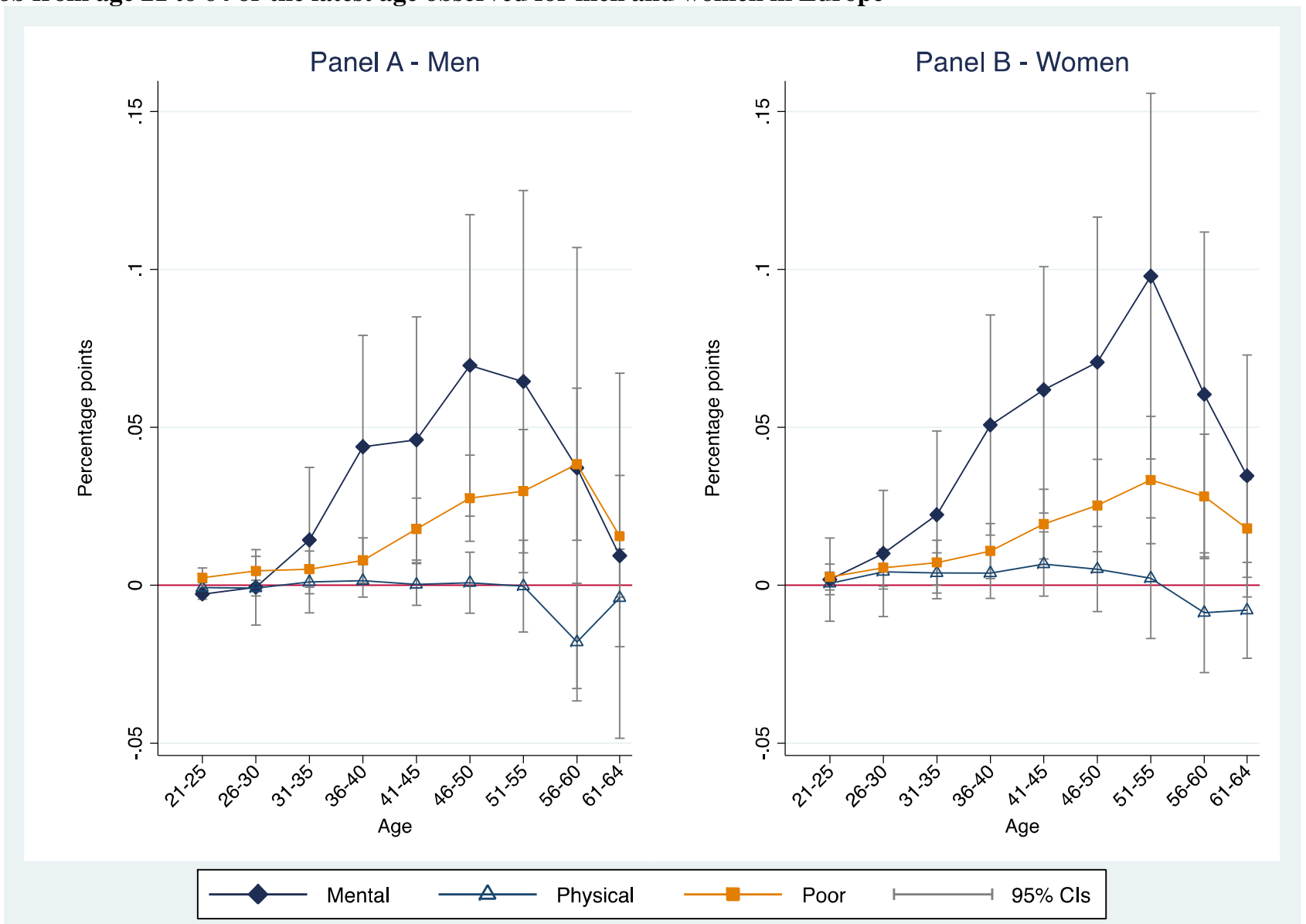

a The figure shows OLS estimates for Mental health problems (0-1), Physical health problems (0-1) and Poor childhood SRH (0-1) obtained from estimating linear models on the probability of retiring from a job between age 21 to 64 or the latest age observed, separately for men and women in Europe. Physical includes those one standard deviation below the mean in an index of childhood physical health and Poor those with "Poor, fair or changing childhood SRH". All models include all the variables listed in Table 1, except age and the mediating factors, plus country dummies and five-year cohort dummies. 95\% confidence intervals are based on robust standard errors. The full set of estimates are shown in Tables A-7 and A-8. 
Table 1: Sample means and standard deviations of childhood and adulthood variables for men and women in Europe ${ }^{\mathrm{a}}$

\begin{tabular}{|c|c|c|c|c|c|c|}
\hline & \multicolumn{3}{|l|}{ Men } & \multicolumn{3}{|c|}{ Women } \\
\hline & Mean & SD & $\mathrm{N}$ & Mean & SD & $\mathrm{N}$ \\
\hline \multicolumn{7}{|l|}{ Childhood health variables (0-15 years) } \\
\hline Emotional problems or epilepsy $(0-1)($ Mental $)$ & 0.012 & 0.109 & 26741 & 0.017 & 0.129 & 34151 \\
\hline Physical health index (those 1SD below the mean) (0-1) (Physical) & 0.180 & 0.384 & 26741 & 0.130 & 0.336 & 34151 \\
\hline Poor, fair or changing self-reported health (0-1) (Poor/fair) & 0.090 & 0.287 & 26741 & 0.107 & 0.309 & 34151 \\
\hline Severe headaches or migraines when $0-15$ years $(0-1)$ & 0.035 & 0.185 & 26741 & 0.055 & 0.228 & 34151 \\
\hline \multicolumn{7}{|l|}{ Childhood SES (at age of 10$)$ and health care (0-15 years) } \\
\hline Rooms per person when 10 years old ${ }^{\mathrm{b}}$ & 0.727 & 0.423 & 26741 & 0.704 & 0.416 & 34151 \\
\hline Bookcase at home when 10 years old $(0-1)(1=>25 \text { books })^{\mathrm{c}}$ & 0.372 & 0.483 & 26741 & 0.388 & 0.487 & 34151 \\
\hline Number of facilities at home when 10 years old $(0-5)^{\mathrm{d}}$ & 2.221 & 1.842 & 26741 & 2.181 & 1.841 & 34151 \\
\hline Born in an urban area $(0-1)$ & 0.350 & 0.477 & 26741 & 0.344 & 0.475 & 34151 \\
\hline Regular dental care since childhood $(0-1)$ & 0.470 & 0.499 & 26741 & 0.550 & 0.498 & 34151 \\
\hline \multicolumn{7}{|l|}{ Other control variables } \\
\hline Age (in years) & 67.1 & 9.2 & 26741 & 66.8 & 9.8 & 34151 \\
\hline \multicolumn{7}{|l|}{ Mediating factors } \\
\hline Years in full-time education & 14.2 & 5.4 & 26741 & 13.3 & 5.5 & 34151 \\
\hline Low education $(0-1)$ & 0.355 & 0.479 & 26646 & 0.430 & 0.495 & 34040 \\
\hline Medium education ( $0-1)$ & 0.395 & 0.489 & 26646 & 0.365 & 0.482 & 34040 \\
\hline Ever married $(0-1)$ & 0.924 & 0.266 & 26741 & 0.938 & 0.242 & 34151 \\
\hline Ever had a natural child (0-1) & 0.857 & 0.350 & 26741 & 0.885 & 0.318 & 34151 \\
\hline \multicolumn{7}{|l|}{ Life course health outcomes } \\
\hline $1+$ periods of ill health in adulthood $(0-1)$ & 0.177 & 0.382 & 26727 & 0.187 & 0.390 & 34128 \\
\hline $2+$ periods of ill health in adulthood $(0-1)$ & 0.048 & 0.215 & 26727 & 0.060 & 0.237 & 34128 \\
\hline Retired because of bad health $(0-1)$ & 0.123 & 0.328 & 16975 & 0.125 & 0.331 & 17685 \\
\hline Ever worked $(0-1)$ & 0.988 & 0.109 & 26741 & 0.889 & 0.314 & 34151 \\
\hline Fraction of years worked (25-64 or latest age) & 0.877 & 0.183 & 26741 & 0.615 & 0.369 & 34151 \\
\hline Fraction of years worked FT always (25-64 or latest age) & 0.857 & 0.212 & 26741 & 0.495 & 0.396 & 34151 \\
\hline Number of career gaps (since career start) & 4.2 & 5.9 & 26404 & 11.5 & 12.6 & 30322 \\
\hline
\end{tabular}

a This table depicts the final sample of all men. The first three rows show childhood mental, physical and self-reported health. ${ }^{\mathrm{b}}$ The number of rooms include bedrooms, but

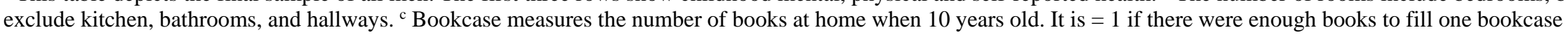
(26-100 books), two bookcases (101-200 books) or two or more bookcases ( $>200$ books), and $=0$ if there were none or very few books (0-10 books) or enough to fill one shelf only (11-25 books). ${ }^{\mathrm{d}}$ Includes fixed bath, cold and hot running water supply, inside toilet and central heating. 
Table 2: Marginal effects of childhood health variables on health during adulthood in Europe ${ }^{\mathrm{a}}$

\begin{tabular}{|c|c|c|c|c|c|c|c|}
\hline Men & $\begin{array}{l}\text { Ever worked } \\
(0-1) \\
(1)\end{array}$ & $\begin{array}{l}\text { N. of career } \\
\text { gaps } \\
(2)\end{array}$ & $\begin{array}{l}\text { Fraction } \\
\text { worked } \\
\text { (3) }\end{array}$ & $\begin{array}{l}\text { Frac. worked } \\
\text { full time } \\
\text { (4) }\end{array}$ & $\begin{array}{l}1+\text { ill health } \\
(0-1) \\
(5)\end{array}$ & $\begin{array}{l}2+\text { ill health } \\
(0-1) \\
(6)\end{array}$ & $\begin{array}{l}\text { Retired due to own ill health } \\
(0-1) \\
(7)\end{array}$ \\
\hline Mental (0-1) & $\begin{array}{l}-0.039 * * * \\
(0.012)\end{array}$ & $\begin{array}{l}3.153 * * * \\
(0.533)\end{array}$ & $\begin{array}{l}-0.120^{* * *} \\
(0.017)\end{array}$ & $\begin{array}{l}-0.128 * * * \\
(0.018)\end{array}$ & $\begin{array}{l}0.140 * * * \\
(0.026)\end{array}$ & $\begin{array}{l}0.072 * * * \\
(0.017)\end{array}$ & $\begin{array}{l}0.052^{*} \\
(0.029)\end{array}$ \\
\hline Physical (1SD below the mean) $(0-1)$ & $\begin{array}{l}-0.000 \\
(0.002)\end{array}$ & $\begin{array}{l}0.019 \\
(0.093)\end{array}$ & $\begin{array}{l}0.000 \\
(0.003)\end{array}$ & $\begin{array}{l}-0.005 \\
(0.004)\end{array}$ & $\begin{array}{l}0.039 * * * \\
(0.007)\end{array}$ & $\begin{array}{l}0.018^{* * *} \\
(0.004)\end{array}$ & $\begin{array}{l}0.012 * \\
(0.007)\end{array}$ \\
\hline Poor/fair/changing SRH (0-1) & $\begin{array}{l}-0.008 * * \\
(0.003)\end{array}$ & $\begin{array}{l}0.839 * * * \\
(0.144)\end{array}$ & $\begin{array}{l}-0.029 * * * \\
(0.004)\end{array}$ & $\begin{array}{l}-0.035^{* * *} \\
(0.005)\end{array}$ & $\begin{array}{l}0.097 * * * \\
(0.010)\end{array}$ & $\begin{array}{l}0.044 * * * \\
(0.006)\end{array}$ & $\begin{array}{l}0.033 * * * \\
(0.009)\end{array}$ \\
\hline Severe headaches or migraines $(0-1)$ & $\begin{array}{l}-0.004 \\
(0.004)\end{array}$ & $\begin{array}{l}0.427^{* *} \\
(0.202)\end{array}$ & $\begin{array}{l}-0.014^{* *} \\
(0.006)\end{array}$ & $\begin{array}{l}-0.020^{* * *} \\
(0.008)\end{array}$ & $\begin{array}{l}0.029 * * \\
(0.013)\end{array}$ & $\begin{array}{l}0.017 * * \\
(0.008)\end{array}$ & $\begin{array}{l}0.038^{* *} \\
(0.015)\end{array}$ \\
\hline Rooms (an increase of one room) & $\begin{array}{l}-0.004^{* * *} \\
(0.001)\end{array}$ & $\begin{array}{l}-0.355^{* * *} \\
(0.099)\end{array}$ & $\begin{array}{l}0.002 \\
(0.003)\end{array}$ & $\begin{array}{l}0.002 \\
(0.003)\end{array}$ & $\begin{array}{l}-0.031 * * * \\
(0.007)\end{array}$ & $\begin{array}{l}-0.006 \\
(0.004)\end{array}$ & $\begin{array}{l}-0.027 * * * \\
(0.008)\end{array}$ \\
\hline Bookcase $(0-1)(1=>25$ books $)$ & $\begin{array}{l}0.007^{* * * *} \\
(0.001)\end{array}$ & $\begin{array}{l}-0.564^{* * *} \\
(0.086)\end{array}$ & $\begin{array}{l}0.014^{* * *} \\
(0.003)\end{array}$ & $\begin{array}{l}0.007 * * \\
(0.003)\end{array}$ & $\begin{array}{l}-0.016^{* * *} \\
(0.006)\end{array}$ & $\begin{array}{l}-0.006^{*} \\
(0.003)\end{array}$ & $\begin{array}{l}-0.024^{* * *} \\
(0.006)\end{array}$ \\
\hline Number of facilities at home when 10 years old $(0-4)$ & $\begin{array}{l}-0.000 \\
(0.000)\end{array}$ & $\begin{array}{l}-0.221^{* * *} \\
(0.027)\end{array}$ & $\begin{array}{l}0.005^{* * *} \\
(0.001)\end{array}$ & $\begin{array}{l}0.005^{* * * *} \\
(0.001)\end{array}$ & $\begin{array}{l}-0.005^{* * *} \\
(0.002)\end{array}$ & $\begin{array}{l}-0.002^{* *} \\
(0.001)\end{array}$ & $\begin{array}{l}-0.005^{* * *} \\
(0.002)\end{array}$ \\
\hline Born in urban area $(0-1)$ & $\begin{array}{l}-0.001 \\
(0.002)\end{array}$ & $\begin{array}{l}0.234^{* * *} \\
(0.079)\end{array}$ & $\begin{array}{l}-0.009 * * * \\
(0.002)\end{array}$ & $\begin{array}{l}-0.007 * * \\
(0.003)\end{array}$ & $\begin{array}{l}-0.012 * * \\
(0.005)\end{array}$ & $\begin{array}{l}-0.001 \\
(0.003)\end{array}$ & $\begin{array}{l}-0.010^{*} \\
(0.006)\end{array}$ \\
\hline Regular dental care since childhood (0-1) & $\begin{array}{l}0.001 \\
(0.002)\end{array}$ & $\begin{array}{l}-0.485^{* * *} \\
(0.085)\end{array}$ & $\begin{array}{l}0.012 * * * \\
(0.003)\end{array}$ & $\begin{array}{l}0.011^{* * * *} \\
(0.003)\end{array}$ & $\begin{array}{l}-0.013^{* *} \\
(0.005)\end{array}$ & $\begin{array}{l}-0.004 \\
(0.003)\end{array}$ & $\begin{array}{l}-0.008 \\
(0.006)\end{array}$ \\
\hline R-squared & & 0.089 & 0.062 & 0.038 & & & \\
\hline Pseudo R-squared & 0.116 & & & & 0.038 & 0.044 & 0.066 \\
\hline Observations & 26741 & 26404 & 26741 & 26741 & 26727 & 26727 & 16975 \\
\hline
\end{tabular}


Table 2: Continued

\begin{tabular}{|c|c|c|c|c|c|c|c|}
\hline Women & $\begin{array}{l}\text { Ever worked } \\
(0-1) \\
(1)\end{array}$ & $\begin{array}{l}\text { N. of career } \\
\text { gaps } \\
\text { (2) }\end{array}$ & $\begin{array}{l}\text { Fraction } \\
\text { worked } \\
\text { (3) }\end{array}$ & $\begin{array}{l}\text { Frac. worked } \\
\text { full time } \\
\text { (4) }\end{array}$ & $\begin{array}{l}1+\text { ill health } \\
(0-1) \\
(5)\end{array}$ & $\begin{array}{l}2+\text { ill health } \\
(0-1) \\
(6)\end{array}$ & $\begin{array}{l}\text { Retired due to own ill health } \\
(0-1) \\
(7)\end{array}$ \\
\hline Mental (0-1) & $\begin{array}{l}0.008 \\
(0.014)\end{array}$ & $\begin{array}{l}1.304 * * * \\
(0.491)\end{array}$ & $\begin{array}{l}-0.039 * * * \\
(0.013)\end{array}$ & $\begin{array}{l}-0.044 * * * \\
(0.015)\end{array}$ & $\begin{array}{l}0.136 * * * \\
(0.019)\end{array}$ & $\begin{array}{l}0.083 * * * \\
(0.014)\end{array}$ & $\begin{array}{l}0.077^{* * * *} \\
(0.024)\end{array}$ \\
\hline Physical (1SD below the mean) $(0-1)$ & $\begin{array}{l}0.025 * * * \\
(0.005)\end{array}$ & $\begin{array}{l}-0.438^{* *} \\
(0.187)\end{array}$ & $\begin{array}{l}0.021^{* * *} \\
(0.005)\end{array}$ & $\begin{array}{l}0.000 \\
(0.006)\end{array}$ & $\begin{array}{l}0.048 * * * \\
(0.007)\end{array}$ & $\begin{array}{l}0.024 * * * \\
(0.004)\end{array}$ & $\begin{array}{l}0.014^{*} \\
(0.008)\end{array}$ \\
\hline Poor/fair/changing SRH (0-1) & $\begin{array}{l}-0.001 \\
(0.006)\end{array}$ & $\begin{array}{l}1.781^{* * *} \\
(0.224)\end{array}$ & $\begin{array}{l}-0.041^{* * *} \\
(0.006)\end{array}$ & $\begin{array}{l}-0.033^{* * *} \\
(0.006)\end{array}$ & $\begin{array}{l}0.113^{* * *} \\
(0.008)\end{array}$ & $\begin{array}{l}0.056 * * * \\
(0.005)\end{array}$ & $\begin{array}{l}0.067 * * * \\
(0.009)\end{array}$ \\
\hline Severe headaches or migraines $(0-1)$ & $\begin{array}{l}-0.007 \\
(0.007)\end{array}$ & $\begin{array}{l}0.428 \\
(0.292)\end{array}$ & $\begin{array}{l}-0.013^{*} \\
(0.008)\end{array}$ & $\begin{array}{l}-0.021^{* *} \\
(0.009)\end{array}$ & $\begin{array}{l}0.040^{* * *} \\
(0.010)\end{array}$ & $\begin{array}{l}0.017 * * * \\
(0.006)\end{array}$ & $\begin{array}{l}0.034 * * * \\
(0.012)\end{array}$ \\
\hline Rooms (an increase of one room) & $\begin{array}{l}-0.012 * * * \\
(0.004)\end{array}$ & $\begin{array}{l}-1.294 * * * \\
(0.188)\end{array}$ & $\begin{array}{l}0.018 * * * \\
(0.005)\end{array}$ & $\begin{array}{l}0.017 * * * \\
(0.006)\end{array}$ & $\begin{array}{l}-0.037 * * * \\
(0.006)\end{array}$ & $\begin{array}{l}-0.012 * * * \\
(0.004)\end{array}$ & $\begin{array}{l}-0.018^{* *} \\
(0.009)\end{array}$ \\
\hline Bookcase $(0-1)(1=>25$ books $)$ & $\begin{array}{l}0.037 * * * \\
(0.004)\end{array}$ & $\begin{array}{l}-1.737^{* * *} \\
(0.150)\end{array}$ & $\begin{array}{l}0.057 * * * \\
(0.004)\end{array}$ & $\begin{array}{l}0.052^{* * *} \\
(0.005)\end{array}$ & $\begin{array}{l}-0.003 \\
(0.005)\end{array}$ & $\begin{array}{l}-0.007^{* *} \\
(0.003)\end{array}$ & $\begin{array}{l}-0.010^{*} \\
(0.006)\end{array}$ \\
\hline Number of facilities at home when 10 years old $(0-4)$ & $\begin{array}{l}0.005^{* * *} \\
(0.001)\end{array}$ & $\begin{array}{l}-0.425^{* * *} \\
(0.048)\end{array}$ & $\begin{array}{l}0.013^{* * *} \\
(0.001)\end{array}$ & $\begin{array}{l}0.008 * * * \\
(0.001)\end{array}$ & $\begin{array}{l}-0.009 * * * \\
(0.002)\end{array}$ & $\begin{array}{l}-0.004 * * * \\
(0.001)\end{array}$ & $\begin{array}{l}-0.006 * * * \\
(0.002)\end{array}$ \\
\hline Born in urban area $(0-1)$ & $\begin{array}{l}0.010 * * * \\
(0.003)\end{array}$ & $\begin{array}{l}0.082 \\
(0.146)\end{array}$ & $\begin{array}{l}0.002 \\
(0.004)\end{array}$ & $\begin{array}{l}0.013^{* * *} \\
(0.004)\end{array}$ & $\begin{array}{l}0.009 * \\
(0.005)\end{array}$ & $\begin{array}{l}0.007 * * \\
(0.003)\end{array}$ & $\begin{array}{l}-0.002 \\
(0.006)\end{array}$ \\
\hline Regular dental care since childhood (0-1) & $\begin{array}{l}0.033 * * * \\
(0.003)\end{array}$ & $\begin{array}{l}-1.247^{* * *} \\
(0.159)\end{array}$ & $\begin{array}{l}0.052 * * * \\
(0.004)\end{array}$ & $\begin{array}{l}0.051 * * * \\
(0.005)\end{array}$ & $\begin{array}{l}-0.018 * * * \\
(0.005)\end{array}$ & $\begin{array}{l}-0.003 \\
(0.003)\end{array}$ & $\begin{array}{l}-0.006 \\
(0.006)\end{array}$ \\
\hline R-squared & & 0.202 & 0.256 & 0.215 & & & \\
\hline Pseudo R-squared & 0.264 & & & & 0.043 & 0.051 & 0.058 \\
\hline Observations & 34151 & 30322 & 34151 & 34151 & 34128 & 34128 & 17685 \\
\hline
\end{tabular}


Table 3: Marginal effects of childhood health variables on measures of human capital and wellbeing during adulthood in Europe ${ }^{\mathrm{a}}$

\begin{tabular}{|c|c|c|c|c|c|c|}
\hline Men & $\begin{array}{l}\text { Years in full-time } \\
\text { education } \\
\text { (1) }\end{array}$ & $\begin{array}{l}\text { Education level } \\
\text { Low educ. (ISCED } \\
0-2) \\
(2)\end{array}$ & $\begin{array}{l}\text { Medium educ. (ISCED } \\
3-4) \\
\text { (3) }\end{array}$ & $\begin{array}{l}\text { High educ. (ISCED } \\
5-6) \\
(4)\end{array}$ & $\begin{array}{l}\text { Ever } \\
\text { married } \\
(0-1) \\
(5)\end{array}$ & $\begin{array}{l}\text { Ever had a natural } \\
\text { child } \\
(0-1) \\
(6)\end{array}$ \\
\hline Mental (0-1) & $\begin{array}{l}-0.179 \\
(0.330)\end{array}$ & $\begin{array}{l}0.045^{* *} \\
(0.021)\end{array}$ & $\begin{array}{l}-0.007 * * \\
(0.003)\end{array}$ & $\begin{array}{l}-0.038 * * \\
(0.018)\end{array}$ & $\begin{array}{l}-0.093 * * * \\
(0.020)\end{array}$ & $\begin{array}{l}-0.093^{* * *} \\
(0.023)\end{array}$ \\
\hline Physical (1SD below the mean) $(0-1)$ & $\begin{array}{l}0.363 * * * \\
(0.077)\end{array}$ & $\begin{array}{l}-0.031^{* * *} \\
(0.006)\end{array}$ & $\begin{array}{l}0.005^{* * *} \\
(0.001)\end{array}$ & $\begin{array}{l}0.026 * * * \\
(0.005)\end{array}$ & $\begin{array}{l}0.001 \\
(0.004)\end{array}$ & $\begin{array}{l}0.005 \\
(0.006)\end{array}$ \\
\hline Poor/fair/changing SRH (0-1) & $\begin{array}{l}-0.051 \\
(0.113)\end{array}$ & $\begin{array}{l}0.006 \\
(0.008)\end{array}$ & $\begin{array}{l}-0.001 \\
(0.001)\end{array}$ & $\begin{array}{l}-0.005 \\
(0.007)\end{array}$ & $\begin{array}{l}-0.031 * * * \\
(0.007)\end{array}$ & $\begin{array}{l}-0.041 * * * \\
(0.008)\end{array}$ \\
\hline Severe headaches or migraines $(0-1)$ & $\begin{array}{l}-0.217 \\
(0.157)\end{array}$ & $\begin{array}{l}-0.001 \\
(0.012)\end{array}$ & $\begin{array}{l}0.000 \\
(0.002)\end{array}$ & $\begin{array}{l}0.001 \\
(0.010)\end{array}$ & $\begin{array}{l}0.007 \\
(0.008)\end{array}$ & $\begin{array}{l}0.004 \\
(0.011)\end{array}$ \\
\hline Rooms (an increase of one room) & $\begin{array}{l}0.880^{* * *} \\
(0.088)\end{array}$ & $\begin{array}{l}-0.078^{* * *} \\
(0.007)\end{array}$ & $\begin{array}{l}0.012 * * * \\
(0.001)\end{array}$ & $\begin{array}{l}0.067 * * * \\
(0.006)\end{array}$ & $\begin{array}{l}-0.011 * * * \\
(0.004)\end{array}$ & $\begin{array}{l}-0.028 * * * \\
(0.005)\end{array}$ \\
\hline Bookcase $(0-1)(1=>25$ books $)$ & $\begin{array}{l}2.012 * * * \\
(0.070)\end{array}$ & $\begin{array}{l}-0.156^{* * *} \\
(0.005)\end{array}$ & $\begin{array}{l}0.023 * * * \\
(0.001)\end{array}$ & $\begin{array}{l}0.133^{* * *} \\
(0.004)\end{array}$ & $\begin{array}{l}0.014^{* * *} \\
(0.004)\end{array}$ & $\begin{array}{l}0.005 \\
(0.005)\end{array}$ \\
\hline $\begin{array}{l}\text { Number of facilities at home when } 10 \text { years } \\
\text { old }(0-4)\end{array}$ & $\begin{array}{l}0.342 * * * \\
(0.022)\end{array}$ & $\begin{array}{l}-0.027 * * * \\
(0.002)\end{array}$ & $\begin{array}{l}0.004^{* * *} \\
(0.000)\end{array}$ & $\begin{array}{l}0.023 * * * \\
(0.001)\end{array}$ & $\begin{array}{l}0.001 \\
(0.001)\end{array}$ & $\begin{array}{l}-0.002 \\
(0.002)\end{array}$ \\
\hline Born in urban area $(0-1)$ & $\begin{array}{l}0.714^{* * *} \\
(0.067)\end{array}$ & $\begin{array}{l}-0.072^{* * *} \\
(0.005)\end{array}$ & $\begin{array}{l}0.011^{* * *} \\
(0.001)\end{array}$ & $\begin{array}{l}0.061^{* * *} \\
(0.004)\end{array}$ & $\begin{array}{l}0.005 \\
(0.004)\end{array}$ & $\begin{array}{l}-0.014^{* * *} \\
(0.005)\end{array}$ \\
\hline Regular dental care since childhood $(0-1)$ & $\begin{array}{l}0.792 * * * \\
(0.069)\end{array}$ & $\begin{array}{l}-0.073^{* * *} \\
(0.005)\end{array}$ & $\begin{array}{l}0.011^{* * *} \\
(0.001)\end{array}$ & $\begin{array}{l}0.062 * * * \\
(0.004)\end{array}$ & $\begin{array}{l}0.013^{* * *} \\
(0.004)\end{array}$ & $\begin{array}{l}0.015^{* * *} \\
(0.005)\end{array}$ \\
\hline R-squared & 0.214 & & & & & \\
\hline Pseudo R-squared & & 0.137 & & & 0.039 & 0.020 \\
\hline Observations & 26741 & 26646 & & & 26741 & 26741 \\
\hline
\end{tabular}


Table 3: Continued

\begin{tabular}{|c|c|c|c|c|c|c|}
\hline Women & $\begin{array}{l}\text { Years in full-time } \\
\text { education } \\
(1)\end{array}$ & $\begin{array}{l}\text { Education level } \\
\text { Low educ. (ISCED } \\
0-2) \\
(2)\end{array}$ & $\begin{array}{l}\text { Medium educ. (ISCED } \\
3-4) \\
(3)\end{array}$ & $\begin{array}{l}\text { High educ. (ISCED } \\
5-6) \\
(4)\end{array}$ & $\begin{array}{l}\text { Ever } \\
\text { married } \\
(0-1) \\
(5)\end{array}$ & $\begin{array}{l}\text { Ever had a natural } \\
\text { child } \\
(0-1) \\
(6)\end{array}$ \\
\hline Mental (0-1) & $\begin{array}{l}0.104 \\
(0.235)\end{array}$ & $\begin{array}{l}-0.007 \\
(0.016)\end{array}$ & $\begin{array}{l}0.002 \\
(0.004)\end{array}$ & $\begin{array}{l}0.005 \\
(0.012)\end{array}$ & $\begin{array}{l}-0.029 * * \\
(0.012)\end{array}$ & $\begin{array}{l}-0.040 * * * \\
(0.015)\end{array}$ \\
\hline Physical (1SD below the mean) $(0-1)$ & $\begin{array}{l}0.422 * * * \\
(0.081)\end{array}$ & $\begin{array}{l}-0.042^{* * *} \\
(0.006)\end{array}$ & $\begin{array}{l}0.011 * * * \\
(0.002)\end{array}$ & $\begin{array}{l}0.031 * * * \\
(0.004)\end{array}$ & $\begin{array}{l}-0.008^{*} \\
(0.004)\end{array}$ & $\begin{array}{l}-0.010^{*} \\
(0.005)\end{array}$ \\
\hline Poor/fair/changing SRH (0-1) & $\begin{array}{l}-0.314^{* * *} \\
(0.087)\end{array}$ & $\begin{array}{l}0.041^{* * *} \\
(0.007)\end{array}$ & $\begin{array}{l}-0.011^{* * *} \\
(0.002)\end{array}$ & $\begin{array}{l}-0.030 * * * \\
(0.005)\end{array}$ & $\begin{array}{l}-0.007 \\
(0.005)\end{array}$ & $\begin{array}{l}-0.032 * * * \\
(0.006)\end{array}$ \\
\hline Severe headaches or migraines $(0-1)$ & $\begin{array}{l}-0.151 \\
(0.109)\end{array}$ & $\begin{array}{l}0.021 * * \\
(0.009)\end{array}$ & $\begin{array}{l}-0.006 * * \\
(0.002)\end{array}$ & $\begin{array}{l}-0.015^{* *} \\
(0.006)\end{array}$ & $\begin{array}{l}0.005 \\
(0.005)\end{array}$ & $\begin{array}{l}0.009 \\
(0.007)\end{array}$ \\
\hline Rooms (an increase of one room) & $\begin{array}{l}1.092^{* * *} \\
(0.122)\end{array}$ & $\begin{array}{l}-0.087 * * * \\
(0.007)\end{array}$ & $\begin{array}{l}0.023 * * * \\
(0.002)\end{array}$ & $\begin{array}{l}0.064^{* * *} \\
(0.005)\end{array}$ & $\begin{array}{l}-0.005 \\
(0.004)\end{array}$ & $\begin{array}{l}-0.020^{* * *} \\
(0.004)\end{array}$ \\
\hline Bookcase $(0-1)(1=>25$ books $)$ & $\begin{array}{l}1.807 * * * \\
(0.064)\end{array}$ & $\begin{array}{l}-0.179 * * * \\
(0.004)\end{array}$ & $\begin{array}{l}0.048 * * * \\
(0.001)\end{array}$ & $\begin{array}{l}0.131^{* * *} \\
(0.003)\end{array}$ & $\begin{array}{l}-0.005 \\
(0.003)\end{array}$ & $\begin{array}{l}-0.011^{* * *} \\
(0.004)\end{array}$ \\
\hline $\begin{array}{l}\text { Number of facilities at home when } 10 \text { years } \\
\text { old }(0-4)\end{array}$ & $\begin{array}{l}0.378^{* * *} \\
(0.021)\end{array}$ & $\begin{array}{l}-0.032^{* * *} \\
(0.001)\end{array}$ & $\begin{array}{l}0.009^{* * *} \\
(0.000)\end{array}$ & $\begin{array}{l}0.023^{* * *} \\
(0.001)\end{array}$ & $\begin{array}{l}-0.004 * * * \\
(0.001)\end{array}$ & $\begin{array}{l}-0.007 * * * \\
(0.001)\end{array}$ \\
\hline Born in urban area $(0-1)$ & $\begin{array}{l}0.423 * * * \\
(0.062)\end{array}$ & $\begin{array}{l}-0.058^{* * * *} \\
(0.004)\end{array}$ & $\begin{array}{l}0.015^{* * *} \\
(0.001)\end{array}$ & $\begin{array}{l}0.042^{* * *} \\
(0.003)\end{array}$ & $\begin{array}{l}-0.006^{*} \\
(0.003)\end{array}$ & $\begin{array}{l}-0.022^{* * *} \\
(0.004)\end{array}$ \\
\hline Regular dental care since childhood (0-1) & $\begin{array}{l}0.725^{* * *} \\
(0.061)\end{array}$ & $\begin{array}{l}-0.087 * * * \\
(0.005)\end{array}$ & $\begin{array}{l}0.023^{* * *} \\
(0.001)\end{array}$ & $\begin{array}{l}0.063 * * * \\
(0.003)\end{array}$ & $\begin{array}{l}0.001 \\
(0.003)\end{array}$ & $\begin{array}{l}-0.007^{*} \\
(0.004)\end{array}$ \\
\hline R-squared & 0.252 & & & & & \\
\hline Pseudo R-squared & & 0.179 & & & 0.029 & 0.033 \\
\hline Observations & 34151 & 34040 & & & 34151 & 34151 \\
\hline
\end{tabular}




\section{Appendix}

This appendix provides additional analyses and results to the main paper.

\section{A.1 Assessing omitted variables bias}

As discussed in the main text, several studies using siblings (Currie et al., 2010; Smith, 2009b) have shown that the positive association between childhood health and later life health and labor market outcomes remains robust to siblings fixed effects (FE) approaches that account for, possibly many, unobserved family and neighborhood effects. The SHARE data is not suited to implement a siblings FE approach, as siblings are not part of the target population unless when they live in the same household, which is very rare for persons aged 50+. Therefore, to gauge the importance of unobserved characteristics in our analysis, we implement Oster's (2019) test of coefficient stability when there is omitted variable bias. This test-based on earlier work by Altonji et al. (2005)-uses the information contained in the changes in coefficient and in R-squared when moving from an uncontrolled to a controlled regression. Selection on observables is assumed to be informative about selection on unobservables. There are two key parameters in this test, $R_{\max }$ and $\delta$; given bounding values for both, one can calculate an identified set for the effect of interest (in our study, we are interested in the coefficients of childhood Mental, Physical, Poor, fair or changing health and Severe headaches or migraines which we denote as $\tilde{\beta}_{i}$, where $i=$ Mental, Physical, Poor or Migraines). $\delta$ represents the value for the relative degree of selection on observed and unobserved variables, and $R_{\max }$ is the R-squared that would result from a hypothetical regression of the outcome on our variable of interest and both observed and unobserved controls. Oster argues that equal selection (i.e., $\delta=1$, meaning that observables are as important as the unobservables) is an appropriate upper bound on $\delta$ because empirical studies typically include the regression controls that are believed ex-ante to be the most important ones. In our study, $R_{\max }<1$ for at least two reasons: (1) life course health results to a large extent from decisions that are taken after childhood, and (2) there is measurement error in our measures of life course health. Oster suggests using $R_{\max }=$ $\Pi \times \tilde{R}$ with $\Pi=1.3$ as cutoff, where $\tilde{R}$ is the R-squared from the regression with all observed controls (more precisely, $R_{\max }=\min \{1, \Pi \times \tilde{R}\}$ ). The value for $\Pi$ is taken from randomized studies. The logic is that in (correctly) randomized studies, including controls does not change the coefficient of interest because there is no confounding. Hence, the effects estimated in randomized data are causal and should survive an omitted variable test. It turns out that $90 \%$ of the randomized studies published in top journals that Oster considers pass her test when $\Pi=1.3$. We thus compute Oster's recommended identified set for Mental, Physical, Poor and Migraines $\left[\tilde{\beta}_{i}, \beta_{i}^{*}(1.3 \tilde{R}, 1)\right]$, where $\beta_{i}^{*}(1.3 \tilde{R}, 1)=\tilde{\beta}_{i}-\frac{\left(\dot{\beta}_{l}-\widetilde{\beta}_{i}\right)(1.3 \tilde{R}-\tilde{R})}{\left(\tilde{R}-\dot{R}_{l}\right)}$, with $\dot{\beta}_{l}$ being the coefficient from the short regression of the outcome on, correspondingly, Mental, Physical, Poor or Migraines and a constant term, and $\dot{R}_{i}$ being the R-squared from that regression (see Oster (2019) for details). The original estimates with the corresponding recommended sets that we obtain are shown for life course onset of a CVD in Figure A-13, for accumulated career gaps in Figure A-14 and for the probability of retiring in Figure A-15, for both men and women. As discussed in the 
main text in section "Ties to life course health", the recommended sets concerning our main results exclude all the zero suggesting that there is a (small) causal effect of our childhood health variables on these life course health outcomes. This holds for instance for the increased risk of a CVD at ages 46-50 for men with early poor/fair health and women with severe headaches in figures A-13, for the increasing number of career gaps over the life course for men and women with mental health problems and poor/fair health in figure A-14, and for the concave retirement profiles over the life course also for men and women with mental health problems and poor/fair health in figure A-15. Using other cutoffs for $R_{\max }$, for instance $R_{\max }=2.2 \tilde{R}$ as in Mian and Sufi (2014), gives identified set values for our childhood health variables as shown in Figures A-16 to A-18. They do not change the main results leading to the same conclusions, as discussed in the main text. 


\section{A.2. Additional figures and tables}

Figure A-1: Probability of Having CVDs or a Lung Disease by Age and Childhood Health for Men and Women ${ }^{\mathrm{a}}$ Panel A. Probability of onset

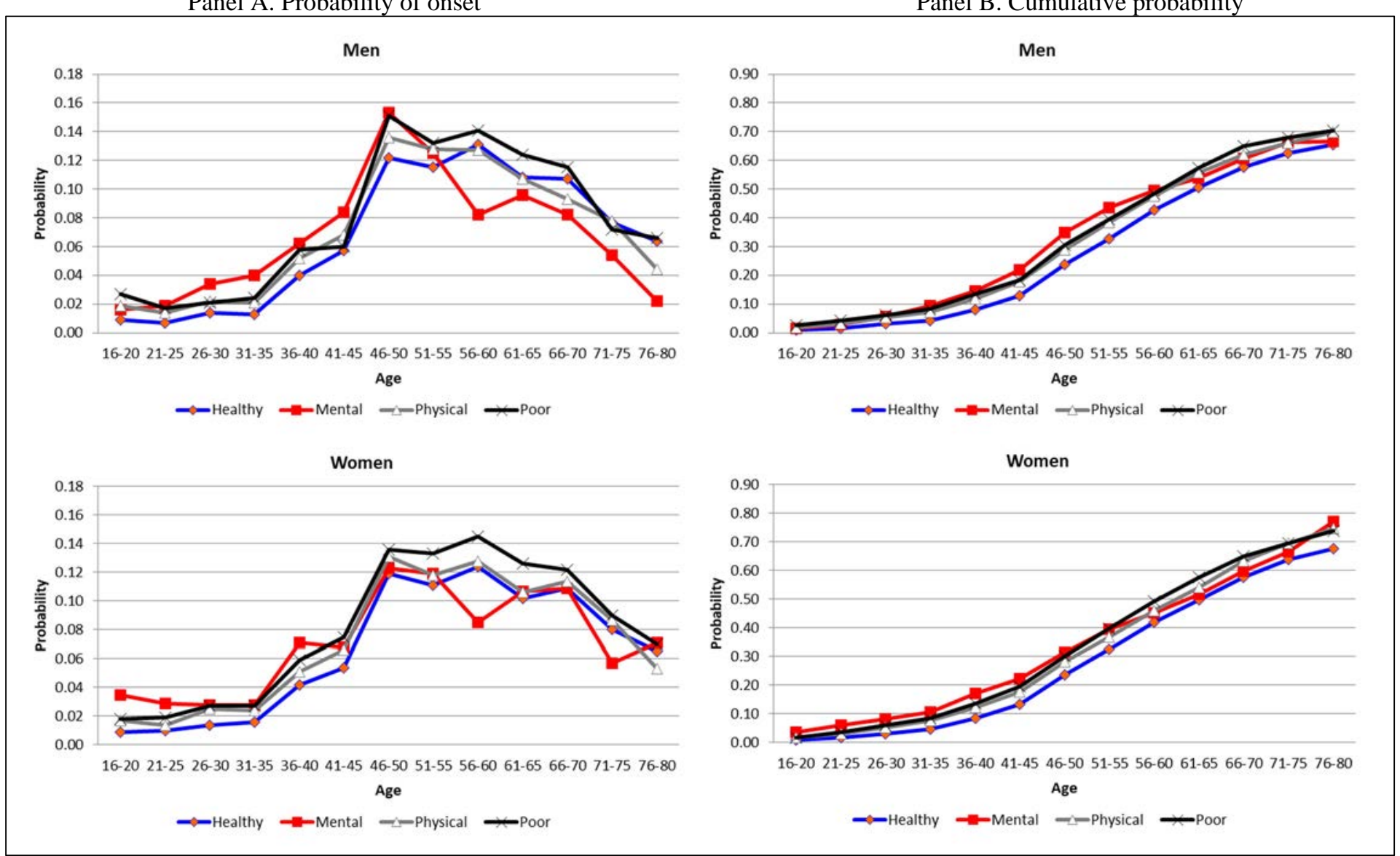

${ }^{a}$ CVDs include a heart attack or other heart problems, high blood pressure, high blood cholesterol, a stroke or cerebral vascular disease, and diabetes. Physical includes individuals one standard deviation below the mean in an index of childhood physical health and Poor/fair those with "Poor, fair or changing childhood SRH". The numbers of respondents used are given in Table A-2. 
Figure A-2: Tests for homogeneous childhood health effects on CVDs (0-1) over ages 16 to 80 years for men and women in Europe ${ }^{\mathrm{a}}$

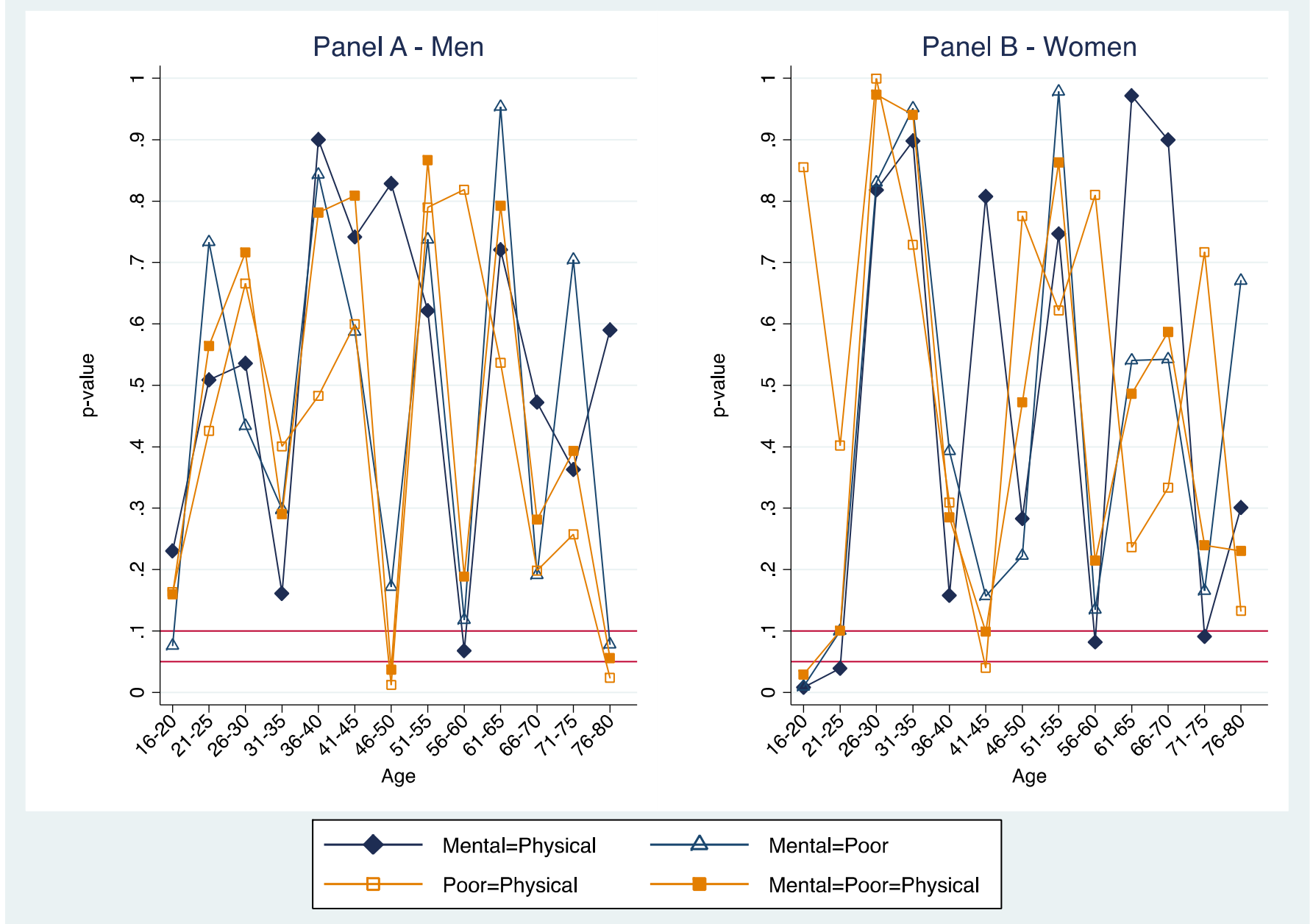

a The figure shows p-values from homogeneity tests on the estimates for Mental health problems (0-1), Physical health problems (0-1) and Poor childhood SRH (0-1) that are obtained in Figure 4. All possible comparisons are tested. The specific null hypothesis that is tested is shown in the legend. The alternative hypothesis is always that the null hypothesis is not true. 
Figure A-3: Estimates of mental and physical health problems and poor self-reported health prior to age 16 from linear regressions on CVDs or lung disease (0-1) for men and women over ages 16 to 80 years in Europe ${ }^{\mathrm{a}}$
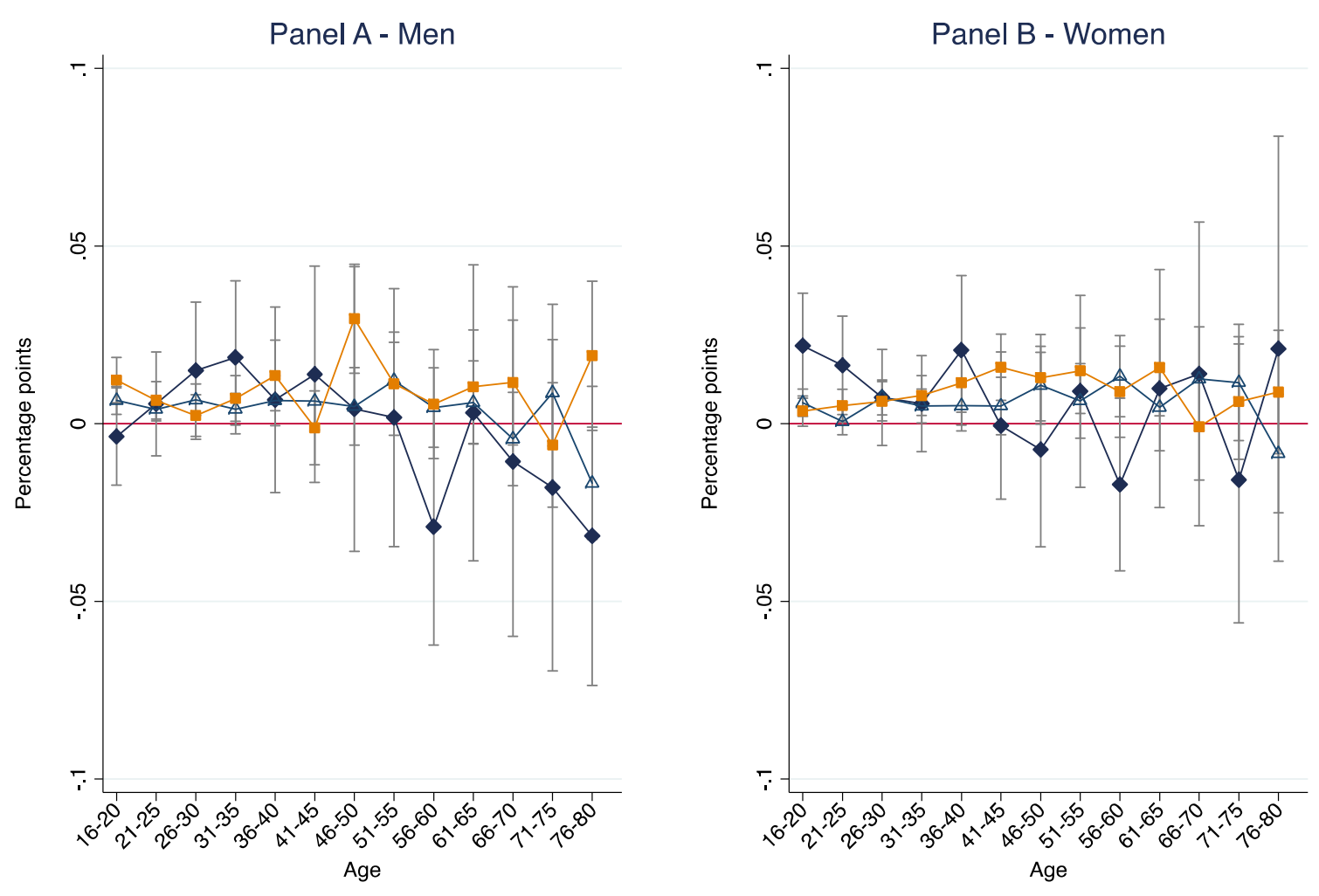

$\longrightarrow$ Mental $\longrightarrow$ Physical $\longrightarrow$ Poor $\longmapsto$ Cls

a The figure shows OLS estimates for Mental health problems (0-1), Physical health problems (0-1) and Poor childhood SRH (0-1) obtained from estimating linear models on the probability of having a serious health condition (0-1) for men at five-year intervals over ages 16 to 80 years in Europe. Physical includes those one standard deviation below the mean in an index of childhood physical health and Poor those with "Poor, fair or changing childhood SRH". CVDs include a heart attack or other heart problems, high blood pressure, high blood cholesterol, a stroke or cerebral vascular disease, and diabetes. All models include all the variables listed in Table 1, except age and the mediating factors, plus country dummies and five-year cohort dummies. 95\% confidence intervals are based on robust standard errors. 
Figure A-4: Tests for homogeneous childhood health effects on CVDs or lung disease (0-1) for men and women over ages 16 to 80 years in Europe ${ }^{\mathrm{a}}$

Panel A - Men

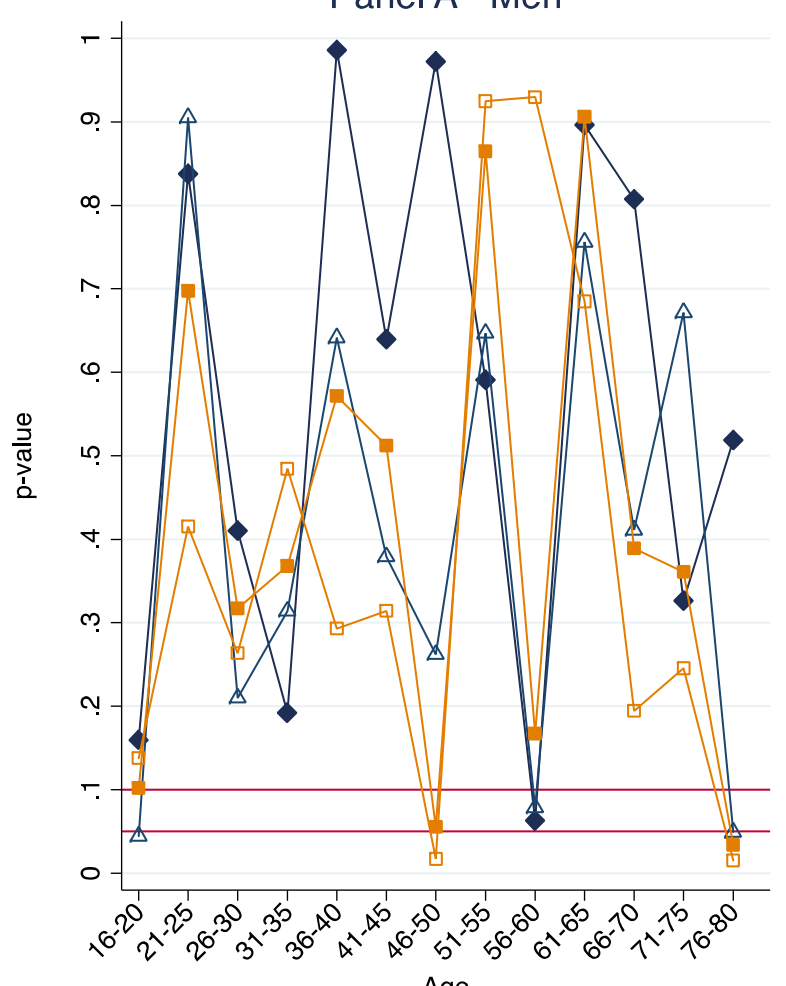

Age

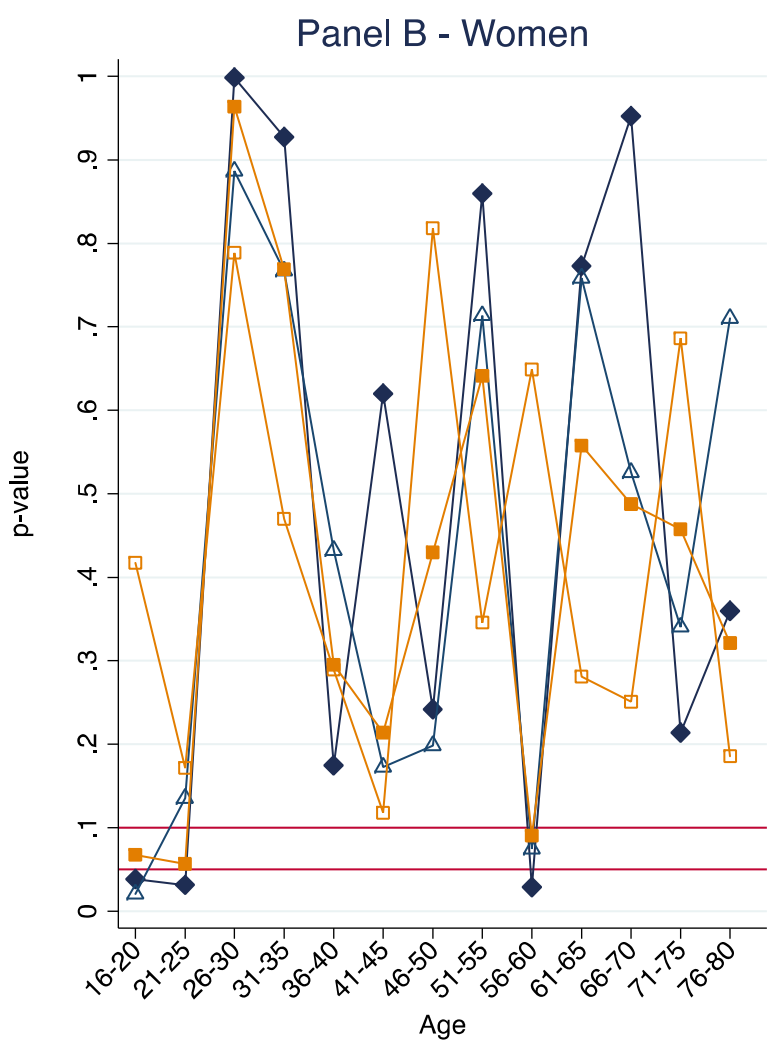

$\begin{array}{llll}\longrightarrow & \begin{array}{l}\text { Mental=Physical } \\ \text { Poor=Physical }\end{array} \quad \text { Mental=Poor } \\ \square & \square & \text { Mental=Poor=Physical }\end{array}$

${ }^{a}$ The figure shows p-values from homogeneity tests on the estimates for Mental health problems (0-1), Physical health problems (0-1) and Poor childhood SRH (0-1) that are obtained in Figure A-3. All possible comparisons are tested. The specific null hypothesis that is tested is shown in the legend. The alternative hypothesis is always that the null hypothesis is not true. 
Figure A-5: Tests for homogeneous childhood health effects on accumulated career gaps since career start from age 21 to 64 or the latest age observed for men and women in Europe ${ }^{\mathrm{a}}$

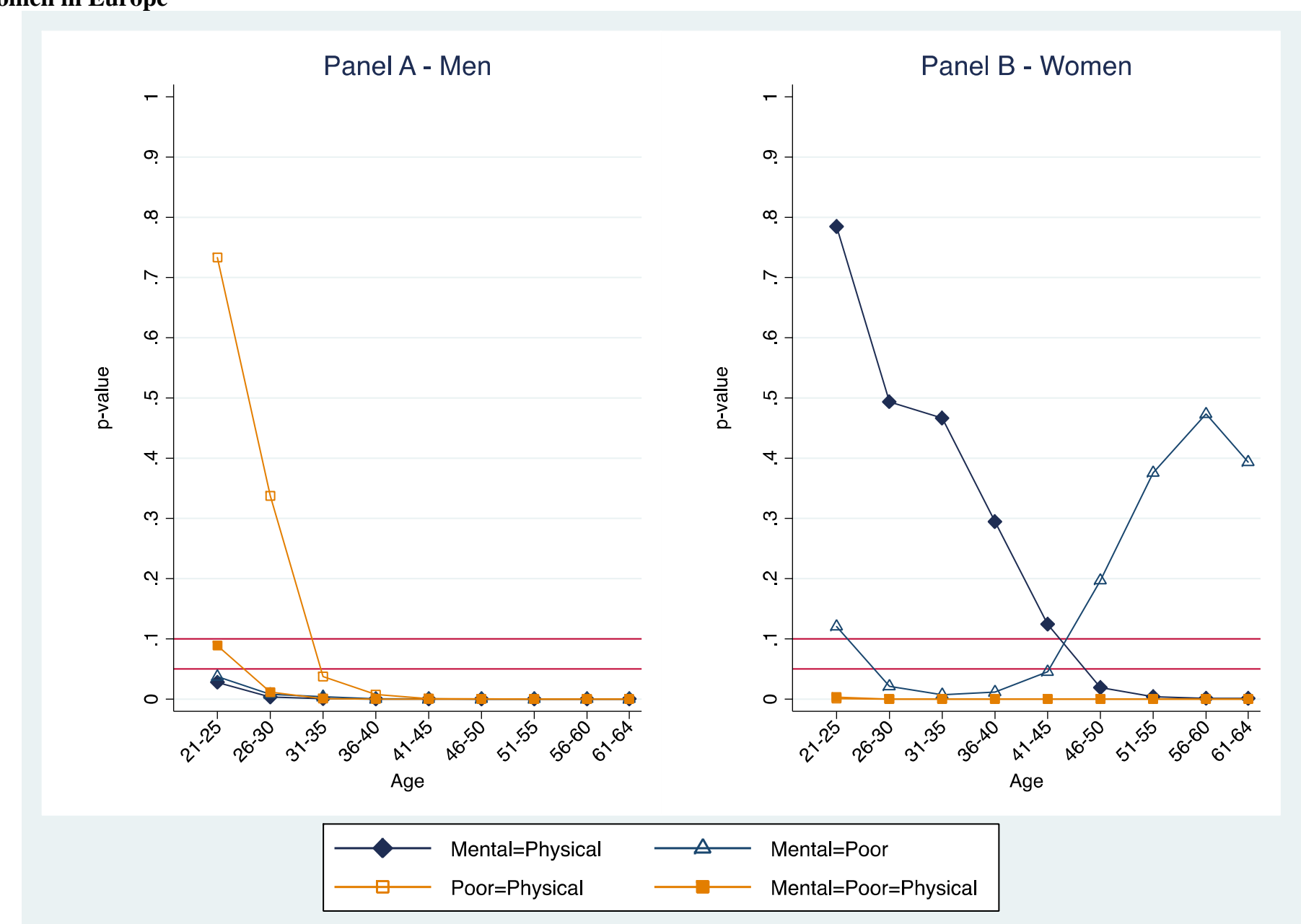

${ }^{\text {a }}$ The figure shows p-values from homogeneity tests on the estimates for Mental health problems (0-1), Physical health problems (0-1) and Poor childhood SRH $(0-1)$ that are obtained in Figure 5. All possible comparisons are tested. The specific null hypothesis that is tested is shown in the legend. The alternative hypothesis is always that the null hypothesis is not true. 
Figure A-6: Tests for homogeneous childhood health effects on the probability of retiring from a job from age 21 to 64 or the latest age observed for men and women in Europe ${ }^{\mathrm{a}}$

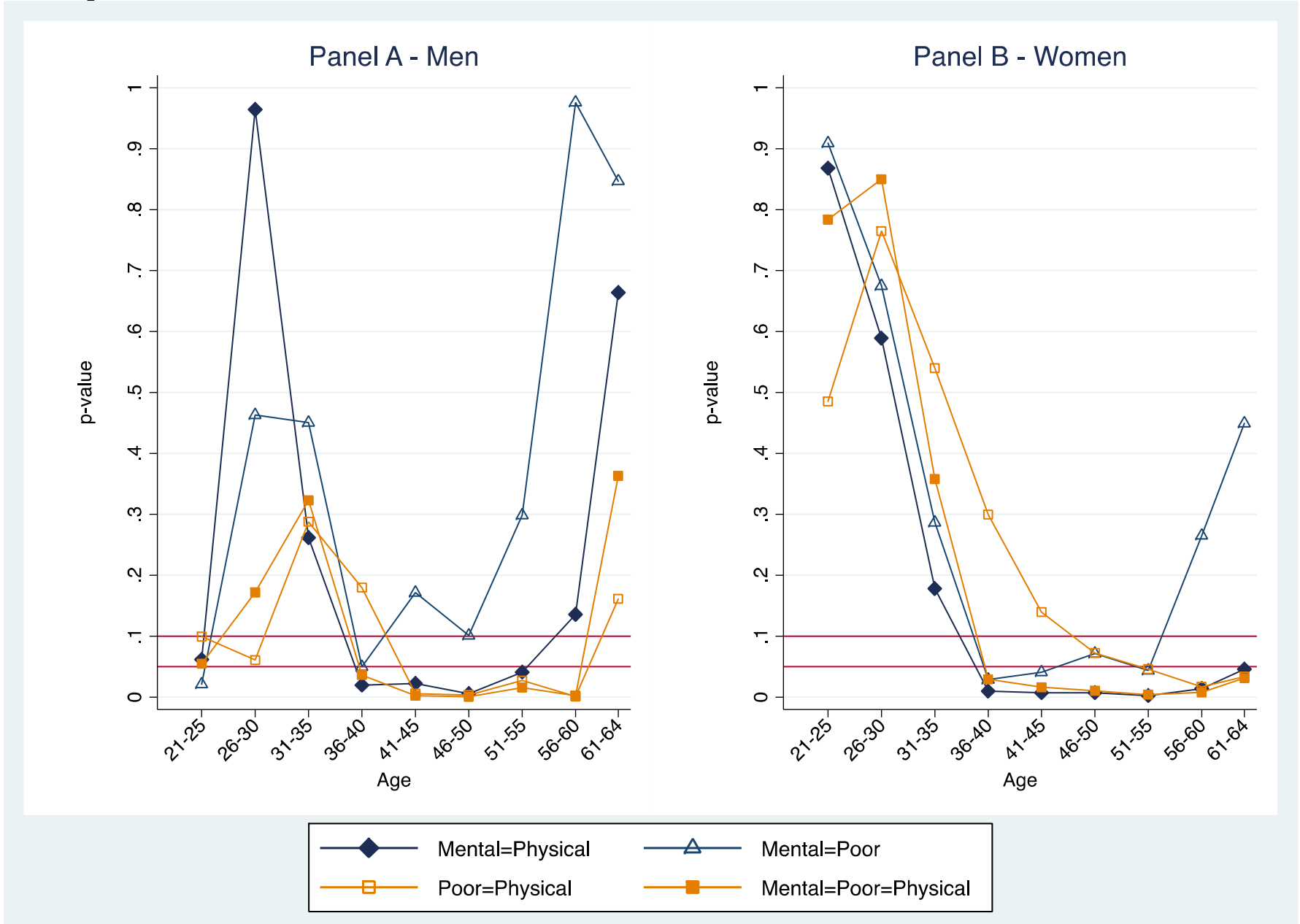

${ }^{a}$ The figure shows p-values from homogeneity tests on the estimates for Mental health problems (0-1), Physical health problems (0-1) and Poor childhood SRH $(0-1)$ that are obtained in Figure 6. All possible comparisons are tested. The specific null hypothesis that is tested is shown in the legend. The alternative hypothesis is always that the null hypothesis is not true. 
Figure A-7: Estimates of mental and physical health problems and poor self-reported health prior to age 16 from linear regressions on CVDs (0-1) for men and women over ages 21 to 80 years in Europe with controls for mediating factors ${ }^{\mathrm{a}}$

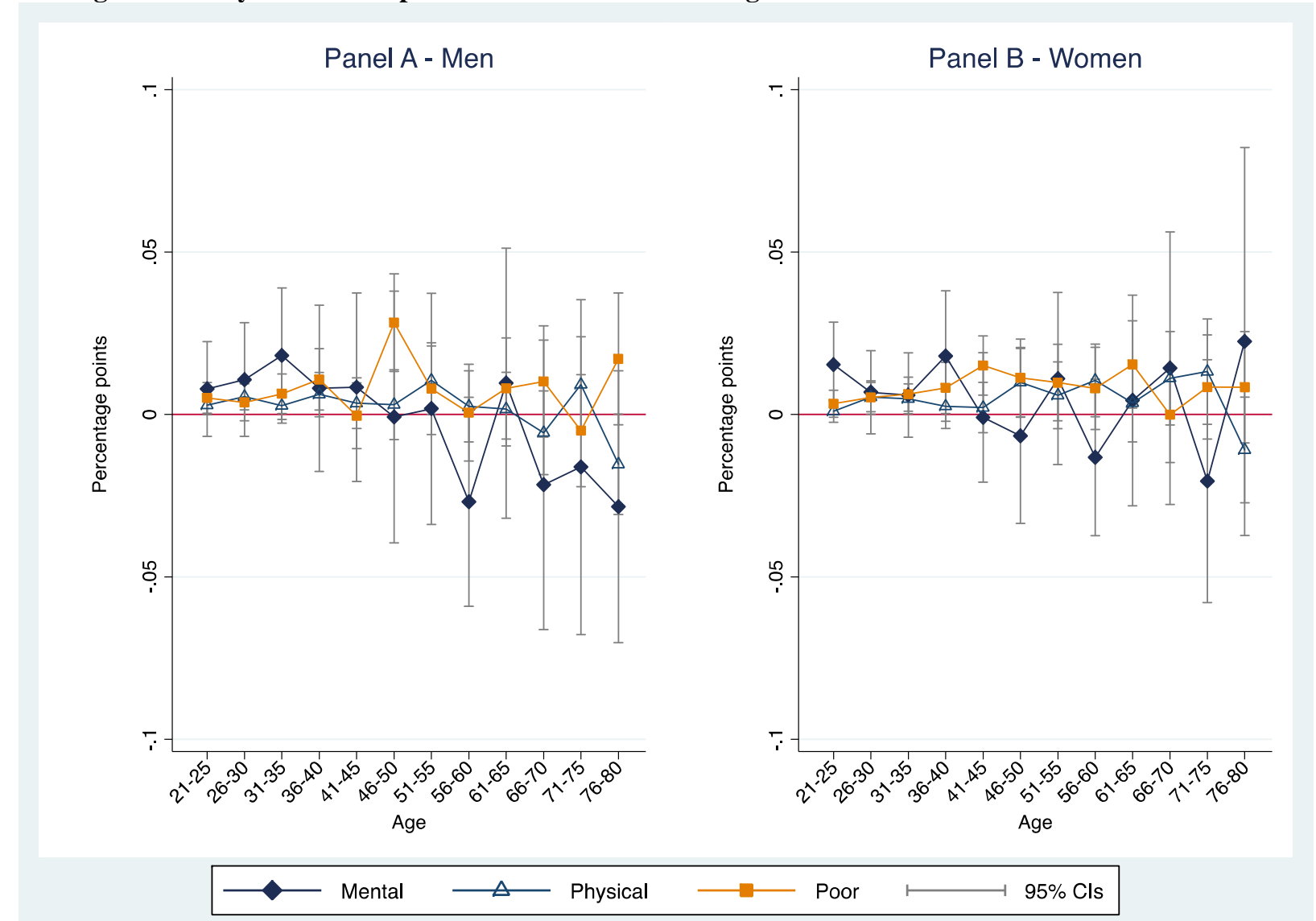

${ }^{a}$ The figure shows OLS estimates for Mental health problems (0-1), Physical health problems (0-1) and Poor childhood SRH (0-1) obtained from estimating linear models on the probability of having a CVD (0-1) at five-year intervals over ages 16 to 80 years, separately for men and women in Europe. Physical includes those one standard deviation below the mean in an index of childhood physical health and Poor those with "Poor, fair or changing childhood SRH". All models include all the variables listed in Table 1, except age, plus country dummies and five-year cohort dummies. Included mediating factors are years in fulltime education and being married (0-1) or have a natural child (0-1) in the corresponding age interval. 95\% confidence intervals are based on robust standard errors. The full set of estimates are available upon request. 
Figure A-8: Estimates of mental and physical health problems and poor self-reported health prior to age 16 from linear regressions on accumulated career gaps since career start from age 21 to 64 or the latest age observed for men and women in Europe with controls for mediating factors ${ }^{\mathrm{a}}$

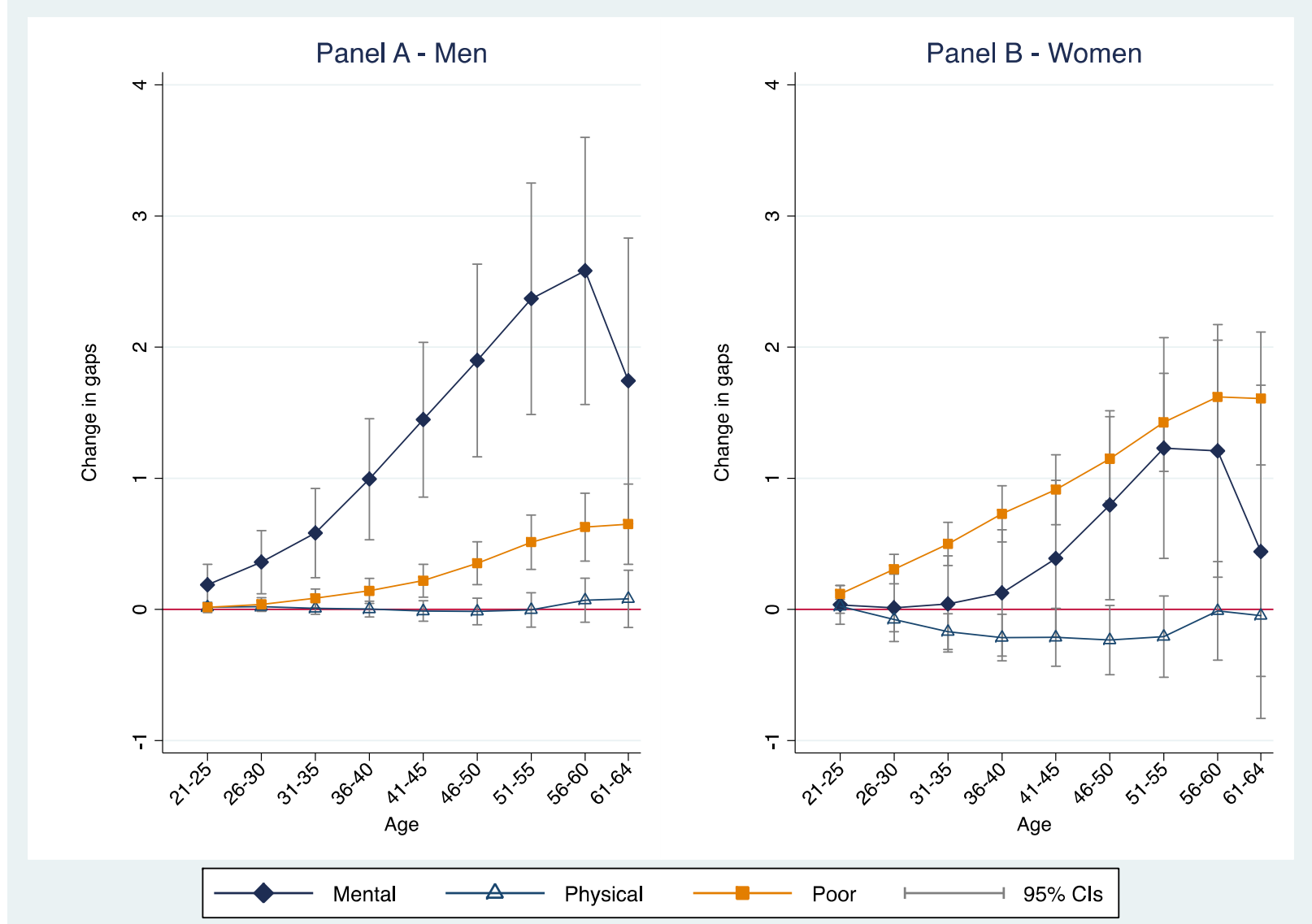

${ }^{a}$ The figure shows OLS estimates for Mental health problems (0-1), Physical health problems (0-1) and Poor childhood SRH (0-1) obtained from estimating linear models on accumulated career gaps between age 21 to 64 or the latest age observed, separately for men and women in Europe. Physical includes those one standard deviation below the mean in an index of childhood physical health and Poor those with "Poor, fair or changing childhood SRH". All models include all the variables listed in Table 1, except age, plus country dummies and five-year cohort dummies. Included mediating factors are years in full-time education and being married (0-1) or have a natural child (0-1) in the corresponding age interval. 95\% confidence intervals are based on robust standard errors. The full set of estimates are available upon request. 
Figure A-9: Estimates of mental and physical health problems and poor self-reported health prior to age 16 from linear regressions on the probability of retiring from a job from age 21 to 64 or the latest age observed for men and women in Europe with controls for mediating factors ${ }^{\mathrm{a}}$

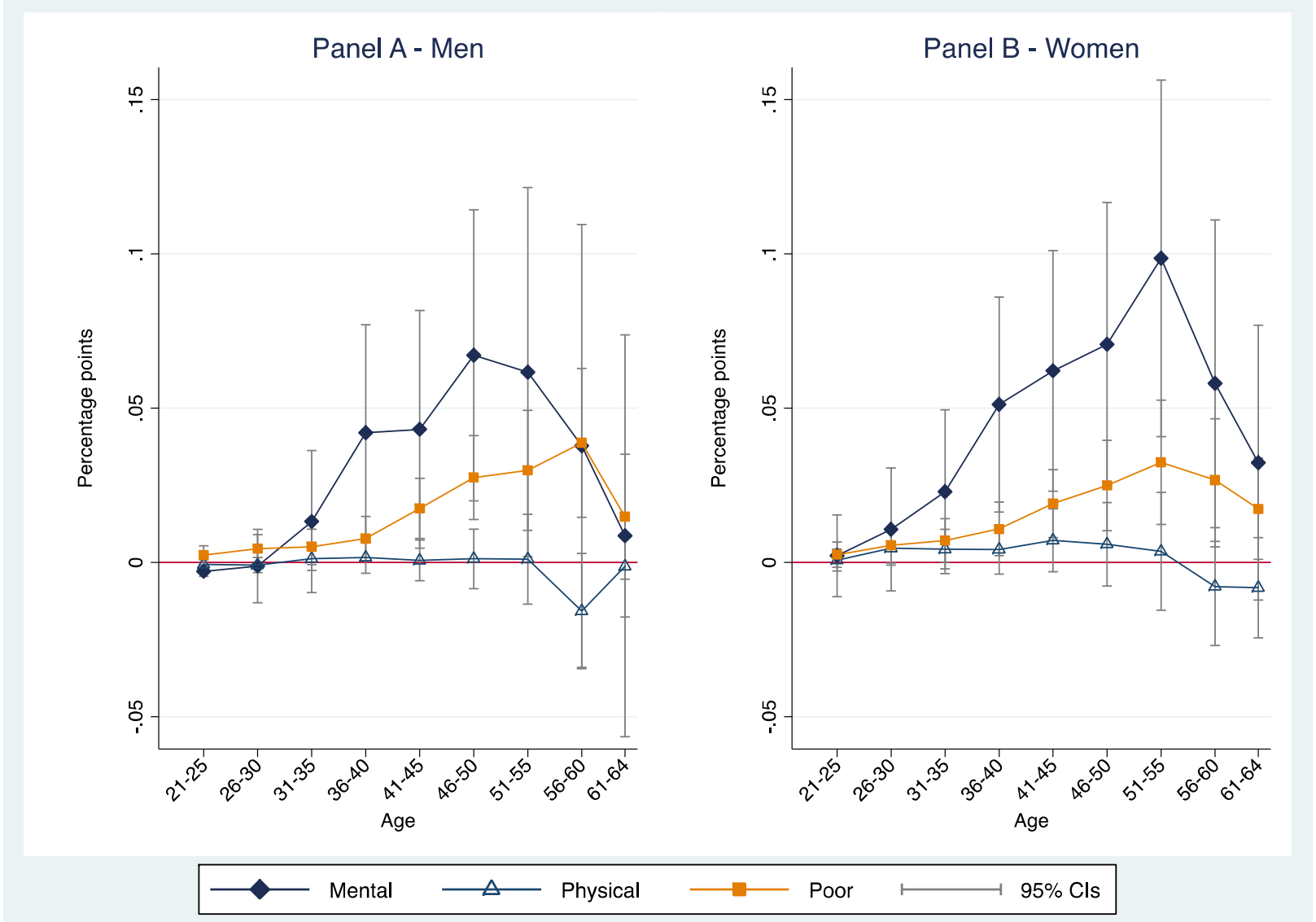

${ }^{a}$ The figure shows OLS estimates for Mental health problems (0-1), Physical health problems (0-1) and Poor childhood SRH (0-1) obtained from estimating linear models on the probability of retiring from a job between age 21 to 64 or the latest age observed, separately for men and women in Europe. Physical includes those one standard deviation below the mean in an index of childhood physical health and Poor those with "Poor, fair or changing childhood SRH". All models include all the variables listed in Table 1, except age, plus country dummies and five-year cohort dummies. Included mediating factors are years in fulltime education and being married (0-1) or have a natural child (0-1) in the corresponding age interval. 95\% confidence intervals are based on robust standard errors. The full set of estimates are available upon request. 
Figure A-10: Tests for homogeneous childhood health effects on CVDs (0-1) over ages 21 to 80 years for men and women in Europe after accounting for mediating factors ${ }^{\mathrm{a}}$

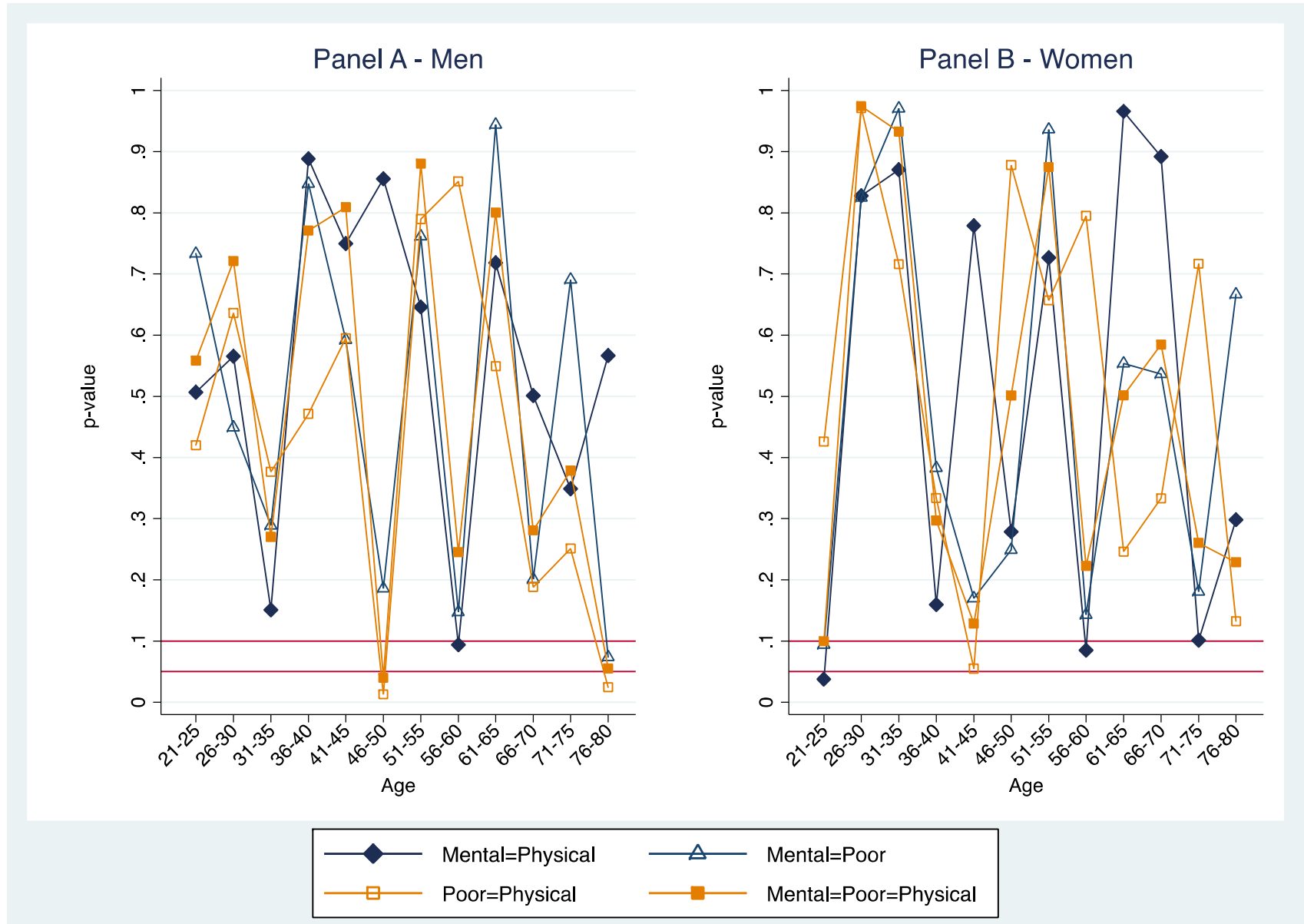

${ }^{a}$ The figure shows p-values from homogeneity tests on the estimates for Mental health problems (0-1), Physical health problems (0-1) and Poor childhood SRH (0-1) that are obtained in Figure A-7. All possible comparisons are tested. The specific null hypothesis that is tested is shown in the legend. The alternative hypothesis is always that the null hypothesis is not true. 
Figure A-11: Tests for homogeneous childhood health effects on accumulated career gaps since career start from age 21 to 64 or the latest age observed for men and women in Europe after accounting for mediating factors ${ }^{\mathrm{a}}$

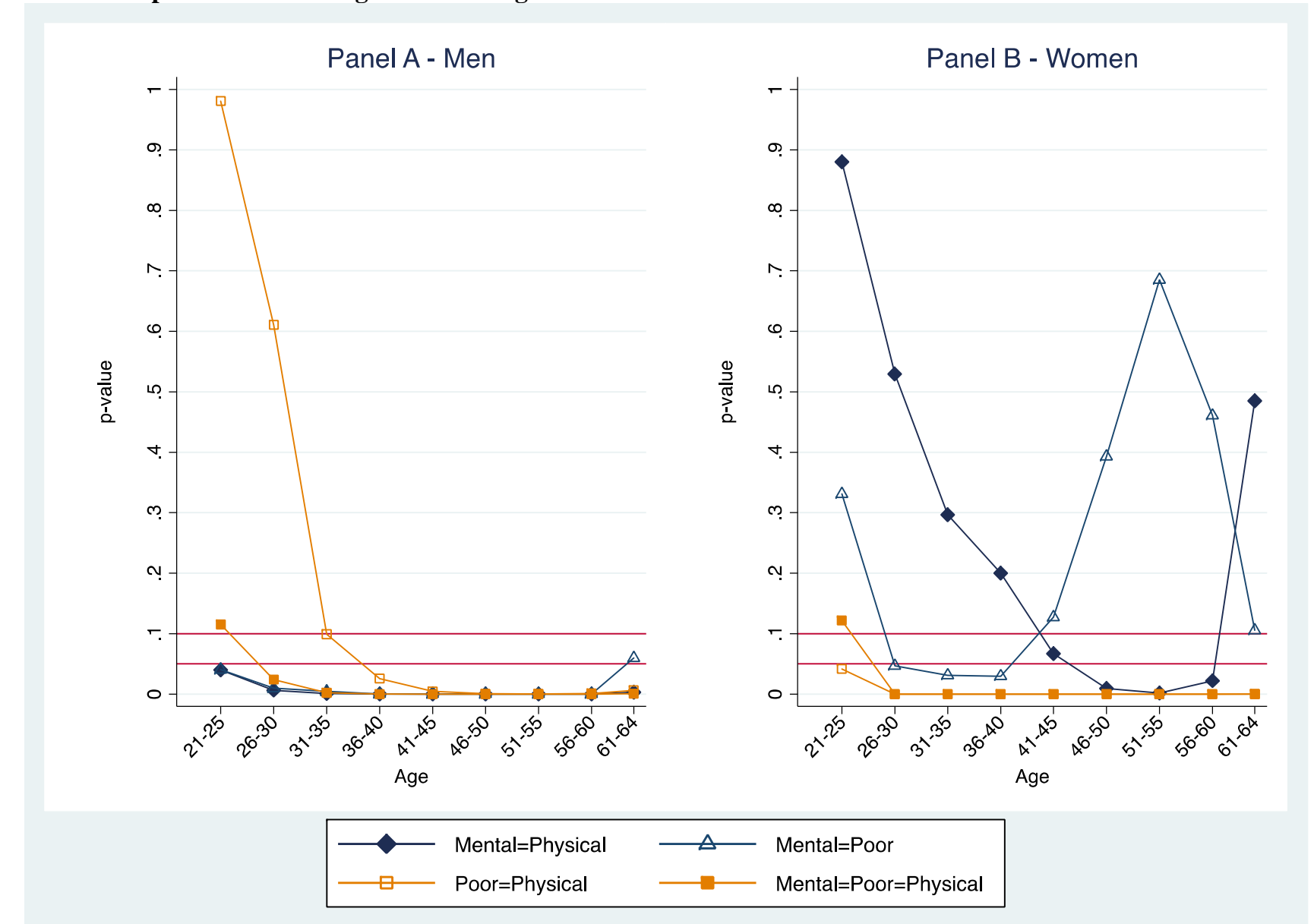

a The figure shows p-values from homogeneity tests on the estimates for Mental health problems (0-1), Physical health problems (0-1) and Poor childhood SRH $(0-1)$ that are obtained in Figure A-8. All possible comparisons are tested. The specific null hypothesis that is tested is shown in the legend. The alternative hypothesis is always that the null hypothesis is not true. 
Figure A-12: Tests for homogeneous childhood health effects on the probability of retiring from a job from age 21 to 64 or the latest age observed for men and women in Europe after accounting for mediating factors ${ }^{\mathrm{a}}$

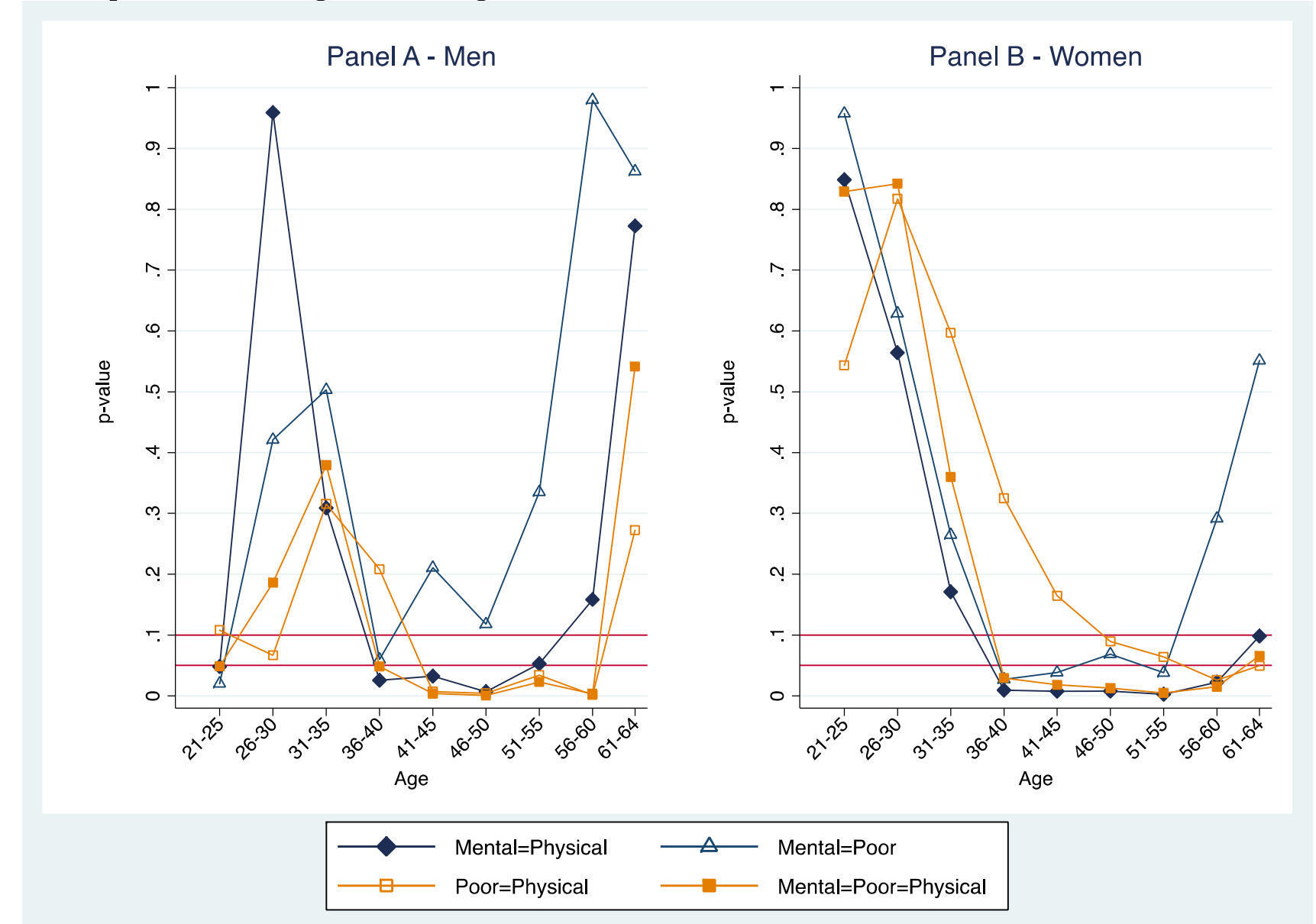

${ }^{a}$ The figure shows p-values from homogeneity tests on the estimates for Mental health problems (0-1), Physical health problems (0-1) and Poor childhood SRH $(0-1)$ that are obtained in Figure A-9. All possible comparisons are tested. The specific null hypothesis that is tested is shown in the legend. The alternative hypothesis is always that the null hypothesis is not true. 
Figure A-13: Estimates of childhood health variables from linear regressions on CVDs (0-1) for men and women over ages 21 to 80 years in Europe with Oster's recommended identified set of estimates ${ }^{\mathrm{a}}$

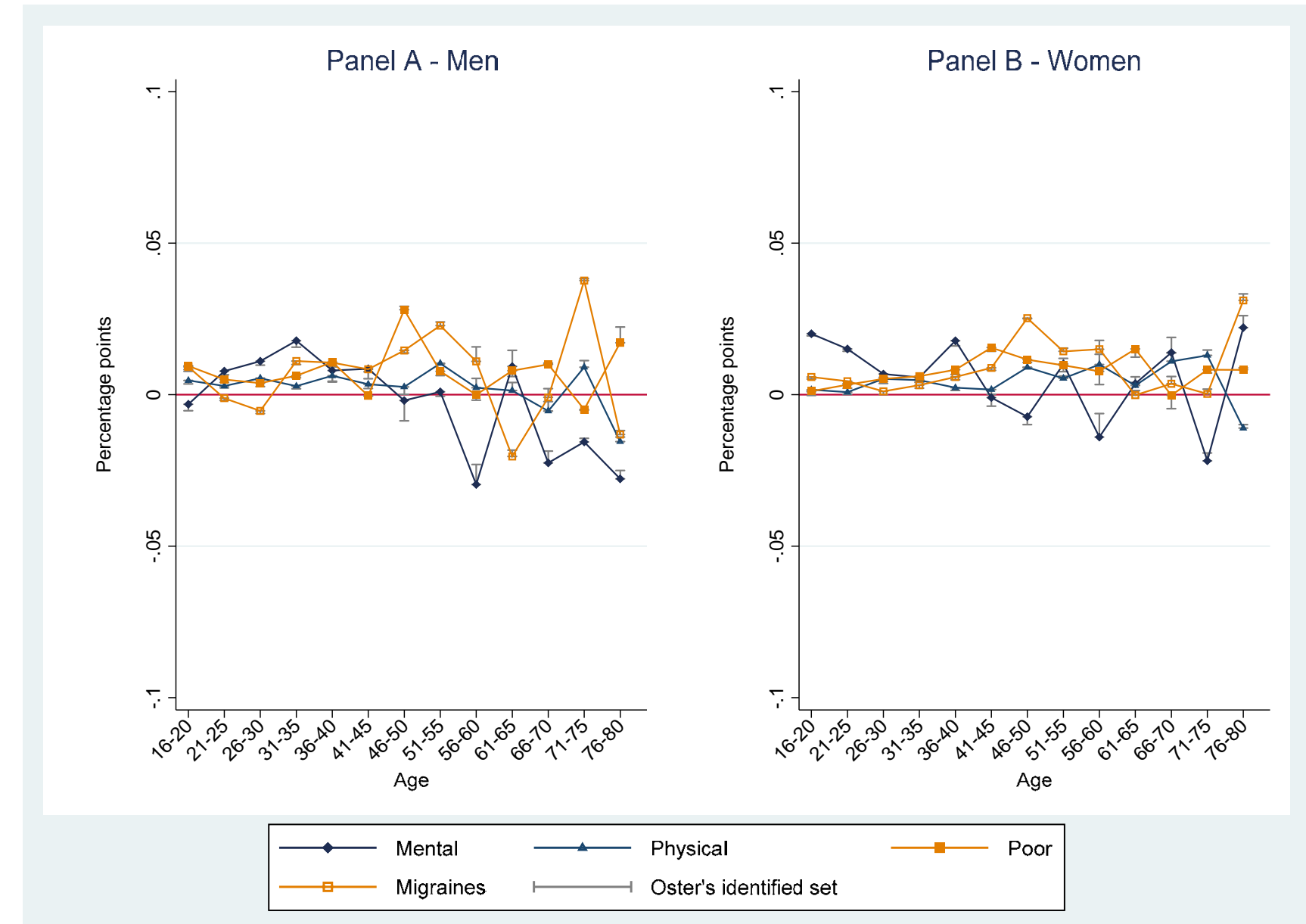

${ }^{a}$ The figure shows OLS estimates for Mental health problems (0-1), Physical health problems (0-1), Poor childhood SRH (0-1) and Severe headaches or migraines (0-1) obtained from estimating linear models on the probability of having a CVD (0-1) at five-year intervals over ages 16 to 80 years, separately for men and women in Europe (see Figure 4 and Tables A-3 and A-4 for details). The vertical bars show Oster's (2019) recommended identified set of estimates when using R2-max = 1.3 x R2 and delta = 1 (see section A.1 for details). 
Figure A-14: Estimates of childhood health variables from linear regressions on accumulated career gaps since career start from age 21 to 64 or the latest age observed for men and women in Europe with Oster's recommended identified set of estimates ${ }^{\mathrm{a}}$

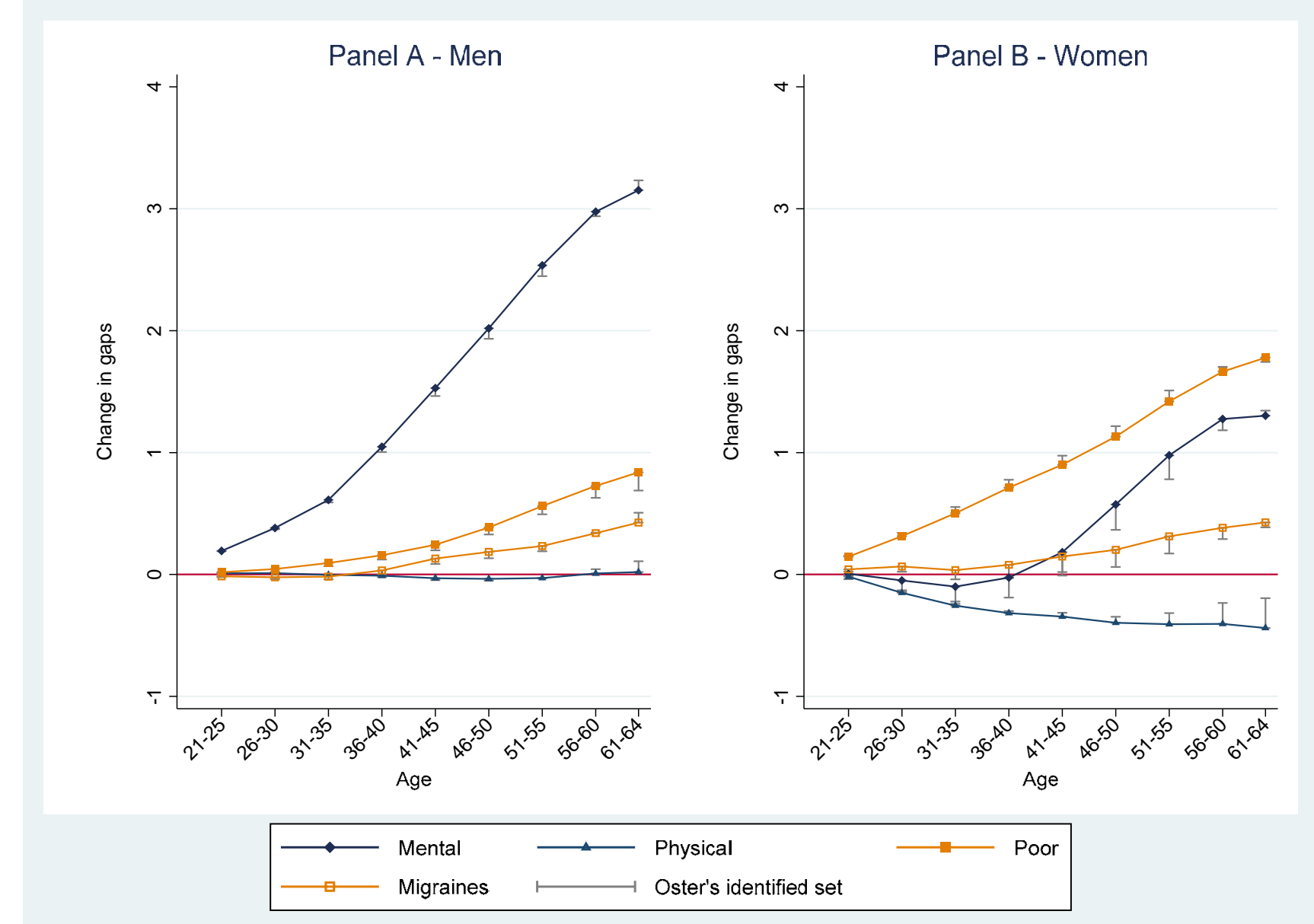

${ }^{\text {a }}$ The figure shows OLS estimates for Mental health problems (0-1), Physical health problems (0-1), Poor childhood SRH (0-1) and Severe headaches or migraines (0-1) obtained from estimating linear models on accumulated career gaps between age 21 to 64 or the latest age observed, separately for men and women in Europe (see Figure 5 and Tables A-5 and A-6 for details). The vertical bars show Oster's (2019) recommended identified set of estimates when using R2-max $=1.3 \times$ R2 and delta $=1$ (see section A.1 for details). 
Figure A-15: Estimates of childhood health variables from linear regressions the probability of retiring from a job from age 21 to 64 or the latest age observed for men and women in Europe with Oster's recommended identified set of estimates ${ }^{\mathrm{a}}$

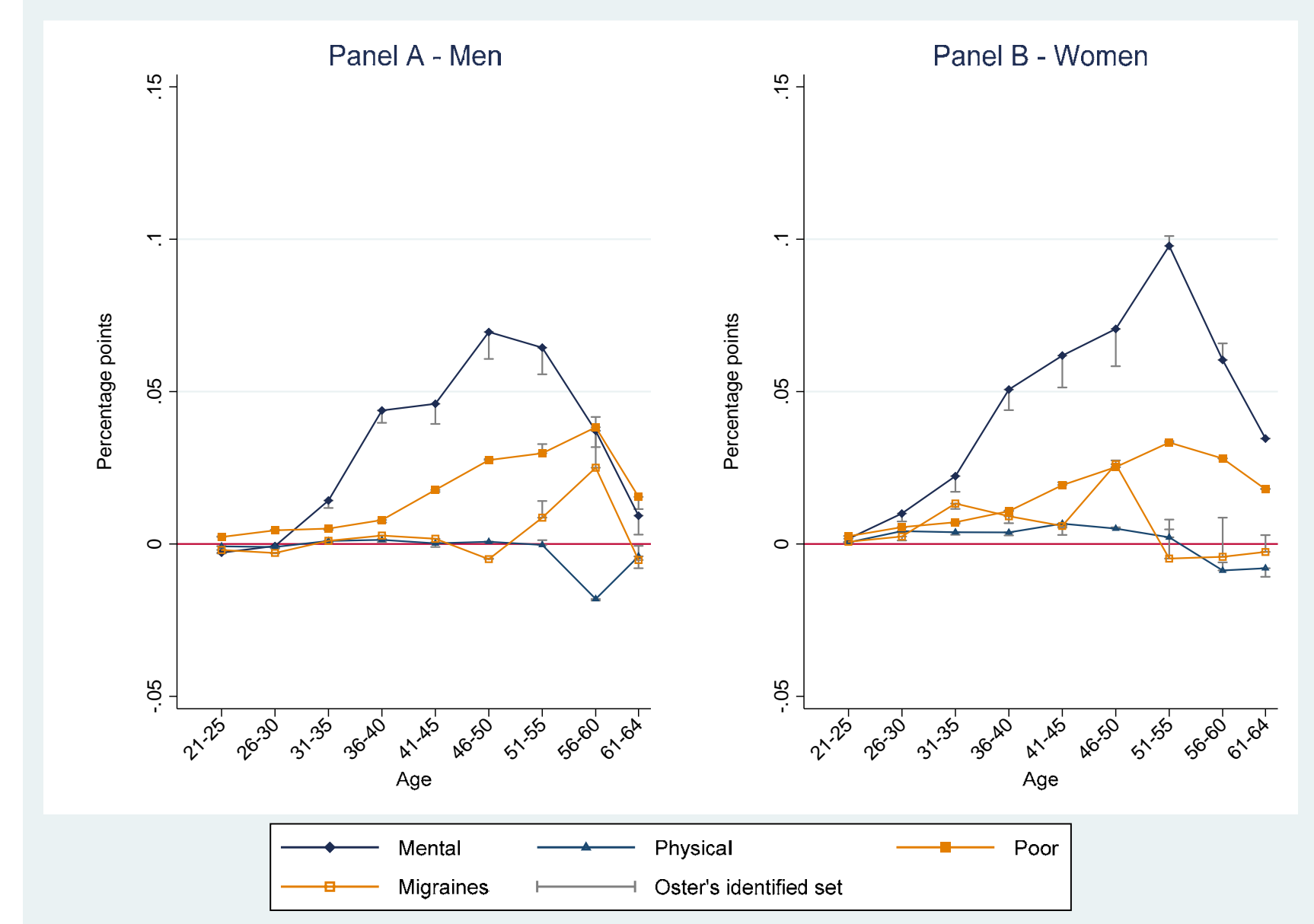

${ }^{\text {a }}$ The figure shows OLS estimates for Mental health problems (0-1), Physical health problems (0-1), Poor childhood SRH (0-1) and Severe headaches or migraines (0-1) obtained from estimating linear models on the probability of retiring from a job between age 21 to 64 or the latest age observed, separately for men and women in Europe (see Figure 5 and Tables A-5 and A-6 for details). The vertical bars show Oster's (2019) recommended identified set of estimates when using R2-max $=1.3$ x R2 and delta $=1$ (see section A.1 for details). 
Figure A-16: Estimates of childhood health variables from linear regressions on CVDs (0-1) for men and women over ages 21 to 80 years in Europe with Oster's identified set of estimates ${ }^{\mathrm{a}}$

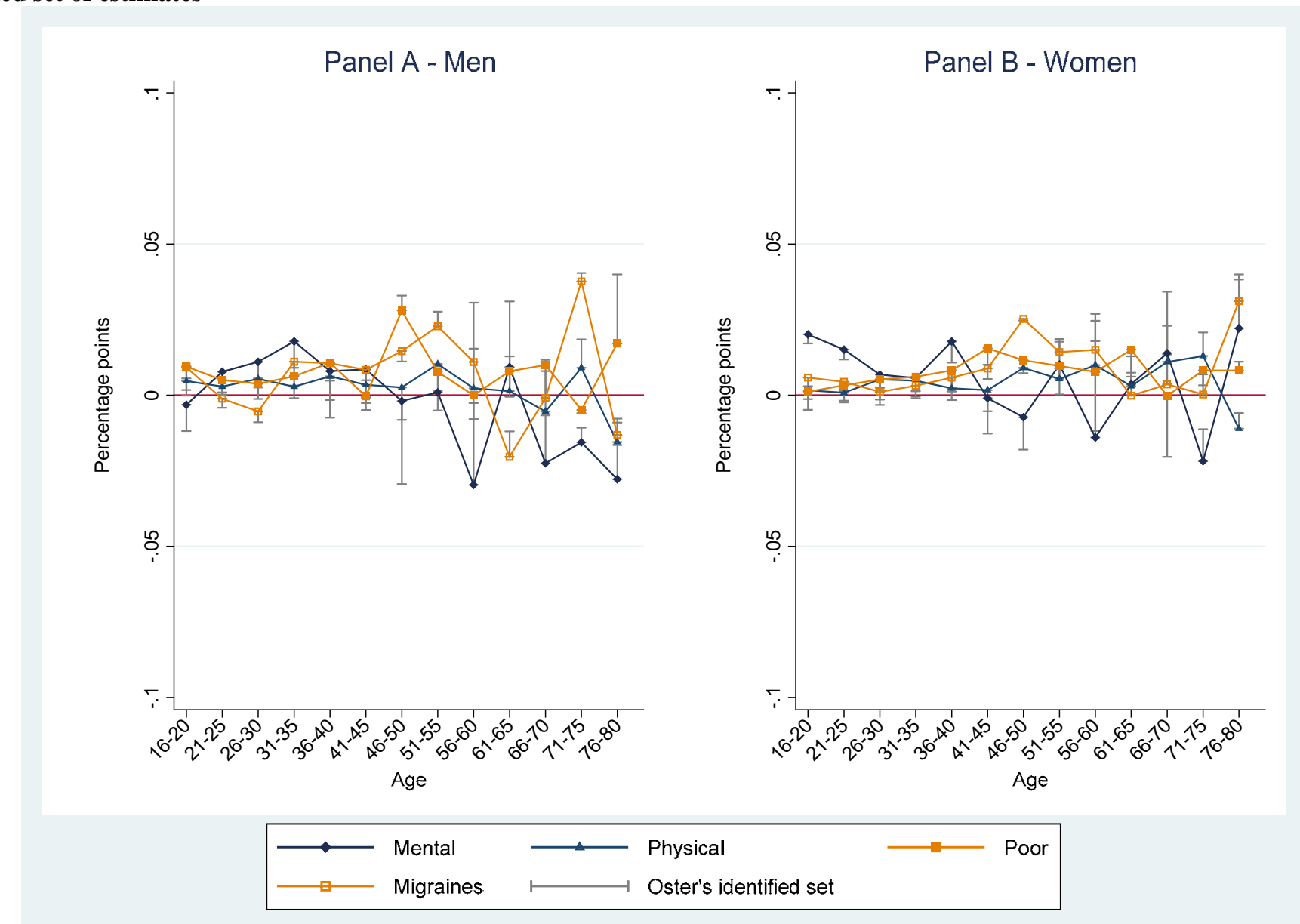

a The figure shows OLS estimates for Mental health problems (0-1), Physical health problems (0-1), Poor childhood SRH (0-1) and Severe headaches or migraines (0-1) obtained from estimating linear models on the probability of having a CVD (0-1) at five-year intervals over ages 16 to 80 years, separately for men and women in Europe (see Figure 4 and Tables A-3 and A-4 for details). The vertical bars show Oster's (2019) identified set of estimates when using R2$\max =2.2 \times$ R2 and delta $=1$ as in Mian and Sufi (2014) (see section A.1 for details). 
Figure A-17: Estimates of childhood health variables from linear regressions on accumulated career gaps since career start from age 21 to 64 or the latest age observed for men and women in Europe with Oster's identified set of estimates ${ }^{\mathrm{a}}$

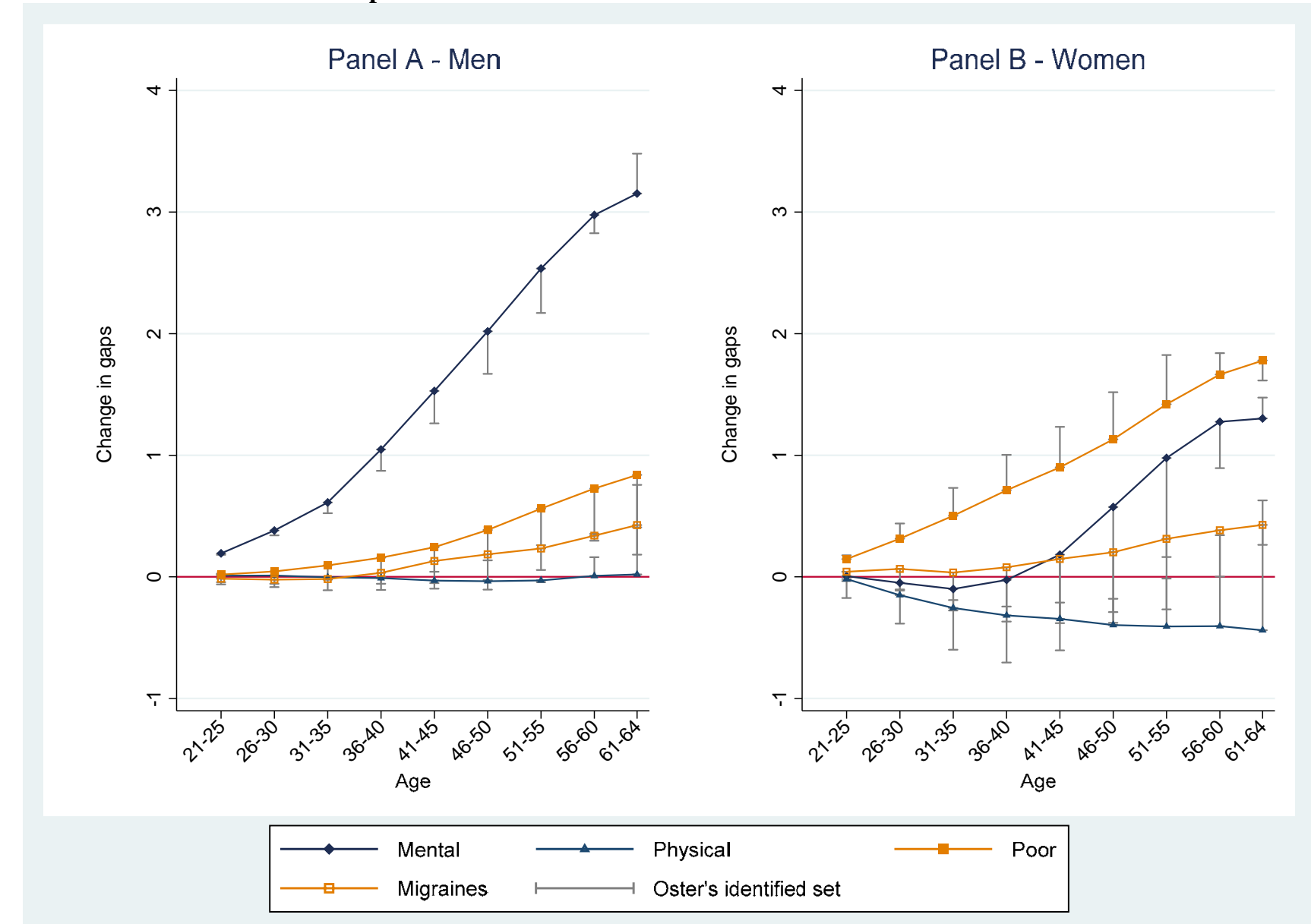

${ }^{\text {a }}$ The figure shows OLS estimates for Mental health problems (0-1), Physical health problems (0-1), Poor childhood SRH (0-1) and Severe headaches or migraines (0-1) obtained from estimating linear models on accumulated career gaps between age 21 to 64 or the latest age observed, separately for men and women in Europe (see Figure 5 and Tables A-5 and A-6 for details). The vertical bars show Oster's (2019) identified set of estimates when using R2-max $=2.2 \mathrm{x}$ R2 and delta $=1$ as in Mian and Sufi (2014) (see section A.1 for details). 
Figure A-18: Estimates of childhood health variables from linear regressions the probability of retiring from a job from age 21 to 64 or the latest age observed for men and women in Europe with Oster's identified set of estimates ${ }^{\mathrm{a}}$

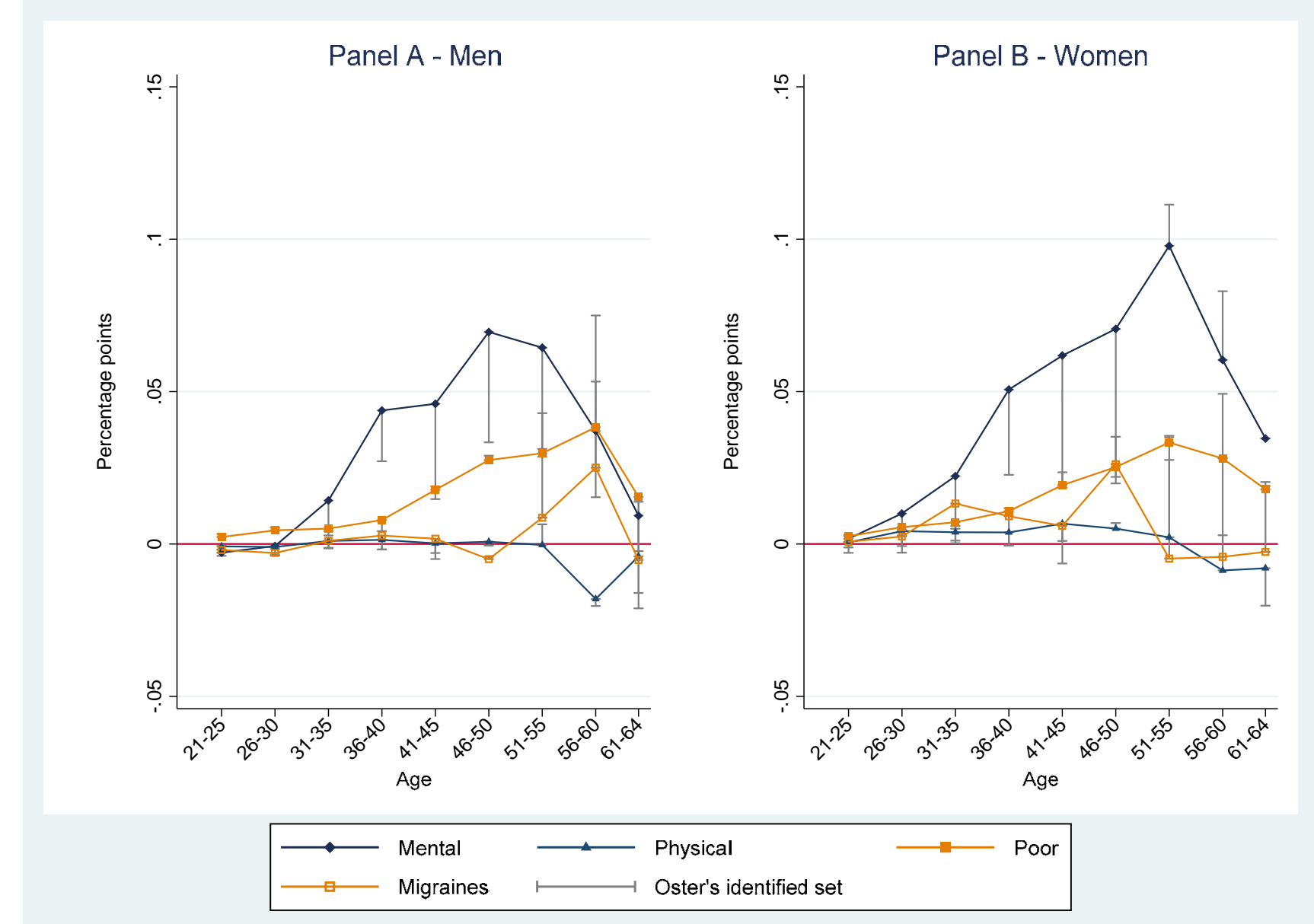

${ }^{\text {a }}$ The figure shows OLS estimates for Mental health problems (0-1), Physical health problems (0-1), Poor childhood SRH (0-1) and Severe headaches or migraines (0-1) obtained from estimating linear models on the probability of retiring from a job between age 21 to 64 or the latest age observed, separately for men and women in Europe (see Figure 5 and Tables A-5 and A-6 for details). The vertical bars show Oster's (2019) identified set of estimates when using R2$\max =2.2 \times$ R2 and delta $=1$ as in Mian and Sufi (2014) (see section A.1 for details). 
Table A-1: Correlations of Childhood Variables ${ }^{\mathrm{a}}$

\begin{tabular}{|c|c|c|c|c|c|c|c|c|c|}
\hline Men & Mental & Physical & Poor & Head & Rooms & Bookcase & Facilities & Urban & Dental \\
\hline Emotional problems or epilepsy (0-1) (Mental) & 1 & & & & & & & & \\
\hline Physical health index (those 1SD below the mean) (0-1) (Physical) & 0.059 & 1 & & & & & & & \\
\hline Poor, fair or changing self-reported health (0-1) (Poor/fair) & 0.131 & 0.205 & 1 & & & & & & \\
\hline Severe headaches or migraines when $0-15$ years $(0-1)$ & 0.089 & 0.091 & 0.087 & 1 & & & & & \\
\hline Rooms per person when 10 years old ${ }^{\mathrm{b}}$ & 0.028 & 0.080 & -0.010 & 0.032 & 1 & & & & \\
\hline Bookcase at home when 10 years old $(0-1)(1=>25 \text { books })^{\mathrm{c}}$ & 0.023 & 0.111 & 0.000 & 0.051 & 0.252 & 1 & & & \\
\hline Number of facilities at home when 10 years old $(0-5)^{\mathrm{d}}$ & 0.029 & 0.119 & -0.038 & 0.048 & 0.356 & 0.447 & 1 & & \\
\hline Born in an urban area $(0-1)$ & 0.007 & 0.056 & 0.005 & 0.021 & 0.080 & 0.203 & 0.290 & 1 & \\
\hline Regular dental care since childhood (0-1) & 0.012 & 0.085 & -0.011 & 0.028 & 0.157 & 0.319 & 0.331 & 0.117 & 1 \\
\hline Women & Mental & Physical & Poor & Head & Rooms & Bookcase & Facilities & Urban & Dental \\
\hline Emotional problems or epilepsy (0-1) (Mental) & 1 & & & & & & & & \\
\hline Physical health index (those 1SD below the mean) (0-1) (Physical) & 0.083 & 1 & & & & & & & \\
\hline Poor, fair or changing self-reported health (0-1) (Poor/fair) & 0.125 & 0.238 & 1 & & & & & & \\
\hline Severe headaches or migraines when $0-15$ years $(0-1)$ & 0.097 & 0.112 & 0.119 & 1 & & & & & \\
\hline Rooms per person when 10 years old ${ }^{b}$ & 0.038 & 0.049 & -0.030 & 0.023 & 1 & & & & \\
\hline Bookcase at home when 10 years old $(0-1)(1=>25 \text { books })^{c}$ & 0.014 & 0.091 & -0.013 & 0.029 & 0.259 & 1 & & & \\
\hline Number of facilities at home when 10 years old $(0-5)^{\mathrm{d}}$ & 0.042 & 0.082 & -0.059 & 0.025 & 0.364 & 0.450 & 1 & & \\
\hline Born in an urban area $(0-1)$ & 0.020 & 0.051 & -0.008 & 0.007 & 0.090 & 0.201 & 0.306 & 1 & \\
\hline Regular dental care since childhood (0-1) & 0.009 & 0.075 & -0.008 & 0.017 & 0.166 & 0.329 & 0.326 & 0.107 & 1 \\
\hline
\end{tabular}

${ }^{a}$ This table depicts the sample correlations between childhood variables. The first three rows show childhood mental, physical and self-reported health. ${ }^{\mathrm{b}}$ The number of rooms include bedrooms, but exclude kitchen, bathrooms, and hallways. ${ }^{c}$ Bookcase measures the number of books at home when 10 years old. It is $=1$ if there were enough books to fill one bookcase (26-100 books), two bookcases (101-200 books) or two or more bookcases ( $>200$ books), and $=0$ if there were none or very few books ( 0 - 10 books) or enough to fill one shelf only (11-25 books). ${ }^{\mathrm{d}}$ Includes fixed bath, cold and hot running water supply, inside toilet and central heating. 
Table A-2: Number of male and female respondents used to construct life course health variables by age and childhood health ${ }^{\mathrm{a}}$

\begin{tabular}{|c|c|c|c|c|c|c|c|c|}
\hline & Men & & & & Women & & & \\
\hline Age & Healthy & Mental & Physical & Poor & Healthy & Mental & Physical & Poor \\
\hline $16-20$ & 20429 & 321 & 4812 & 2414 & 27130 & 577 & 4434 & 3650 \\
\hline $21-25$ & 20429 & 321 & 4812 & 2414 & 27130 & 577 & 4434 & 3650 \\
\hline $26-30$ & 20429 & 321 & 4812 & 2414 & 27130 & 577 & 4434 & 3650 \\
\hline 31-35 & 20429 & 321 & 4812 & 2414 & 27130 & 577 & 4434 & 3650 \\
\hline $36-40$ & 20429 & 321 & 4812 & 2414 & 27130 & 577 & 4434 & 3650 \\
\hline $41-45$ & 20429 & 321 & 4812 & 2414 & 27130 & 577 & 4434 & 3650 \\
\hline $46-50$ & 20429 & 321 & 4812 & 2414 & 27130 & 577 & 4434 & 3650 \\
\hline $51-55$ & 20420 & 321 & 4805 & 2409 & 27046 & 573 & 4424 & 3645 \\
\hline $56-60$ & 18943 & 279 & 4390 & 2262 & 24258 & 507 & 3842 & 3354 \\
\hline $61-65$ & 15125 & 188 & 3365 & 1851 & 19234 & 328 & 2891 & 2752 \\
\hline $66-70$ & 11226 & 122 & 2367 & 1438 & 14165 & 202 & 2035 & 2156 \\
\hline 71-75 & 7510 & 74 & 1482 & 1006 & 9617 & 123 & 1332 & 1526 \\
\hline $76-80$ & 4419 & 45 & 835 & 595 & 5977 & 70 & 797 & 1007 \\
\hline
\end{tabular}

${ }^{a}$ Number of respondents used in Figure 1. Numbers for job-related health outcomes shown in Figures 2 and 3 are somewhat lower. For instance, for retirement in Figure 4 because only the sample of people who retired from a job is used. The numbers in this table do not match exactly the ones in Tables A-3 and A- 4 because there is some double counting for individuals with more than one childhood health problem. 
Table A-3: Estimates of childhood health and SES variables from linear regressions on the probability of onset of a CVD over ages 16 to 80 for men in Europe

\begin{tabular}{|c|c|c|c|c|c|c|c|c|c|c|c|c|c|}
\hline & $16-20$ & $21-25$ & $26-30$ & $31-35$ & $36-40$ & $41-45$ & $46-50$ & $51-55$ & $56-60$ & $61-65$ & $66-70$ & $71-75$ & $76-80$ \\
\hline \multirow[t]{2}{*}{ Mental (0-1) } & -0.003 & 0.008 & 0.011 & $0.018^{*}$ & 0.008 & 0.009 & -0.002 & 0.001 & $-0.030 *$ & 0.009 & -0.023 & -0.016 & -0.028 \\
\hline & $(0.006)$ & $(0.007)$ & $(0.009)$ & $(0.011)$ & $(0.013)$ & $(0.015)$ & $(0.020)$ & $(0.018)$ & $(0.016)$ & $(0.021)$ & $(0.023)$ & $(0.026)$ & $(0.021)$ \\
\hline \multirow[t]{2}{*}{ Physical (1SD below the mean) $(0-1)$} & $0.005 * * *$ & $0.003 *$ & $0.005 * * *$ & k 0.003 & $0.006 *$ & 0.003 & 0.003 & $0.010^{*}$ & 0.002 & 0.001 & -0.005 & 0.009 & $-0.015 * *$ \\
\hline & $(0.002)$ & $(0.002)$ & $(0.002)$ & $(0.002)$ & $(0.003)$ & $(0.004)$ & $(0.005)$ & $(0.005)$ & $(0.006)$ & $(0.006)$ & $(0.007)$ & $(0.008)$ & $(0.008)$ \\
\hline \multirow[t]{2}{*}{ Poor/fair/changing SRH (0-1) } & $0.010 * * *$ & $0.005^{* *}$ & $=0.004$ & $0.006 * *$ & $0.011^{* *}$ & -0.000 & $0.028 * * *$ & 0.008 & -0.000 & 0.008 & 0.010 & -0.005 & $0.017 *$ \\
\hline & $(0.003)$ & $(0.002)$ & $(0.003)$ & $(0.003)$ & $(0.005)$ & $(0.005)$ & $(0.008)$ & $(0.007)$ & $(0.008)$ & $(0.008)$ & $(0.009)$ & $(0.009)$ & $(0.010)$ \\
\hline \multirow[t]{2}{*}{ Severe headaches or migraines $(0-1)$} & $0.009 * *$ & -0.001 & -0.005 & $0.011 * *$ & 0.011 & 0.008 & 0.015 & $0.023 * *$ & 0.011 & $-0.020^{*}$ & -0.001 & $0.038 * *$ & -0.013 \\
\hline & $(0.005)$ & $(0.003)$ & $(0.003)$ & $(0.005)$ & $(0.007)$ & $(0.008)$ & $(0.011)$ & $(0.011)$ & $(0.011)$ & $(0.011)$ & $(0.013)$ & $(0.018)$ & $(0.016)$ \\
\hline \multirow[t]{2}{*}{ Rooms (an increase of one room) } & 0.000 & 0.000 & -0.000 & -0.000 & -0.004 & 0.001 & -0.005 & 0.008 & $-0.016^{* * *}$ & -0.001 & -0.004 & -0.010 & -0.008 \\
\hline & $(0.002)$ & $(0.001)$ & $(0.002)$ & $(0.002)$ & $(0.003)$ & $(0.004)$ & $(0.005)$ & $(0.005)$ & $(0.005)$ & $(0.005)$ & $(0.007)$ & $(0.007)$ & $(0.006)$ \\
\hline \multirow[t]{2}{*}{ Bookcase $(0-1)(1=>25$ books $)$} & $0.003 * *$ & 0.001 & 0.001 & 0.003 & 0.001 & -0.003 & -0.005 & -0.002 & -0.008 & -0.005 & $-0.013^{* *}$ & -0.002 & 0.008 \\
\hline & $(0.002)$ & $(0.001)$ & $(0.002)$ & $(0.002)$ & $(0.003)$ & $(0.003)$ & $(0.005)$ & $(0.005)$ & $(0.005)$ & $(0.005)$ & $(0.006)$ & $(0.007)$ & $(0.008)$ \\
\hline \multirow[t]{2}{*}{ Number of facilities at home when 10 years old $(0-4)$} & -0.001 & 0.000 & -0.001 & $-0.001 * *$ & -0.000 & -0.000 & -0.001 & -0.002 & $0.003 * *$ & -0.000 & -0.000 & $-0.004^{* *}$ & -0.000 \\
\hline & $(0.000)$ & $(0.000)$ & $(0.001)$ & $(0.001)$ & $(0.001)$ & $(0.001)$ & $(0.001)$ & $(0.001)$ & $(0.002)$ & $(0.002)$ & $(0.002)$ & $(0.002)$ & $(0.002)$ \\
\hline \multirow[t]{2}{*}{ Born in urban area $(0-1)$} & 0.001 & 0.000 & -0.000 & -0.000 & -0.000 & 0.003 & $0.009 * *$ & -0.004 & -0.002 & -0.001 & 0.003 & 0.006 & -0.001 \\
\hline & $(0.001)$ & $(0.001)$ & $(0.002)$ & $(0.002)$ & $(0.003)$ & $(0.003)$ & $(0.005)$ & $(0.004)$ & $(0.005)$ & $(0.005)$ & $(0.006)$ & $(0.006)$ & $(0.007)$ \\
\hline \multirow[t]{2}{*}{ Regular dental care since childhood (0-1) } & -0.001 & -0.000 & -0.000 & 0.000 & 0.004 & -0.000 & 0.001 & -0.001 & -0.006 & 0.000 & -0.004 & $0.010^{*}$ & 0.002 \\
\hline & $(0.001)$ & $(0.001)$ & $(0.002)$ & $(0.002)$ & $(0.003)$ & $(0.003)$ & $(0.005)$ & $(0.005)$ & $(0.005)$ & $(0.005)$ & $(0.006)$ & $(0.006)$ & $(0.007)$ \\
\hline R-squa & 0.007 & 0.004 & 0.005 & 0.004 & 0.007 & 0.012 & 0.015 & 0.018 & 0.036 & 0.038 & 0.053 & 0.044 & 0.055 \\
\hline Observations & 26741 & 26741 & 26741 & 26741 & 26741 & 26741 & 26741 & 26723 & 24747 & 19647 & 14506 & 9640 & 5649 \\
\hline
\end{tabular}

a OLS estimates of childhood health and SES variables from linear regressions on the probability of onset of a CVD over ages 16 to 80 for men in Europe. All models include also dummies for country and 5-year birth cohorts. Robust standard errors in parentheses. Significance levels: $* * * \mathrm{p}<0.01 * * \mathrm{p}<0.05 * \mathrm{p}<0.10$. 
Table A-4: Estimates of childhood health and SES variables from linear regressions on the probability of onset of a CVD over ages 16 to 80 for women in Europe

\begin{tabular}{|c|c|c|c|c|c|c|c|c|c|c|c|c|c|}
\hline & $16-20$ & $21-25$ & $26-30$ & $31-35$ & $36-40$ & $41-45$ & $46-50$ & $51-55$ & $56-60$ & $61-65$ & $66-70$ & 71-75 & $76-80$ \\
\hline \multirow[t]{2}{*}{ Mental (0-1) } & $0.020 * * *$ & $0.015^{* *}$ & 0.007 & 0.006 & $0.018^{*}$ & -0.001 & -0.007 & 0.010 & -0.014 & 0.004 & 0.014 & -0.022 & 0.022 \\
\hline & $(0.007)$ & $(0.007)$ & $(0.007)$ & $(0.007)$ & $(0.010)$ & $(0.010)$ & $(0.014)$ & $(0.014)$ & $(0.012)$ & $(0.017)$ & $(0.021)$ & $(0.019)$ & $(0.030)$ \\
\hline \multirow[t]{2}{*}{ Physical (1SD below the mean) $(0-1)$} & 0.002 & 0.001 & $0.005 * *$ & $0.005 * *$ & 0.002 & 0.002 & $0.009 *$ & 0.005 & $0.010^{*}$ & 0.003 & 0.011 & 0.013 & -0.011 \\
\hline & $(0.002)$ & $(0.002)$ & $(0.002)$ & $(0.002)$ & $(0.003)$ & $(0.004)$ & $(0.005)$ & $(0.005)$ & $(0.006)$ & $(0.006)$ & $(0.007)$ & $(0.008)$ & $(0.008)$ \\
\hline \multirow[t]{2}{*}{ Poor/fair/changing SRH (0-1) } & 0.001 & 0.003 & $0.005 * *$ & $0.006 * *$ & $0.008 * *$ & $0.016 * * *$ & $0.012 *$ & 0.010 & 0.008 & $0.015 * *$ & -0.000 & 0.008 & 0.008 \\
\hline & $(0.002)$ & $(0.002)$ & $(0.003)$ & $(0.003)$ & $(0.004)$ & $(0.005)$ & $(0.006)$ & $(0.006)$ & $(0.006)$ & $(0.007)$ & $(0.008)$ & $(0.008)$ & $(0.009)$ \\
\hline \multirow[t]{2}{*}{ Severe headaches or migraines $(0-1)$} & $0.006 * *$ & 0.004 & 0.001 & 0.003 & 0.006 & 0.009 & $0.025 * * *$ & $0.014^{*}$ & $0.015^{*}$ & -0.000 & 0.004 & 0.000 & $0.031 * *$ \\
\hline & $(0.003)$ & $(0.003)$ & $(0.003)$ & $(0.003)$ & $(0.005)$ & $(0.006)$ & $(0.008)$ & $(0.008)$ & $(0.008)$ & $(0.009)$ & $(0.010)$ & $(0.011)$ & $(0.015)$ \\
\hline \multirow[t]{2}{*}{ Rooms (an increase of one room) } & 0.004 & -0.001 & 0.001 & $-0.004 * *$ & -0.002 & $-0.009 * * *$ & $-0.012 * *$ & 0.002 & $-0.012 * * *$ & $-0.015^{* * *}$ & -0.002 & -0.006 & 0.005 \\
\hline & $(0.003)$ & $(0.001)$ & $(0.002)$ & $(0.002)$ & $(0.003)$ & $(0.003)$ & $(0.005)$ & $(0.005)$ & $(0.005)$ & $(0.005)$ & $(0.006)$ & $(0.007)$ & $(0.010)$ \\
\hline \multirow[t]{2}{*}{ Bookcase (0-1) (1 = >25 books) } & -0.002 & -0.001 & -0.001 & 0.001 & $-0.007 * * *$ & -0.003 & -0.004 & -0.007 & -0.006 & -0.007 & -0.007 & -0.009 & -0.009 \\
\hline & $(0.001)$ & $(0.001)$ & $(0.002)$ & $(0.002)$ & $(0.003)$ & $(0.003)$ & $(0.004)$ & $(0.004)$ & $(0.004)$ & $(0.005)$ & $(0.006)$ & $(0.006)$ & $(0.007)$ \\
\hline \multirow[t]{2}{*}{ Number of facilities at home when 10 years old $(0-4)$} & -0.000 & -0.000 & -0.000 & -0.001 & $-0.002 * * *$ & $-0.004 * * *$ & $-0.006 * * *$ & $-0.002 *$ & $-0.006 * * *$ & -0.002 & -0.001 & -0.000 & 0.002 \\
\hline & $(0.000)$ & $(0.000)$ & $(0.000)$ & $(0.001)$ & $(0.001)$ & $(0.001)$ & $(0.001)$ & $(0.001)$ & $(0.001)$ & $(0.001)$ & $(0.002)$ & $(0.002)$ & $(0.002)$ \\
\hline \multirow[t]{2}{*}{ Born in urban area $(0-1)$} & 0.001 & -0.001 & 0.001 & -0.001 & 0.003 & $0.007^{* *}$ & 0.002 & -0.003 & 0.004 & 0.006 & 0.006 & -0.001 & $-0.014^{* *}$ \\
\hline & $(0.001)$ & $(0.001)$ & $(0.001)$ & $(0.002)$ & $(0.002)$ & $(0.003)$ & $(0.004)$ & $(0.004)$ & $(0.004)$ & $(0.004)$ & $(0.005)$ & $(0.006)$ & $(0.006)$ \\
\hline \multirow[t]{2}{*}{ Regular dental care since childhood (0-1) } & -0.002 & 0.001 & $-0.004 * *$ & 0.001 & -0.001 & $-0.007 * *$ & $-0.011^{* *}$ & -0.006 & $-0.008 *$ & 0.006 & $-0.013^{* *}$ & 0.000 & 0.003 \\
\hline & $(0.001)$ & $(0.001)$ & $(0.002)$ & $(0.002)$ & $(0.003)$ & $(0.003)$ & $(0.004)$ & (0.004) & $(0.004)$ & (0.005) & $(0.005)$ & $(0.006)$ & $(0.006)$ \\
\hline R-squared & 0.004 & 0.003 & 0.003 & 0.003 & 0.005 & 0.012 & 0.015 & 0.022 & 0.041 & 0.038 & 0.057 & 0.047 & 0.053 \\
\hline Observations & 34151 & 34151 & 34151 & 34151 & 34151 & 34151 & 34151 & 34049 & 30501 & 24080 & 17730 & 12037 & 7508 \\
\hline
\end{tabular}

${ }^{a}$ OLS estimates of childhood health and SES variables from linear regressions on the probability of onset of a CVD over ages 16 to 80 for women in Europe. All models include also dummies for country and 5-year birth cohorts. Robust standard errors in parentheses. Significance levels: $* * * \mathrm{p}<0.01 * * \mathrm{p}<0.05 * \mathrm{p}<0.10$. 
Table A-5: Estimates of childhood health and SES variables from linear regressions on accumulated career gaps since career start from age 21 to 64 or the latest age observed for men in Europe ${ }^{\mathrm{a}}$

\begin{tabular}{|c|c|c|c|c|c|c|c|c|c|}
\hline & $21-25$ & $26-30$ & $31-35$ & $36-40$ & $41-45$ & $46-50$ & $51-55$ & $56-60$ & $61-64$ \\
\hline Mental (0-1) & $\begin{array}{l}0.194 * * \\
(0.081)\end{array}$ & $\begin{array}{l}0.381^{* * *} \\
(0.124)\end{array}$ & $\begin{array}{l}0.612^{* * *} \\
(0.176)\end{array}$ & $\begin{array}{l}1.048 * * * \\
(0.239)\end{array}$ & $\begin{array}{l}1.529 * * * \\
(0.307)\end{array}$ & $\begin{array}{l}2.019 * * * \\
(0.384)\end{array}$ & $\begin{array}{l}2.536 * * * \\
(0.463)\end{array}$ & $\begin{array}{l}2.976^{* * *} \\
(0.514)\end{array}$ & $\begin{array}{l}3.153 * * * \\
(0.533)\end{array}$ \\
\hline Physical (1SD below the mean) $(0-1)$ & $\begin{array}{l}0.010 \\
(0.014)\end{array}$ & $\begin{array}{l}0.012 \\
(0.018)\end{array}$ & $\begin{array}{l}-0.003 \\
(0.023)\end{array}$ & $\begin{array}{l}-0.010 \\
(0.031)\end{array}$ & $\begin{array}{l}-0.031 \\
(0.040)\end{array}$ & $\begin{array}{l}-0.035 \\
(0.052)\end{array}$ & $\begin{array}{l}-0.029 \\
(0.067)\end{array}$ & $\begin{array}{l}0.008 \\
(0.083)\end{array}$ & $\begin{array}{l}0.020 \\
(0.093)\end{array}$ \\
\hline Poor/fair/changing SRH (0-1) & $\begin{array}{l}0.019 \\
(0.020)\end{array}$ & $\begin{array}{l}0.045^{*} \\
(0.027)\end{array}$ & $\begin{array}{l}0.095^{* * *} \\
(0.036)\end{array}$ & $\begin{array}{l}0.158^{* * *} \\
(0.049)\end{array}$ & $\begin{array}{l}0.244^{* * *} \\
(0.065)\end{array}$ & $\begin{array}{l}0.386^{* * *} \\
(0.084)\end{array}$ & $\begin{array}{l}0.562 * * * \\
(0.108)\end{array}$ & $\begin{array}{l}0.727^{* * *} \\
(0.131)\end{array}$ & $\begin{array}{l}0.839 * * * \\
(0.144)\end{array}$ \\
\hline Severe headaches or migraines $(0-1)$ & $\begin{array}{l}-0.015 \\
(0.027)\end{array}$ & $\begin{array}{l}-0.022 \\
(0.037)\end{array}$ & $\begin{array}{l}-0.017 \\
(0.050)\end{array}$ & $\begin{array}{l}0.033 \\
(0.068)\end{array}$ & $\begin{array}{l}0.131 \\
(0.093)\end{array}$ & $\begin{array}{l}0.185 \\
(0.122)\end{array}$ & $\begin{array}{l}0.234 \\
(0.156)\end{array}$ & $\begin{array}{l}0.339 * \\
(0.185)\end{array}$ & $\begin{array}{l}0.426^{* *} \\
(0.202)\end{array}$ \\
\hline Rooms (an increase of one room) & $\begin{array}{l}-0.028 * \\
(0.016)\end{array}$ & $\begin{array}{l}-0.030 * \\
(0.018)\end{array}$ & $\begin{array}{l}-0.034 \\
(0.024)\end{array}$ & $\begin{array}{l}-0.039 \\
(0.031)\end{array}$ & $\begin{array}{l}-0.055 \\
(0.042)\end{array}$ & $\begin{array}{l}-0.075 \\
(0.055)\end{array}$ & $\begin{array}{l}-0.130 * \\
(0.072)\end{array}$ & $\begin{array}{l}-0.243^{* * *} \\
(0.089)\end{array}$ & $\begin{array}{l}-0.355^{* * * *} \\
(0.099)\end{array}$ \\
\hline Bookcase $(0-1)(1=>25$ books $)$ & $\begin{array}{l}-0.012 \\
(0.012)\end{array}$ & $\begin{array}{l}-0.025 \\
(0.016)\end{array}$ & $\begin{array}{l}-0.044^{* *} \\
(0.022)\end{array}$ & $\begin{array}{l}-0.066 * * \\
(0.029)\end{array}$ & $\begin{array}{l}-0.109 * * * \\
(0.038)\end{array}$ & $\begin{array}{l}-0.170^{* * * *} \\
(0.049)\end{array}$ & $\begin{array}{l}-0.268 * * * \\
(0.063)\end{array}$ & $\begin{array}{l}-0.432^{* * *} \\
(0.077)\end{array}$ & $\begin{array}{l}-0.565 * * * \\
(0.086)\end{array}$ \\
\hline Number of facilities at home when 10 years old (0-4) & $\begin{array}{l}-0.013 * * * \\
(0.004)\end{array}$ & $\begin{array}{l}-0.018^{* * *} \\
(0.005)\end{array}$ & $\begin{array}{l}-0.027 * * * \\
(0.007)\end{array}$ & $\begin{array}{l}-0.040 * * * \\
(0.009)\end{array}$ & $\begin{array}{l}-0.060 * * * \\
(0.012)\end{array}$ & $\begin{array}{l}-0.091^{* * *} \\
(0.016)\end{array}$ & $\begin{array}{l}-0.130^{* * *} \\
(0.021)\end{array}$ & $\begin{array}{l}-0.178^{* * *} \\
(0.025)\end{array}$ & $\begin{array}{l}-0.221^{* * *} \\
(0.027)\end{array}$ \\
\hline Born in urban area $(0-1)$ & $\begin{array}{l}0.018 \\
(0.011)\end{array}$ & $\begin{array}{l}0.043^{* * *} \\
(0.015)\end{array}$ & $\begin{array}{l}0.077^{* * *} \\
(0.020)\end{array}$ & $\begin{array}{l}0.112^{* * *} \\
(0.027)\end{array}$ & $\begin{array}{l}0.165^{* * *} \\
(0.035)\end{array}$ & $\begin{array}{l}0.233^{* * *} \\
(0.045)\end{array}$ & $\begin{array}{l}0.294^{* * *} \\
(0.058)\end{array}$ & $\begin{array}{l}0.276^{* * *} \\
(0.071)\end{array}$ & $\begin{array}{l}0.234^{* * *} \\
(0.079)\end{array}$ \\
\hline Regular dental care since childhood (0-1) & $\begin{array}{l}-0.045^{* * *} \\
(0.012)\end{array}$ & $\begin{array}{l}-0.059 * * * \\
(0.016)\end{array}$ & $\begin{array}{l}-0.081 * * * \\
(0.021)\end{array}$ & $\begin{array}{l}-0.113^{* * *} \\
(0.028)\end{array}$ & $\begin{array}{l}-0.147^{* * *} \\
(0.037)\end{array}$ & $\begin{array}{l}-0.210^{* * *} \\
(0.049)\end{array}$ & $\begin{array}{l}-0.301^{* * *} \\
(0.063)\end{array}$ & $\begin{array}{l}-0.403^{* * *} \\
(0.077)\end{array}$ & $\begin{array}{l}-0.483 * * * \\
(0.085)\end{array}$ \\
\hline R-squared & 0.028 & 0.020 & 0.018 & 0.021 & 0.026 & 0.033 & 0.040 & 0.050 & 0.089 \\
\hline Observations & 23592 & 25755 & 26155 & 26283 & 26340 & 26370 & 26386 & 26399 & 26401 \\
\hline
\end{tabular}

All models include also dummies for country and 5-year birth cohorts. Robust standard errors in parentheses. Significance levels: $* * * \mathrm{p}<0.01 * *$ observed for men $<0.05 * \mathrm{p}<0.10$. 
Table A-6: Estimates of childhood health and SES variables from linear regressions on accumulated career gaps since career start from age 21 to 64 or the latest age observed for women in Europe ${ }^{\mathrm{a}}$

\begin{tabular}{|c|c|c|c|c|c|c|c|c|c|}
\hline & $21-25$ & $26-30$ & $31-35$ & $36-40$ & $41-45$ & $46-50$ & $51-55$ & $56-60$ & $61-64$ \\
\hline Mental (0-1) & $\begin{array}{l}0.006 \\
(0.081)\end{array}$ & $\begin{array}{l}-0.048 \\
(0.139)\end{array}$ & $\begin{array}{l}-0.100 \\
(0.198)\end{array}$ & $\begin{array}{l}-0.025 \\
(0.259)\end{array}$ & $\begin{array}{l}0.183 \\
(0.319)\end{array}$ & $\begin{array}{l}0.574 \\
(0.385)\end{array}$ & $\begin{array}{l}0.978 * * \\
(0.444)\end{array}$ & $\begin{array}{l}1.275^{* * *} \\
(0.479)\end{array}$ & $\begin{array}{l}1.303^{* * *} \\
(0.491)\end{array}$ \\
\hline Physical (1SD below the mean) $(0-1)$ & $\begin{array}{l}-0.018 \\
(0.028)\end{array}$ & $\begin{array}{l}-0.150^{* * *} \\
(0.050)\end{array}$ & $\begin{array}{l}-0.256^{* * * *} \\
(0.072)\end{array}$ & $\begin{array}{l}-0.317 * * * \\
(0.094)\end{array}$ & $\begin{array}{l}-0.345^{* * *} \\
(0.116)\end{array}$ & $\begin{array}{l}-0.396 * * * \\
(0.139)\end{array}$ & $\begin{array}{l}-0.407 * * \\
(0.162)\end{array}$ & $\begin{array}{l}-0.405^{* *} \\
(0.179)\end{array}$ & $\begin{array}{l}-0.439 * * \\
(0.187)\end{array}$ \\
\hline Poor/fair/changing SRH (0-1) & $\begin{array}{l}0.146^{* * *} \\
(0.034)\end{array}$ & $\begin{array}{l}0.314 * * * \\
(0.060)\end{array}$ & $\begin{array}{l}0.503^{* * *} \\
(0.087)\end{array}$ & $\begin{array}{l}0.713 * * * \\
(0.114)\end{array}$ & $\begin{array}{l}0.901^{* * *} \\
(0.140)\end{array}$ & $\begin{array}{l}1.131^{* * *} \\
(0.168)\end{array}$ & $\begin{array}{l}1.420 * * * \\
(0.195)\end{array}$ & $\begin{array}{l}1.664^{* * *} \\
(0.215)\end{array}$ & $\begin{array}{l}1.780^{* * * *} \\
(0.224)\end{array}$ \\
\hline Severe headaches or migraines $(0-1)$ & $\begin{array}{l}0.042 \\
(0.045)\end{array}$ & $\begin{array}{l}0.066 \\
(0.079)\end{array}$ & $\begin{array}{l}0.036 \\
(0.113)\end{array}$ & $\begin{array}{l}0.079 \\
(0.147)\end{array}$ & $\begin{array}{l}0.148 \\
(0.182)\end{array}$ & $\begin{array}{l}0.203 \\
(0.218)\end{array}$ & $\begin{array}{l}0.313 \\
(0.253)\end{array}$ & $\begin{array}{l}0.383 \\
(0.280)\end{array}$ & $\begin{array}{l}0.427 \\
(0.292)\end{array}$ \\
\hline Rooms (an increase of one room) & $\begin{array}{l}-0.200^{* * * *} \\
(0.026)\end{array}$ & $\begin{array}{l}-0.392 * * * \\
(0.047)\end{array}$ & $\begin{array}{l}-0.531^{* * * *} \\
(0.069)\end{array}$ & $\begin{array}{l}-0.627 * * * \\
(0.091)\end{array}$ & $\begin{array}{l}-0.751^{* * * *} \\
(0.113)\end{array}$ & $\begin{array}{l}-0.881 * * * \\
(0.137)\end{array}$ & $\begin{array}{l}-1.040 * * * \\
(0.161)\end{array}$ & $\begin{array}{l}-1.218^{* * *} \\
(0.179)\end{array}$ & $\begin{array}{l}-1.296 * * * \\
(0.188)\end{array}$ \\
\hline Bookcase $(0-1)(1=>25$ books $)$ & $\begin{array}{l}-0.246^{* * *} \\
(0.022)\end{array}$ & $\begin{array}{l}-0.451^{* * *} \\
(0.040)\end{array}$ & $\begin{array}{l}-0.604^{* * *} \\
(0.058)\end{array}$ & $\begin{array}{l}-0.739 * * * \\
(0.076)\end{array}$ & $\begin{array}{l}-0.907^{* * *} \\
(0.094)\end{array}$ & $\begin{array}{l}-1.116^{* * *} \\
(0.112)\end{array}$ & $\begin{array}{l}-1.360^{* * *} \\
(0.130)\end{array}$ & $\begin{array}{l}-1.619^{* * *} \\
(0.144)\end{array}$ & $\begin{array}{l}-1.738^{* * *} \\
(0.150)\end{array}$ \\
\hline Number of facilities at home when 10 years old (0-4) & $\begin{array}{l}-0.057 * * * \\
(0.007)\end{array}$ & $\begin{array}{l}-0.102^{* * *} \\
(0.013)\end{array}$ & $\begin{array}{l}-0.140^{* * *} \\
(0.019)\end{array}$ & $\begin{array}{l}-0.182 * * * \\
(0.024)\end{array}$ & $\begin{array}{l}-0.227 * * * \\
(0.030)\end{array}$ & $\begin{array}{l}-0.268^{* * *} \\
(0.036)\end{array}$ & $\begin{array}{l}-0.333^{* * *} \\
(0.042)\end{array}$ & $\begin{array}{l}-0.397 * * * \\
(0.046)\end{array}$ & $\begin{array}{l}-0.424 * * * \\
(0.048)\end{array}$ \\
\hline Born in urban area $(0-1)$ & $\begin{array}{l}-0.007 \\
(0.022)\end{array}$ & $\begin{array}{l}-0.015 \\
(0.039)\end{array}$ & $\begin{array}{l}-0.005 \\
(0.057)\end{array}$ & $\begin{array}{l}0.074 \\
(0.075)\end{array}$ & $\begin{array}{l}0.120 \\
(0.092)\end{array}$ & $\begin{array}{l}0.143 \\
(0.110)\end{array}$ & $\begin{array}{l}0.138 \\
(0.128)\end{array}$ & $\begin{array}{l}0.097 \\
(0.141)\end{array}$ & $\begin{array}{l}0.082 \\
(0.146)\end{array}$ \\
\hline Regular dental care since childhood (0-1) & $\begin{array}{l}-0.189 * * * \\
(0.024)\end{array}$ & $\begin{array}{l}-0.334^{* * *} \\
(0.042)\end{array}$ & $\begin{array}{l}-0.475^{* * *} \\
(0.061)\end{array}$ & $\begin{array}{l}-0.584^{* * *} \\
(0.081)\end{array}$ & $\begin{array}{l}-0.703^{* * *} \\
(0.100)\end{array}$ & $\begin{array}{l}-0.867^{* * *} \\
(0.119)\end{array}$ & $\begin{array}{l}-1.029 * * * \\
(0.139)\end{array}$ & $\begin{array}{l}-1.183^{* * *} \\
(0.153)\end{array}$ & $\begin{array}{l}-1.248^{* * *} \\
(0.159)\end{array}$ \\
\hline R-squared & 0.062 & 0.115 & 0.149 & 0.161 & 0.164 & 0.162 & 0.160 & 0.170 & 0.202 \\
\hline Observations & 27159 & 28707 & 29370 & 29816 & 30075 & 30217 & 30282 & 30310 & 30318 \\
\hline
\end{tabular}

${ }^{\mathrm{a}}$ OLS estimates of childhood health and SES variables from linear regressions on accumulated career gaps between age 21 to 64 or the latest age observed for men in Europe.

All models include also dummies for country and 5-year birth cohorts. Robust standard errors in parentheses. Significance levels: $* * * \mathrm{p}<0.01 * * \mathrm{p}<0.05 * \mathrm{p}<0.10$. 
Table A-7: Estimates of childhood health and SES variables from linear regressions on the probability of retiring from a job from age 21 to 64 or the latest age observed for men in Europe ${ }^{\mathrm{a}}$

\begin{tabular}{|c|c|c|c|c|c|c|c|c|c|}
\hline & $21-25$ & $26-30$ & $31-35$ & $36-40$ & $41-45$ & $46-50$ & $51-55$ & $56-60$ & $61-64$ \\
\hline Mental (0-1) & $\begin{array}{l}-0.003^{* * *} \\
(0.001)\end{array}$ & $\begin{array}{l}-0.001 \\
(0.006)\end{array}$ & $\begin{array}{l}0.014 \\
(0.012)\end{array}$ & $\begin{array}{l}0.044^{* *} \\
(0.018)\end{array}$ & $\begin{array}{l}0.046^{* *} \\
(0.020)\end{array}$ & $\begin{array}{l}0.070 * * * \\
(0.024)\end{array}$ & $\begin{array}{l}0.064^{* *} \\
(0.031)\end{array}$ & $\begin{array}{l}0.037 \\
(0.036)\end{array}$ & $\begin{array}{l}0.009 \\
(0.029)\end{array}$ \\
\hline Physical (1SD below the mean) $(0-1)$ & $\begin{array}{l}-0.001 \\
(0.001)\end{array}$ & $\begin{array}{l}-0.001 \\
(0.001)\end{array}$ & $\begin{array}{l}0.001 \\
(0.002)\end{array}$ & $\begin{array}{l}0.001 \\
(0.003)\end{array}$ & $\begin{array}{l}0.000 \\
(0.003)\end{array}$ & $\begin{array}{l}0.001 \\
(0.005)\end{array}$ & $\begin{array}{l}-0.000 \\
(0.007)\end{array}$ & $\begin{array}{l}-0.018 * \\
(0.010)\end{array}$ & $\begin{array}{l}-0.004 \\
(0.008)\end{array}$ \\
\hline Poor/fair/changing SRH (0-1) & $\begin{array}{l}0.002 \\
(0.002)\end{array}$ & $\begin{array}{l}0.004^{*} \\
(0.002)\end{array}$ & $\begin{array}{l}0.005 * \\
(0.003)\end{array}$ & $\begin{array}{l}0.008^{* *} \\
(0.004)\end{array}$ & $\begin{array}{l}0.018 * * * \\
(0.005)\end{array}$ & $\begin{array}{l}0.028 * * * \\
(0.007)\end{array}$ & $\begin{array}{l}0.030 * * * \\
(0.010)\end{array}$ & $\begin{array}{l}0.038 * * * \\
(0.012)\end{array}$ & $\begin{array}{l}0.015 \\
(0.010)\end{array}$ \\
\hline Severe headaches or migraines $(0-1)$ & $\begin{array}{l}-0.002^{* * *} \\
(0.000)\end{array}$ & $\begin{array}{l}-0.003 \\
(0.002)\end{array}$ & $\begin{array}{l}0.001 \\
(0.004)\end{array}$ & $\begin{array}{l}0.003 \\
(0.006)\end{array}$ & $\begin{array}{l}0.002 \\
(0.007)\end{array}$ & $\begin{array}{l}-0.005 \\
(0.009)\end{array}$ & $\begin{array}{l}0.009 \\
(0.015)\end{array}$ & $\begin{array}{l}0.025 \\
(0.019)\end{array}$ & $\begin{array}{l}-0.005 \\
(0.017)\end{array}$ \\
\hline Rooms (an increase of one room) & $\begin{array}{l}0.001^{*} \\
(0.001)\end{array}$ & $\begin{array}{l}-0.000 \\
(0.001)\end{array}$ & $\begin{array}{l}0.000 \\
(0.002)\end{array}$ & $\begin{array}{l}-0.002 \\
(0.002)\end{array}$ & $\begin{array}{l}-0.002 \\
(0.003)\end{array}$ & $\begin{array}{l}-0.004 \\
(0.005)\end{array}$ & $\begin{array}{l}-0.013^{*} \\
(0.007)\end{array}$ & $\begin{array}{l}-0.035^{* * *} \\
(0.010)\end{array}$ & $\begin{array}{l}-0.025^{* * *} \\
(0.008)\end{array}$ \\
\hline Bookcase $(0-1)(1=>25$ books $)$ & $\begin{array}{l}-0.000 \\
(0.001)\end{array}$ & $\begin{array}{l}-0.002 \\
(0.001)\end{array}$ & $\begin{array}{l}-0.001 \\
(0.002)\end{array}$ & $\begin{array}{l}-0.001 \\
(0.002)\end{array}$ & $\begin{array}{l}-0.002 \\
(0.003)\end{array}$ & $\begin{array}{l}-0.009^{* *} \\
(0.004)\end{array}$ & $\begin{array}{l}-0.029 * * * \\
(0.007)\end{array}$ & $\begin{array}{l}-0.058^{* * *} \\
(0.009)\end{array}$ & $\begin{array}{l}-0.035^{* * *} \\
(0.007)\end{array}$ \\
\hline Number of facilities at home when 10 years old (0-4) & $\begin{array}{l}-0.000 \\
(0.000)\end{array}$ & $\begin{array}{l}-0.000 \\
(0.000)\end{array}$ & $\begin{array}{l}-0.000 \\
(0.001)\end{array}$ & $\begin{array}{l}-0.002 * * \\
(0.001)\end{array}$ & $\begin{array}{l}-0.003^{* * *} \\
(0.001)\end{array}$ & $\begin{array}{l}-0.005^{* * *} \\
(0.001)\end{array}$ & $\begin{array}{l}-0.004^{* *} \\
(0.002)\end{array}$ & $\begin{array}{l}-0.011^{* * *} \\
(0.003)\end{array}$ & $\begin{array}{l}-0.008^{* * *} \\
(0.002)\end{array}$ \\
\hline Born in urban area $(0-1)$ & $\begin{array}{l}0.000 \\
(0.001)\end{array}$ & $\begin{array}{l}0.001 \\
(0.001)\end{array}$ & $\begin{array}{l}0.002 \\
(0.002)\end{array}$ & $\begin{array}{l}0.003 \\
(0.002)\end{array}$ & $\begin{array}{l}0.007 * * \\
(0.003)\end{array}$ & $\begin{array}{l}0.011^{* *} \\
(0.004)\end{array}$ & $\begin{array}{l}0.005 \\
(0.006)\end{array}$ & $\begin{array}{l}0.000 \\
(0.008)\end{array}$ & $\begin{array}{l}0.009 \\
(0.007)\end{array}$ \\
\hline Regular dental care since childhood (0-1) & $\begin{array}{l}-0.000 \\
(0.001)\end{array}$ & $\begin{array}{l}0.001 \\
(0.001)\end{array}$ & $\begin{array}{l}0.000 \\
(0.002)\end{array}$ & $\begin{array}{l}0.001 \\
(0.002)\end{array}$ & $\begin{array}{l}0.001 \\
(0.003)\end{array}$ & $\begin{array}{l}-0.002 \\
(0.004)\end{array}$ & $\begin{array}{l}-0.002 \\
(0.006)\end{array}$ & $\begin{array}{l}-0.006 \\
(0.008)\end{array}$ & $\begin{array}{l}-0.007 \\
(0.007)\end{array}$ \\
\hline R-squared & 0.003 & 0.007 & 0.024 & 0.043 & 0.060 & 0.092 & 0.103 & 0.164 & 0.142 \\
\hline Observations & 17671 & 17671 & 17671 & 17671 & 17671 & 17671 & 17671 & 17671 & 17671 \\
\hline
\end{tabular}

a OLS estimates of childhood health and SES variables from linear regressions on the probability of retiring from a job between age 21 to 64 or the latest age observed for men in Europe. All models include also dummies for country and 5-year birth cohorts. Robust standard errors in parentheses. Significance levels: $* * * \mathrm{p}<0.01 * * \mathrm{p}<0.05 *$ $\mathrm{p}<0.10$. 
Table A-8: Estimates of childhood health and SES variables from linear regressions on the probability of retiring from a job from age 21 to 64 or the latest age observed for women in Europe ${ }^{\mathrm{a}}$

\begin{tabular}{|c|c|c|c|c|c|c|c|c|c|}
\hline & $21-25$ & $26-30$ & 31-35 & $36-40$ & $41-45$ & $46-50$ & $51-55$ & $56-60$ & $61-64$ \\
\hline Mental (0-1) & $\begin{array}{l}0.002 \\
(0.007)\end{array}$ & $\begin{array}{l}0.010 \\
(0.010)\end{array}$ & $\begin{array}{l}0.022 \\
(0.014)\end{array}$ & $\begin{array}{l}0.051^{* * *} \\
(0.018)\end{array}$ & $\begin{array}{l}0.062 * * * \\
(0.020)\end{array}$ & $\begin{array}{l}0.071^{* * *} \\
(0.023)\end{array}$ & $\begin{array}{l}0.098 * * * \\
(0.030)\end{array}$ & $\begin{array}{l}0.060 * * \\
(0.026)\end{array}$ & $\begin{array}{l}0.035^{*} \\
(0.020)\end{array}$ \\
\hline Physical (1SD below the mean) $(0-1)$ & $\begin{array}{l}0.001 \\
(0.002)\end{array}$ & $\begin{array}{l}0.004 \\
(0.003)\end{array}$ & $\begin{array}{l}0.004 \\
(0.003)\end{array}$ & $\begin{array}{l}0.004 \\
(0.004)\end{array}$ & $\begin{array}{l}0.007 \\
(0.005)\end{array}$ & $\begin{array}{l}0.005 \\
(0.007)\end{array}$ & $\begin{array}{l}0.002 \\
(0.010)\end{array}$ & $\begin{array}{l}-0.009 \\
(0.010)\end{array}$ & $\begin{array}{l}-0.008 \\
(0.008)\end{array}$ \\
\hline Poor/fair/changing SRH (0-1) & $\begin{array}{l}0.003 \\
(0.002)\end{array}$ & $\begin{array}{l}0.006^{*} \\
(0.003)\end{array}$ & $\begin{array}{l}0.007^{* *} \\
(0.004)\end{array}$ & $\begin{array}{l}0.011^{* *} \\
(0.004)\end{array}$ & $\begin{array}{l}0.019 * * * \\
(0.006)\end{array}$ & $\begin{array}{l}0.025^{* * *} \\
(0.007)\end{array}$ & $\begin{array}{l}0.033^{* * *} \\
(0.010)\end{array}$ & $\begin{array}{l}0.028 * * * \\
(0.010)\end{array}$ & $\begin{array}{l}0.018^{* *} \\
(0.008)\end{array}$ \\
\hline Severe headaches or migraines $(0-1)$ & $\begin{array}{l}0.001 \\
(0.003)\end{array}$ & $\begin{array}{l}0.002 \\
(0.004)\end{array}$ & $\begin{array}{l}0.013 * * \\
(0.006)\end{array}$ & $\begin{array}{l}0.009 \\
(0.007)\end{array}$ & $\begin{array}{l}0.006 \\
(0.008)\end{array}$ & $\begin{array}{l}0.026 * * \\
(0.011)\end{array}$ & $\begin{array}{l}-0.005 \\
(0.014)\end{array}$ & $\begin{array}{l}-0.004 \\
(0.014)\end{array}$ & $\begin{array}{l}-0.003 \\
(0.012)\end{array}$ \\
\hline Rooms (an increase of one room) & $\begin{array}{l}0.001 \\
(0.001)\end{array}$ & $\begin{array}{l}-0.000 \\
(0.002)\end{array}$ & $\begin{array}{l}-0.001 \\
(0.003)\end{array}$ & $\begin{array}{l}-0.004 \\
(0.003)\end{array}$ & $\begin{array}{l}-0.003 \\
(0.006)\end{array}$ & $\begin{array}{l}-0.013^{*} \\
(0.007)\end{array}$ & $\begin{array}{l}-0.027 * * * \\
(0.009)\end{array}$ & $\begin{array}{l}-0.017 * \\
(0.010)\end{array}$ & $\begin{array}{l}-0.015^{*} \\
(0.008)\end{array}$ \\
\hline Bookcase $(0-1)(1=>25$ books $)$ & $\begin{array}{l}-0.001 \\
(0.001)\end{array}$ & $\begin{array}{l}0.002 \\
(0.002)\end{array}$ & $\begin{array}{l}0.002 \\
(0.002)\end{array}$ & $\begin{array}{l}-0.000 \\
(0.003)\end{array}$ & $\begin{array}{l}-0.002 \\
(0.004)\end{array}$ & $\begin{array}{l}-0.013^{* *} \\
(0.005)\end{array}$ & $\begin{array}{l}-0.044^{* * *} \\
(0.008)\end{array}$ & $\begin{array}{l}-0.031^{* * *} \\
(0.007)\end{array}$ & $\begin{array}{l}-0.015^{* * *} \\
(0.006)\end{array}$ \\
\hline Number of facilities at home when 10 years old $(0-4)$ & $\begin{array}{l}-0.001 \\
(0.000)\end{array}$ & $\begin{array}{l}-0.001 \\
(0.001)\end{array}$ & $\begin{array}{l}-0.001 \\
(0.001)\end{array}$ & $\begin{array}{l}-0.001 \\
(0.001)\end{array}$ & $\begin{array}{l}-0.002 * \\
(0.001)\end{array}$ & $\begin{array}{l}-0.001 \\
(0.002)\end{array}$ & $\begin{array}{l}-0.009^{* * *} \\
(0.002)\end{array}$ & $\begin{array}{l}-0.007^{* * *} \\
(0.002)\end{array}$ & $\begin{array}{l}-0.004 * * \\
(0.002)\end{array}$ \\
\hline Born in urban area (0-1) & $\begin{array}{l}0.001 \\
(0.001)\end{array}$ & $\begin{array}{l}-0.002 \\
(0.002)\end{array}$ & $\begin{array}{l}0.000 \\
(0.002)\end{array}$ & $\begin{array}{l}0.002 \\
(0.003)\end{array}$ & $\begin{array}{l}0.004 \\
(0.004)\end{array}$ & $\begin{array}{l}0.005 \\
(0.005)\end{array}$ & $\begin{array}{l}0.008 \\
(0.007)\end{array}$ & $\begin{array}{l}0.016^{* *} \\
(0.007)\end{array}$ & $\begin{array}{l}0.019 * * * \\
(0.006)\end{array}$ \\
\hline Regular dental care since childhood (0-1) & $\begin{array}{l}-0.003^{* *} \\
(0.001)\end{array}$ & $\begin{array}{l}-0.003 \\
(0.002)\end{array}$ & $\begin{array}{l}-0.006 * * \\
(0.002)\end{array}$ & $\begin{array}{l}-0.005 * \\
(0.003)\end{array}$ & $\begin{array}{l}-0.010^{* * *} \\
(0.004)\end{array}$ & $\begin{array}{l}-0.014^{* * *} \\
(0.005)\end{array}$ & $\begin{array}{l}-0.002 \\
(0.007)\end{array}$ & $\begin{array}{l}-0.001 \\
(0.007)\end{array}$ & $\begin{array}{l}0.003 \\
(0.006)\end{array}$ \\
\hline R-squared & 0.008 & 0.023 & 0.027 & 0.033 & 0.047 & 0.070 & 0.141 & 0.234 & 0.155 \\
\hline Observations & 18508 & 18508 & 18508 & 18508 & 18508 & 18508 & 18508 & 18508 & 18508 \\
\hline
\end{tabular}

